UC-706

Issued: January 1994

A Comparison of the Dynamic Stiffness

of the Goldcrown GC-500 Grinding Machine

for Three Slide Designs

Joel G. Bennett

Peggy Goldman

Donald C. Williams

Charles R. Farrar 


\section{EXECUTIVE SUMMARY}

\section{Models, Calculations, and Methodology}

This report provides a summary of the results obtained from the calculations that compare the dynamic stiffness of three slide design systems for the Goldcrown GC-500 centerless grinder; it also describes the models and procedures used to develop the calculations, the assumptions made, and the details that went into performing this work. We developed analytical models of the three Goldcrown slide designs and performed several computational studies to determine the dynamic stiffness of the designs. The three slide systems are hereafter referred to as the plane slide, the INA slide, and the polymer-coated slide. The plane slide is the dovetail slide and way traditionally used in machine tool designs. The INA slide is a design created by Goldcrown using INA Bearing Company recirculating roller bearings, and dampers on a rail guideway. The polymer-coated slide is a design using a low friction polymer coating for a modified plane slide system. A study of the drawings indicated that a comparison could be made, within a reasonable amount of time and effort, that would be indicative of the dynamic stiffness of the three designs if the machine was modeled as being composed of the following seven structural components: (1) the base, (2) the swivel plate, (3) the lower slide, (4) the upper housing, (5) the regulating whecl housing, (6) the ball screw, and (7) the in-feed body.

These components represent the load paths from the part being ground and the part that is in contact with the regulating wheel, through the machine and back to the part, because the base includes a representation of the grinding wheel location. The geometry of the machine is basically rectangular, with the "long" axis defined as the longitudinal direction (x-axis), the "short" axis as the transverse direction (z-axis), and the vertical axis as the vertical direction ( $y$-axis). Several computational studies were performed to investigate the dynamic stiffness. Comparisons were made at a given load level for a 6500 surface-ft/min grinding rate. One of the magnitudes chosen represents a force level variation typical of a light "cut" and of a material such as aluminum. This level does not challenge the machine's performance. In this case, the responses calculated using the models are in the linear or near-linear regime, even though the models themselves are nonlinear. This case is the easiest case to understand physically and is probably indicative of the load level for which only the INA slide has been actually placed in service as of this writing (a 0.003 -in.-grind on aluminum valves).

In another case, we attempted to characterize the dynamic stiffness of the designs in the nonlinear regime. A relatively large random force was applied to the regulating wheel housing. This force had a frequency variation with good energy content from 30 to $250 \mathrm{~Hz}$. This calculation represents an operation in which chatter regimes and some tuning of the machine control system (feed rates, etc.) could be expected.

In terms of actual magnitudes, Table I shows the force levels applied for the comparative studies at a 6500 surface- $\mathrm{ft} / \mathrm{min}$ grind rate, along with their locations and directions. These loads all were all of the form $\mathrm{F}=\mathrm{F} 0 * \sin \left(\mathrm{w}^{*} \mathrm{t}\right)$, with a frequency $\mathrm{f}=\mathrm{w} /(2 * \mathrm{Pi})$ of $33 \mathrm{~Hz}$. Note that the magnitudes represent a perturbation load, or a variation of the load that would be acting, in addition to a steady or static component.

The response of the models of the machines chosen for comparison is the accele:ation response of the mass center of the upper housing divided by the longitudinal direction furce input at the regulating wheel housing. All comparisons were made in the frequency domain and converted to psuedo-dynamic stiffness by the following method. Let $A(w)$ represent 
the Fourier transform of the acceleration response of the upper housing, and $F(w)$ represent the Fourier transform of the force input, with $w$ being the circular frequency. Then, the system frequency response function, $\mathrm{H}(\mathrm{w})$, is given by the relationship that

$$
A(w)=H(w) * F(w)
$$

TABLE I

APPLIED FORCES FOR "LIGHT"-CUT STUDY

\begin{tabular}{|c|c|}
\hline Location & Force (lb) \\
\hline $\begin{array}{c}\text { Regulating Wheel } \\
\text { Housing }\end{array}$ & $\begin{array}{r}25 \\
25 \\
5\end{array}$ \\
\hline Grinding Wheel & $\begin{array}{c}-25 \\
25 \\
5\end{array}$ \\
\hline
\end{tabular}

The psuedo-dynamic stiffness, $S(w)$, is then given as

$$
\mathrm{S}(\mathrm{w})=\left(\mathrm{w}^{* * 2}\right) / \mathrm{H}(\mathrm{w}) \text {. }
$$

\section{Results}

Table II is a summary of the dynamic stiffness comparisons of the three designs for the "light"-cut load level. Static stiffnesses are also shown for comparison. We also calculated the undamped natural frequencies of the models. A study of their magnitudes, participation factors, and effective mass shows that the responses reported in Table II were predominantly linear for all three designs.

Table III is a summary of the stiffness found in the nonlinear regime. The stick-slip and other nonlinear springs in the model give a response that can be very confusing, and several different time windows were taken of the response to determine the minimum dynamic stiffness that might be expected. We report on the minimum dynamic stiffness found from the acceleration response of the upper housing in the $x$-direction divided by the longitudinal force applied to the regulating wheel housing because the friction effects are in the $x-z$ plane.

\section{Discussion}

For the plane slide and polymer coated slide models, the lowest values of dynamic stiffness occur in the vertical direction in Table II. However, this result occurs not because the machines are not as stiff vertically, but because of the rotational response about the transverse direction. In a sense, it is the "bending" of the machine in the $x-y$ plane. The lowest value of dynamic stiffness is in the INA slide model, at $93 \mathrm{~Hz}$, is in the longitudinal direction because the recirculating roller bearings offer essentially no stiffness (resistance) in this direction, and the load path is through the ball screw and infeed body into the swivel plate. Some improvement could be made in the magnitude of this value by stiffening the components in this load path. 
In the vertical and transverse directions, values of dynamic stiffness are slightly better in the INA than in the plane or polymer coated slide designs. At this load level, the responses of the plane slide design is about the same as those of the polymer-coated slide design pecause these designs are nearly identical, except for the values of the coefficient of friction on the slide-way mating surfaces. This difference shows up drastically in the nonlinear regime comparison. The dynamic stiffness in the polymer-coated slide decreases in the $x$-direction .o a value of $5800 \mathrm{lb} / \mathrm{in}$. The plane slide model also decreases to $10,000 \mathrm{lb} / \mathrm{in}$,, but the INA slide design remains essentially unchanged because the INA slide load path does not change.

In terms of overall performance, our study shows that the frequency response of the plane slide design will continue to show good performance at higher load levels, while the polymer coated slide will deteriorate quickly unless some additional damping mechanisms are incorporated into the design. Based on all of our studies, we predict that the coated slide design is the most difficult to control and the least accurate of the three designs; however, more data and more calculations will be required to quantify the magnitude of the difference. One reason for this is because there are many potentially "poor," or near-resonance, frequencies that appear in the frequency response function for which the dynamic stiffness decreases. Such frequency response functions are characteristic of nonlinear stick-slip systems. The performance of the INA design is expected to remain about the same as the "light"-cut levels at larger load levels. The addition of the dampers in the rail-slide system appears to have alleviated some potential control probiems, but there are still more potentially "poor" operating frequencies in this design than in the plane slide design.

TABLE II

LOW LOAD LEVEL DYNAMIC STIFFNESS COMPARISON

Plane Slide

$\frac{\text { Static }}{\text { Magnitude (lb/in.) }}$

Longitudinal
Vertical
Transverse

INA Slide

$\begin{array}{lc}\text { Longitudinal } & 14.6 \times 10^{9} \\ \text { Vertical } & 249,000 \\ \text { Transverse } & 54.8 \times 10^{9}\end{array}$

Polymer Coated Slide

Longitudinal

Vertical

$16.2 \times 10^{9}$

508,120 .

$58.3 \times 10^{9}$

Transverse
$14.9 \times 10^{9}$

508,120 .

$58.3 \times 10^{9}$

\author{
Dynamic \\ Magnitude (lb/in.)
}

739,900

139,500

$1.61 \times 10^{6}$
Dynamic

Frequency/(Hz)

177.

117.

162.
93.

113.

159.
27,540

$1.93 \times 10^{6}$

644,900

139,800

$1.59 \times 10^{6}$
174.

117.

162. 
TABLE III

NONLINEAR COMPARISONS: MINIMUM LONGITUDINAL DIRECTION DYNAMIC STIFFNESS

Slide Type

Plane Slide

INA Slide

Polymer Coated Slide
Magnitude (lb/in)

10,160

24,230

5,853
Frequency $(\mathrm{Hz})$

61.2

39.3

54.5 


\title{
A COMPARISON OF THE DYNAMIC STIFFNESS OF THE \\ GOLDCROWN GC-500 GRINDING MACHINE FOR \\ THREE SLIDE DESIGNS
}

\author{
by \\ Joel G. Bennett, Peggy Goldman, Donald C. Williams, and Charles R. Farrar
}

\begin{abstract}
We have calculated the dynamic stiffnesses of three slide design systems (the plane slide system design, the INA recirculating roller-bearing slide design, and the coated slide design) for the Goldcrown GC-500 centerless grinder. We first developed analytical models of the three Goldcrown slide designs, then performed several computational studies to determine the dynamic stiffness of each design. The results indicate that the plane slide system can be redesigned, paying particular attention to the frequency response within the operating range of the machine, to enhance the accuracy of the machine (particularly the part-to-part repositioning, feed accuracy, and control system). Of the three designs calculated, the INA recirculating roller-bearing slide design shows the most promise. Raising the minimum dynamic stiffness value and its frequency by stiffening the components in the load path could make the accuracy of the INA design superior to that of the plane slide. For the coated slide design, we recommend adding an additional damping mechanism in the slide direction. Without additional damping, we predict that this design will probably be the most difficult to control and the least accurate of the three.
\end{abstract}

\section{INTRODUCTION}

The Los Alamos National Laboratory (LANL), under the auspices of the Department of Energy's (DOE's) National Machine Tool Partnership Program, is modeling a large, centerless grinding machine tool (Model GC-500, manufactured by Goldcrown Machinery of Cincinnati, Ohio). The Goldcrown Machinery company asked the DOE to determine whether it would be possible to calculate and compare the dynamic stiffness of the basic GC-500 for three different slide designs. The basic machine tool slide design, traditionally the so-called plane slide design, is the dovetail design commonly used in many machine tools. The problem with this design is that it is a stick-slip slide design, with large coefficients of friction between the mating surfaces on the slide/way plane. Thus, the repositioning, feed, and grinding accuracy from part-to-part are subject to certain variations. Goldcrown has undertaken two different redesigns of their basic plane slide machine. The first model, which is based on an INA recirculating roller bearing, a damper, and rail system, has been produced, tested, and delivered. This model allows low-friction and excellent positioning control. The second model has a low-friction polymer-coated slide and a way- and surface-contact system. Although it has not been produced or tested as of this writing, it, too, promises low-friction and excellent positioning control.

Both of the machine tool redesigns are designed to obtain better accuracy from the positioning control system by reducing the problem of stick-slip. However, it is not clear whether or not the trade-off would be a sacrifice in grinding accuracy. Traditionally, 
grinding accuracy has been tied to a measure of "dynamic stiffness" for grinding machines. In fact, most of the problems that arise with "lobed parts" can be traced to a loss in dynamic stiffness at a particular frequency. Fixing these problems requires either that the response of a particular component of the tool be damped at the frequency at which the loss in stiffness occurs or that it be operated in a different frequency regime. Thus, the question put before the DOE National Tool Partnership Program was whe ther the national laboratories could calculate the dynamic stiffness of the three designs and, thus, deterimine whether any one of the designs would be better than the others in enhancing the accuracy of the machines.

\section{THE GOLDCROWN GC-500 COMPONENTS}

Figure 1 shows the front piece of an advertising brochure for the Goldcrown GC-500 centerless grinding machine. Note that this complicated machine tool has seven major structural components: (1) the base, (2) the swivel plate, (3) the lower slide, (4) the upper housing, (5) the regulating wheel housing, (6) the ball screw, and (7) the infeed body. In addition to these components, the tool also has a regulating-wheel truing system, a grinding wheel truing system, and the wheels themselves. However, none of these components adds significant mass or stiffness to the overall machine tool. After studying drawings of the three concepts, we decided that the dynamic stiffnesses could compared by modeling the seven major structural components with appropriate changes for the three different slide/way designs. The individual components were modeled using the PATRAN/ABAQUS system that was implemented at Los Alamos to perform finite element analysis problems.

\section{A. Base}

Figures 2-4 show three different views of the finite element model of the base that was developed using the PATRAN system. For our model, we maintained the basic structurally important geometry to preserve the mass and stiffness contribution to a mathematical model, but sacrificed the exact details of the component. Therefore, the model should be accurate enough in the structurally important vibration modes, but less accurate in the local higher frequency modes. Two features pointed out in these figures are the swivel point location and the grinding wheel shaft centerline, both of which are part of the overall load path from the part being ground through the base and through the other components, then back to the part being ground. The basic differences in the designs being compared have arisen from the differences in the details of the lower slides and the swivel plates.

\section{B. Swivel Plate-Plane Slide and Coated Slide Designs}

Figures 5 and 6 show two views of the model of the plane slide design of the swivel plate. The same model was used for the coated slide model. The main difference between the plane slide design and the coated slide design is in the coefficients of friction between the coated mating surfaces.

\section{Lower Slide-Plane Slide and Coated Slide Designs}

Two views of the lower slide model for the plane slide and coated slide analyses are shown in Figs. 7 and 8. We made no attempt to preserve the continuity of the nodal point at the component interfaces because the ultimate use of these models did not require that it be preserved. However, the geometry from one component was used as a starting point for that of the next component. Thus, the geometric changes in the swivel plate required certain nodal placement, and such placements are traceable through the components that were modeled later. Consequently, some of the elements in these, and in subsequent figures, appear "odd- shaped" for no apparent reason. 


\section{Upper Housing}

Figures 9 and 10 show two views of the upper housing, which houses the ball-screw housing and forms the upper slide mechanism. The upper slide can be clamped for a given grinding operational setup. It is considered to be clamped in all the analyses carried out in this work, that is, all of the deformations that occur between the upper housing and the lower slide structure are elastic deformations. The upper housing is the same for all three slide designs. The finite element model is made up of both continuum elements and shell elements. This housing neglects the "cover plates" visible in Fig. 1 because it considers them to be nonstructural. Interestingly, the Goldcrown drawings indicate that the estimated weight of this component is about twice that calculated in our model. When we contacted Goldcrown about the large weight discrepancy, they weighed the finished structure and found that our calculation was within a few percent of the actual weight. Therefore, together with Goldcrown, we concluded that the weight estimate on the drawings was for the casting and that the discrepancy could be explained by the considerable amount of finishing, or machining, that was done on the final part.

\section{E. Regulating Wheel Housing}

The regulating wheel housing finite element model is shown in Figs. 11 and 12 . The centerline of the regulating wheel is indicated in these figures. The finite element models include a beam-element representation of the regulating wheel itself, whereas the regulating wheel housing model is made up entirely of shell finite elements.

\section{E. Ball-Lead Screw}

The ball-lead screw was analyzed as a three-dimensional beam for its component stiffness and mass properties.

\section{G. Infeed Body}

The ball screw pushes against (or is pushed by) the infeed body, and the infeed body holds a stepping motor that controls the feed and position of the slides. Two views of the infeed body are shown in Figs. 13 and 14. The infeed body connects to the end of the swivel plate and is an important component in the load path from the part being ground to the base and, subsequently, back to the grinding wheel.

\section{H. Swivel Plate-INA Slide Model}

The INA slide model of the swivel plate is shown in Figs. 15 and 16. The literature and the design guide of bearings produced by the INA Bearing Company supplied by Goldcrown were helpful in modeling the geometry associated with this slide design. They were also useful in helping us estimate the damping values for the model. We later used the model to calculate the structural properties, which depend primarily on the geometry and the attachments.

\section{Lower Slide-INA Slide Model}

Figures 17 and 18 show the redesign of the lower slide, which incorporates the INA bearing and rail system.

The machine is basically a C-structure, with a load path that goes from the part being ground, through the slides and infeed body, to the swivel plate. The swivel plate transmits 
the loads to the base. The load path from the grinding wheel also goes into the base. A thought visualized simple, free-body diagram reveals that the longitudinal or $x$-direction loads are self-equilibrating through the $\mathrm{C}$-structure. In Figure 19, all the components have been assembled. This figure bears a remarkable similarity to Fig. 1, but without the nonstructural parts of Fig. 1. However, the finite element model in Fig. 19 is far too complicated to use in a parameter study of the dynamic stiffness in the time and resources available for this project. We therefore developed the method described in the next section, which allows comparisons to be calculated.

\section{DEVELOPMENT OF THE OVERALL MODELS}

The principle behind developing the overall models used for comparing the dynamic stiffness is to analyze each of the component finite element models for each of the effects included and to define the force-displacement (spring constant) relationship that will represent that effect. These springs are of four types: linear, compressive only, tension only, or friction. The general force-displacement relationships for each of these types is shown in Figs. 20-23.

For nonlinear springs, ABAQUS requires that the force-displacement be input as point values, while for linear springs, only the spring constant needs to be entered. For compressive only or tension only springs, the force value was entered as an order of magnitude larger than the spring constant, with a corresponding relative displacement value of $10 \mathrm{in}$. to ensure coverage of the full range over which the spring would act. Outside the range of the points specified for the force-displacement relationship for nonlinear springs, $A B A Q U S$ sets the spring constant to zero, i.e., it assumes a constant force level that corresponds to the end of the range. For example, in our analysis of the swivel plate, recall that a free-body diagram is a sketch of the body that was removed from contact with other bodies but that is shown with the effect that the other bodies have on it. Thus, if the swivel plate is visualized as a free-body, the effect of the base that acts on it is the interface contact pressure of the base and the bottom contact surface of the swivel plate, the forces at the swivel pin, and the spring pack. Acting on the top surface is the effect of the lower slide, both the surface contact and the slide/way contact itself. The infeed body is also in contact with the end of the swivel plate, and these effects must be accounted for. Conceptually, the free-body diagram is shown in Fig. 24. The continuum representation of each of these effects is turned into a spring-mass representation, as illustrated by analyzing each effect separately and combining the result. Thus, consider the interaction of the base through the contact with the bottom surface of the swivel plate. The bottom contact surface of the swivel plate is fixed in all three directions, and a uniform body force of $1 \mathrm{~g}$ is applied in all 3

directions to the finite element model of the swivel plate. Then the following analysis is used to determine the spring rates.

The total mass of the swivel plate is given by

$$
M_{i}=\sum_{n=1}^{N} \int_{V_{n}} \rho_{n} I_{i} d V_{n}
$$


where

$\mathrm{M}_{\mathrm{i}} \quad=$ the mass associated with directions $\mathrm{i}$,

$\mathrm{i} \quad=1,2,3($ or $\mathrm{x}, \mathrm{y}, \mathrm{z})$,

$\mathrm{n} \quad=$ the element number with the summation extending over all elements from 1 to $\mathrm{N}$,

$\rho_{n} \quad=$ the mass density associated with the material in the element,

$\mathrm{dV}_{\mathrm{n}}=$ the differential volume for element $\mathrm{n}$, and

$\mathrm{I}_{\mathrm{i}} \quad=\mathrm{a}$ unit vector in the direction $\mathrm{i}$.

As usual, the coordinates of the center of mass of the component $\overline{x_{i}}$ of the structure is given by

$$
\bar{x}_{i}=\sum_{n=1}^{N} \int_{V n} x_{i} d V n \quad \text { where }
$$

$\bar{x}_{i} \quad=$ the coordinate of the center of mass for direction $\mathrm{i}$,

$x_{i} \quad=$ the global coordinate associated with direction $\mathrm{i}$, and

$\mathrm{i} \quad=1,2,3$ (or $\mathrm{x}, \mathrm{y}, \mathrm{z}$ ) in the 3 orthogonal directions,

and the summations extend over all elements 1 through $\mathrm{N}$ in the model.

The equivalent force acting on the center of mass in each direction is

$F_{i}=\sum_{n=1}^{N} \int_{i_{n}} \rho g l_{l} d V_{n}=w_{i}$

(i.e., the weight of the component applied in all three directions).

Under this loading, the movement of the mass center of the swivel plate is given by

$\delta_{i}=\frac{\sum_{n=1}^{N} \int_{V_{n}} \rho_{n}\left(x_{i}+u_{i}\right) d V_{n}}{\sum_{n=1}^{N} \int_{V_{n}} \rho_{n} x_{i} d V_{n}}=\frac{\sum_{n=1}^{N} \int_{V_{n}} \rho_{n} u_{i} d V_{n}}{M}$

where $u_{i}$, are the calculated nodal displacements within the model.

Then, a spring constant, representing the contact with the base in the vertical (y) direction, is

$K_{s y y}=\frac{W_{2}}{\delta_{2}}$ 
However, this spring is compressive only, or zero, if the displacements are such that the surface of the swivel plate separates from the base. The spring for this effect is showr in Fig. 25. In the $x$ - and $z$-directions, the spring constants are given in a similar manner until a breakaway value of friction force is reached. The friction effects are represented as shown in Fig. 26. The breakaway value of friction force is calculated based on the static value of contact force between the surfaces (i.e., the inertia force effects on breakaway are neglected). Thus, for the $x$-direction,

$F_{\text {breakaway }}=\mu N$,

Using the finite element model, the analysis of the swivel plate proceeds for each effect until the representation of the swivel plate is defined, as shown in Fig. 27 in combination with the description given in Table $I$.

\begin{tabular}{|c|c|c|c|c|c|}
\hline SPRING ANALYSIS & $\begin{array}{lr} & \text { TA } \\
\text { OF } & \text { SWIV }\end{array}$ & $\begin{array}{ll}\mathrm{LE} & \mathrm{I} \\
\mathrm{L} & \mathrm{PLATE}\end{array}$ & PLANE & SLIDE & MODEL \\
\hline Description & $\begin{array}{l}\text { Spring } \\
\text { Name }\end{array}$ & Type & $\begin{array}{l}\text { Value } \\
\text { (lb/in.) }\end{array}$ & $\begin{array}{c}F \\
(\mathrm{lb})\end{array}$ & (in.) \\
\hline Effect of the swivel pin and & KSXX & Linear & $68.1 \mathrm{e} 6$ & - & - \\
\hline the spring pack acting on the base & KSYY & Compressive & $0.47 \mathrm{e} 6$ & - & - \\
\hline & $\mathrm{KSZZ}$ & Linear & 7386.6 & - & - \\
\hline Effect of the swivel plate & KFBXX & Friction & $3.31 \mathrm{e} 9$ & 1134 & $3.42 \mathrm{e}-7$ \\
\hline acting on the base contact & KFBYY & Compressive & $823 . e 6$ & & \\
\hline surface & KFBZZ & Friction & $1.57 \mathrm{e} 9$ & 1134 & $7.21 \mathrm{e}-7$ \\
\hline Effect of the swivel acting & KFTXX & Friction & $1.29 \mathrm{e} 9$ & 662 & $5.14 \mathrm{e}-7$ \\
\hline on the top sliding surface in & КСТYY & Compressive & 479.e6 & - & \\
\hline contact with the lower slide & KFTZZ & Friction & $1.42 \mathrm{e} 9$ & 662 & $4.67 \mathrm{e}-7$ \\
\hline Effect of the swivel plate in & KFWXX & Friction & 874.e6 & 365 & $4.18 \mathrm{e}-7$ \\
\hline contact with the lower slide & KTWYY & Tension & $270 . e 6$ & - & - \\
\hline at the way surface & KWZZ & Linear & $625 . e 6$ & - & - \\
\hline Effect of the swivel plate in & KIBXX & Linear & 260.e6 & - & - \\
\hline contact with the infeed body & KIBYY & Linear & $2.67 \mathrm{e} 6$ & - & - \\
\hline & $\mathrm{KIBZZ}$ & Linear & $11.9 \mathrm{e} 6$ & - & - \\
\hline
\end{tabular}




\section{DAMPING IN THE OVERALL MODEL}

A linear damper acts in parallel with each spring. The damping force opposes the relative velocity of the nodes that connect the spring and the dampers. The damping force is given by the relationship that

$$
F_{D}=C \delta \dot{u}
$$

where $\delta \dot{u}$ is the relative velocity. If the spring is a linear or contact spring, the damping is assumed to be given as 0.5 percent of critical damping for a one-degree-of-freedom system. The damping is calculated by the relationsilip that

$$
C=(0.005) 2 \sqrt{K M}
$$

where $\mathrm{M}$ is the component mass and $\mathrm{K}$ is the corresponding spring constant.

However, if the spring is a friction spring, the force-velocity relationship is assumed to be a constant value of force equal to the breakaway value of friction given by

$C=\mu N$,

where

$\mu=$ coefficient of static friction, and

$\mathrm{N}=$ normal force of contact.

For the plane slide models, all the friction coefficients were 0.20 . For the polymer coated slide models, the friction coefficients were 0.02 . In the INA slide model the friction coefficient for the roller bearing-rail contact was 0.002 , in accordance with the literature from the INA Bearing Company, Inc., for the preload specified by Goldcrown ${ }^{1}$. A damping value of 0.5 percent structural was used to account for the viscous action of the damping units.

\section{COMPUTATIONAL MODEL FOR COMPARING DYNAMIC STIFFNESS}

The linear, friction, and contact conditions for each of the seven structural components of the GC-500 were treated in a similar manner. The overall representation of the GC-500 is shown in Fig. 28 in combination with the description given in Table II. A printout of the *SPRING and *DAMPING material properties used in the ABAQUS model is given with comments (the *** lines) in Appendix A.

\footnotetext{
${ }^{1}$ INA Bearing Company publication 305 "Rolling Bearings", INA Bearing Company, INC., Fort Mill, South Carolina 29715, Zerreiss GmbH, Nuremberg, 1988, pp. 23-25.
} 


\section{ANALYSES FOR COMPARING DYNAMIC STIFFNESS}

A number of computations were performed using the system models of Fig. 28 to compare the dynamic stiffness of the three designs. The ABAQUS model in Fig. 28 was subjected to several different step procedures to make the ultimate comparisons and to try to understand the differences in the three designs.

TABLE II

DESCRIPTION OF THE SPRINGS BY NUMBER IN FIGURE 28 PLANE SLIDE AND COATED SLIDE MODELS ${ }^{a}$

Description Of The Effect Represented By The Spring

Motion of the center of mass of the base relative to the floor.

Motion of the center of mass of the base relative to the grinding wheel centerline.

Spring pack-motion of the center of mass of the swivel plate relative to the center of mass of the base.

Motion of the center of mass of the base relative to the swivel pin point of contact.

Motion of the center of mass of the base relative to the surface of contact with the bottom of the swivel plate.

Motion of the center of mass of the swivel plate relative to the surface of contact with the base.

Motion of the center of mass of the swivel plate relative to the contact surface with the lower slide.

Motion of the center of mass of the swivel plate relative to the way contact surface on the lower slide.

Motion of the center of mass of the swivel plate relative to the contacting surfaces of the infeed body.

\begin{tabular}{|c|c|}
\hline Number & Type \\
\hline 8 & Linear \\
\hline 9 & Linear \\
\hline 10 & Linear \\
\hline 74 & Linear \\
\hline 75 & Linear \\
\hline 76 & Linear \\
\hline 22 & Linear \\
\hline 17 & Linear \\
\hline 18 & Linear \\
\hline 19 & Linear \\
\hline 11 & Linear \\
\hline 12 & Linear \\
\hline 13 & Linear \\
\hline 14 & Friction \\
\hline 15 & Compressive \\
\hline 16 & Friction \\
\hline 23 & Friction \\
\hline 24 & Linear \\
\hline 25 & Linear \\
\hline 26 & Friction \\
\hline 27 & Linear \\
\hline 28 & Linear \\
\hline 29 & Linear \\
\hline 30 & Linear \\
\hline 31 & Linear \\
\hline
\end{tabular}


Motion of the center of mass of the lower slide relative to the way surface of contact with the swivel plate.

Motion of the center of mass of the lower slide relative to the contact surface with the swivel plate.

Motion of the center of mass of the infeed the infeed body relative to the surfaces of contact with the swivel plate.

Motion of the center of mass of the infeed body relative to the ball screw push point.

Motion of the center of mass of the the ball screw relative to the infeed infeed body push point.

Motion of the center of mass of the ball screw relative to the ball screw housing push point in the upper housing.

Motion of the center of mass of the upper housing relative to the ball screw housing push point.

Motion of the center of mass of the upper the upper housing relative to the contact surface with the lower slide.

Motion of the center of mass of the upper the upper housing relative to the upper way contact surface on the lower slide.

Motion of the center of mass of the upper surface with the regulating wheel housing.

Motion of the center of mass of the center the center of mass of the regulating wheel housing relative to the contact surface with the upper housing.

Motion of the center of mass of the regulating wheel housing relative to the regulating wheel centerline.
Linear Compressive Linear

Linear

Linear

Linear

Linear

Linear

Linear

Linear

Linear

Linear

$\begin{array}{ll}71 & \text { Linear } \\ 72 & \text { Linear } \\ 73 & \text { Linear }\end{array}$

aFor the INA slide model, the springs 23-25 and 35-37 representing the effect of the surface contact of the lower slide and the swivel plate were eliminated because this contact no longer exists. Springs 26-28 and 32-34 were replaced with the results from analyzing the INA slide design from the FE models of Figs.15-18. 


\section{A. Frequency Analyses of Models}

Frequency analyses were performed for each of the design models to enhance our understanding of their linear responses. These analyses use the zero load values of stiffness for the nonlinear springs, and they explain the low load level response of the system.

Tables III, IV, and V are the tables printed from ABAQUS for the three models. The lowest frequency modes for all three models is about $48 \mathrm{~Hz}$, but the participation factors indicate that this mode will not participate for the predominately $x-y$ plane loadings that the machine will see during grinding operations. This conclusion was verified for the plane slide model by applying a force of $F(x, y, z)=(50,50,10) \mathrm{lb}$ to the regulating wheel node was assumed to vary sinusoidally. We then used the steady-state direct solution and the force procedure in ABAQUS. This procedure calculates the steady-state response of the model as a linear system at a given forcing frequency, and it can be set up to carry out a frequency sweep. We studied plots of the magnitude of the responses of each node. The displacement response of the upper housing is shown in Fig. 29 as plotted by ABAQUS. This plot shows peaks in the response at 200,400 , and $600 \mathrm{~Hz}$, which corresponds to modes 5,9 , and 13 for the plane slide model.

The basic natural frequencies of the plane slide and coated slide models are the same for the first eight modes because the basic geometry and the prebreakaway stiffness are the same. The INA slide design has a lower second mode than either of the other two designs, reflecting the lack of resistance in the slide ( $x$ ) direction supplied by the surface contact in those models. Note that the participation factor indicates that this mode indeed is in the roller/slide ( $\mathrm{x}$ ) direction.

\section{B. Direct Integration Procedure and Frequency Domain Analyses}

The procedure for comparing the dynamic stiffness was to apply a force as a function of time to the ABAQUS model and to use the force time-history and response records of each component and carry out frequency domain analyses of these records. This procedure is analogous to the experimental procedures used to determine dynamic stiffness as a function of frequency.

Although several different studies were made (frequency sweep at constant force levels, random force inputs, and single and frequency inputs using relatively large and small values of force magnitude, etc.), only two studies are reported in this work. The other studies were basically used to verify the results reported here.

Discussions with Goldcrown indicate that their interest in these results are for a 6500 surface-feet/minute grinding rate and that the INA slide machine was designed, tested, and delivered for a relatively "light" load grind (0.003-in. grind on aluminum valves). Therefore, one of the studies is defined as a "low load level" comparison. The force levels are assumed to vary about some steady-state value that was estimated to be $250 \mathrm{lb}$. The force into the model was assumed to be $1 / 10$ of this value and to vary sinusoidally with a frequency of $33 \mathrm{~Hz}$. An arbitrary value of $5 \mathrm{lb}$ of variation was assumed in the transverse direction, and these forces were applied both to the regulating wheel housing "centerline node" and to the grinding wheel "centerline node" in their proper directional senses. Table VI shows this loading. The model was preloaded in the vertical direction with the component weights. 
TABLE III

EIGENVALUE OUTPUT FROM ABAQUS FOR THE PLANE SLIDE MODEL

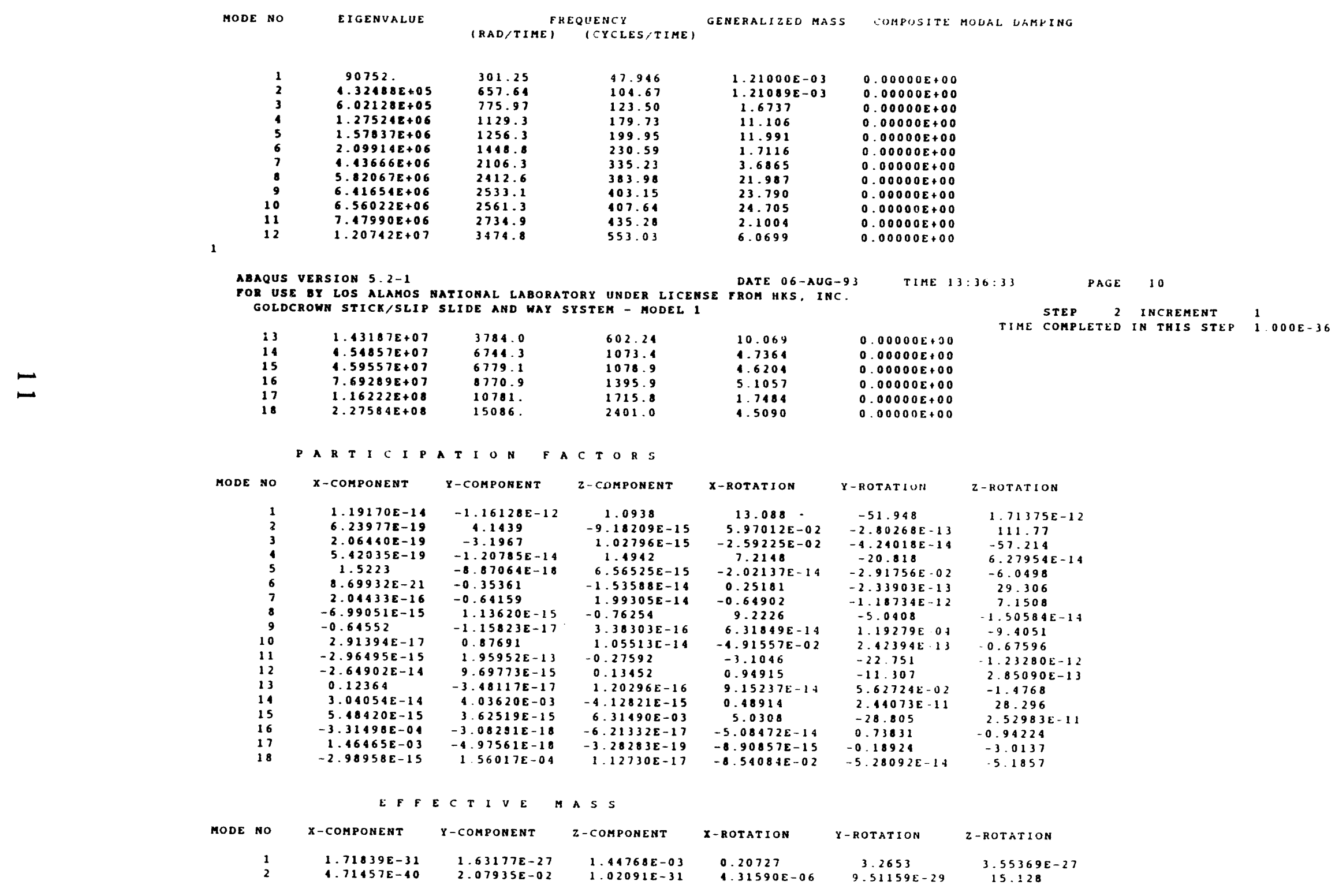


TABLE III, CONTINUED

EIGENVALUE OUPUT FROM ABAQUS FOR THE PLANE SLIDE MODEL

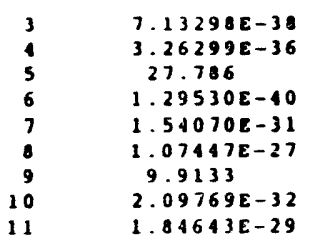

17.103
$1.62027 E-27$
$9.13532 E-34$
0.21102
1.5175
$2.83848 E-29$
$3.191418-33$
18.997
$8.06494 E-26$

$\begin{array}{ll}1.76861 E-30 & 1.12470 E-03 \\ 24.797 & 578.10 \\ 5.16832 E-28 & 1.89933 E-27 \\ 1.03752 E-28 & 0.10853 \\ 1.46438 E-27 & 1.5529 \\ 12.785 & 1870.2 \\ 2.72275 E-30 & 9.19778 E-26 \\ 2.75039 E-27 & 5.96937 E-02 \\ 0.15991 & 20.245\end{array}$

$3.00920 \varepsilon-27$

4813.4
$1.020578-0$

$1.02067 E-02$
$9.36423 E-26$

$5.19713 E-24$

558.70

$3.38474 E-0$

$1.45153 E-24$

1087.2

$5+78 \cdot 9$

$+379+3 E-26$
+38.87

138.87

188.50

$+.985015-27$

2104.4

11.288

ABAQUS VERSTON $5.2-1$ DATE 06-AUG-9

ABAQUS VERSION $5.2-1$ MATIONAL LABORATORY UNDER LICEASE FROM HKS, INC.

GOLDCROWN STICK/SLIP SLIDE AND WAY SYSTEM - MODEL I

PAGE 11

$\begin{array}{lll}\text { STEP } & 2 \text { INCREMENT } & 1 \\ \text { TIME COMPLETED IN THIS STEP } & 1.000 E-36\end{array}$

776.03

$124.259448-27$

$.37876 E-27 \quad 7.71605 E-05$

$1.38965 E-28 \quad 6.07213 E-29$

. $61068 \varepsilon-07 \quad 4.852308-35$

3.75064E-06 4.32844E-35

0.10984
$1.45705 E-31$

5.4683

$8.43411 \varepsilon-26$

$.04252 E-04$

$97107 E-3$

$.88423 \varepsilon-37$

116.94

1. $32004 E-26$

1. $38757 E-28$
3. $28916 E-02$

3792.2

$3833.8 \quad 2.95708 \mathrm{E}-21$

$6.26099 E \quad 02$

4.5329
15.880

TAA

37.853

37.853

37.853

2594.0

11073 .

13663. 
TABLE IV

EIGENVALUE OUTPUT FROM ABAQUS FOR THE INA SLIDE MODEL

MOdE No EIGEHViLLE

1
2
3
4
5
6
7
8
9
10
11
12

90752
$2.77638 E+05$
$1.32383 E+05$
$5.5322 E+05$
$1.22615 E+06$
$1.33477 E+06$
$1.63793 E+06$
$1.32555 E+06$
$5.41263 E+06$
$5.71543 E+06$
$6.17836 E+06$
$6.52363 E+06$

FHEQUENCH
(RAD, TIME) ICXCLES TIME)

GENEHALIZED Majo

MATSELE MATAL LABRINU 301.25
526.91
657.56
743.79
1107.3
1155.2
1279.8
2079.8
2326.5
2390.7
2485.7
2554.1

47.940
83.861
104.65
118.38
176.24
183.85
203.69
331.01
370.27
380.49
395.62
406.50

$1.210005-03$
1.3919
$1.212205-03$
0.67871
10.995
1.8302
10.713
3.5059
1.6766
18.388
24.786
24.643

$0.00000 E+00$

$0.00000 E+00$

$0.00000+00$

$0.00000 E+00$

$0.00000 E+00$

$0.00000 E+00$

$0.00000 E+00$

$0.00000 E+00$

$0.00000 E+00$
$0.00000 E+00$

ABAQUS VERSION $5.2-1$

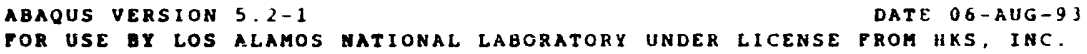
GSE GY LOS ALAMOS NATIONAL LABORATORY UNDER LICE
GOLDCROWN INA SLIDE AND DAMPER SYSTEM - MODEL 2

13
14
15
16
17
18

$1.11015 E+07$
$1.54227 E+07$
$2.618668+07$
$4.06519 E+07$
$7.65126 E+07$
$8.87294 E+07$

3331.9
3927.2
5146.5

5146.5
6375.9

6375.9
8747.1

530.29
625.03
819.09
1014.8
1392.2
1499.2

4.7379
10.866

7.3630

5.0465
5.0547
4.4543

1392.2
1499.2

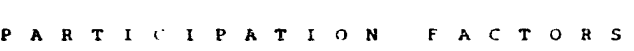

MODE NO

$X$-COMPONENT

$-3.33386 E-13$

-3.7564
-4.9072

1.2821
$-3.57777 E-19$

$-2.54236 \varepsilon-18$

$-1.28928 \varepsilon-17$
$-1.59415 \varepsilon-19$

1.5167

$-5.57842 E-14$

$-0.63017$

1. $85568 \mathrm{E}-1$

-0.65015
$5.23943 E$

2 - COMPONENT

1.0982

$-2.08974 E-14$
$1.91804 E-14$
$-4.70656 E-14$

$-4.78656 E-14$

1.4839

$-6.01881 E-13$

1. $33254 E-15$

$-5.18796 E-15$

$-0.83961$

$-1.24877 E-18$
$6.30094 E-14$

0.20200

0.88404

$2.03006 E-14$

$49039 E-16$

$45989 E-02$
$.97555 E-15$

$.97555 E-15$
$.82234 E-17$

$1.40774 E-16$
$2.12140 E-15$

2. $12140 \mathrm{E}-15$

$1.02630 E-0$
$1.93917 E-17$

1. $03541 E-14$

5. $04216 E-04$

$1.93917 E-17$
$-2.57488 E-16$

$13.136^{\circ}$

$13.136^{\circ}$
$2.00152 E-13$
0.100473

0.10473
$-6.33804 E-02$

7.4989
0.15260

$-1.19833 \mathrm{E}-1$

$-0.6679$

-0.20161
10.120

$-8.76986 \varepsilon-16$
$-5.17385 E-02$

$-5.17385 E-02$
1.3425

$-5.34441 E-15$
0.33202

0.33202
1.6557

4.6557
$-2.04005 E-1$

$-2.84005 E$
-0.30009

$$
\text { EFFECTI VE MAS }
$$

MODE NO
$X$-COMPONENT
$6.79440 E-33$
2.2880
1. $34487 E-28$
1. $36179 E-27$

Z-COMPONENT

$1.45927 E-03$
$6.07850 E-28$

0.20881
$5.57614 E-20$

3.2780
$1.52432 E$
2- RUTATION

5. $36985 E_{1}$

$-9.3+17$
150.79

150.69
94.619

1.63427E:-12

23.590

6. 0516

$1.10435 E-1$

$1.10435 E-13$
$6.07175 E-14$

-9.1144
-0.91198

$-6.99931 \mathrm{E}-1$

1.6220

18.019
$1.599835-13$

$1.59983 E$
-0.66967
-17
PAGE 10

INCREMENT ED IN THIS STEP 1 . OOOE- 36

$.00000 E+00$

$-8.1720$

-8.89310E-14

$-26.032$

3. $04812 \mathrm{t}$

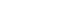

\begin{abstract}
(1)
\end{abstract}
(1) 
TABLE IV, CONTINUED

EIGENVALUE OUTPUT FROM ABAQUS FOR THE INA SLIDE MODEL

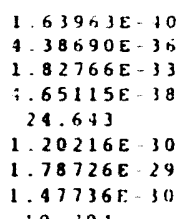

TIME COMPLETED IN THIS STEP 1.000 E- 36

12
13
14
15
16
17
18

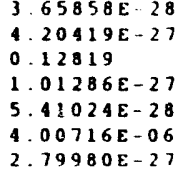

19.259

$1.95253 E-27$

9. $78379 \mathrm{E}-26$
0.19333

$6.59666 E-02$
8.5389 $569278-03$

1.

$2.153278-31$

$.31362 \varepsilon-29$ $90077 E-33$

$.00716 E-06$
$.79980 E-27$

$.67864 E-33$
$13244 E-06$

$2.95322 E-31$

TOTAL

37.853

37.853

37.853

$3.10352 \mathrm{E}-20$

0.81170
109.39

4.07707E-27

0.40113

2622.4

$1.44386 E-24$ $2.21827 E-02$
$5.82324 E-26$ $5.82324 E-26$ 2.8226

$4.14017 \varepsilon-25$ $2.32110 \mathrm{E}-24$

28.585

$1.29163 \mathrm{E}-25$

2.2668
1428.1

10810

13681. 
TABLE V

EIGENVALUE OUTPUT FROM ABAQUS FOR THE COATED SLIDE MODEL

MODE NO

E I.:EETUALUE EREQUENTL
(HAD,TIME) ICYCLES, TIME

ETEHALIZLE MAS:

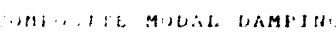

$\begin{array}{lc}1 & 90752 . \\ 2 & 1.32488 E+05 \\ 3 & 6.02128 E+05 \\ 1 & 1.27521 E+06 \\ 5 & 1.52712 E+06 \\ 6 & 2.09914 E+06 \\ 7 & 1.13666 E+06 \\ 8 & 5.82067 E+06 \\ 9 & 6.21046 E+06 \\ 10 & 6.56022 E+06 \\ 11 & 7.47990 E+06 \\ 12 & 1.20742 E+07\end{array}$

301.25
657.64
775.97
1129.3
1235.9
1448.8
2106.3
2412.6
2192.1
2561.3
2734.9
3474.8

47.946
104.67
123.50
179.73
196.70
230.59
335.23
383.98
396.63
407.64
435.28
$553.0 ?$

$1.210008-03$
$1.210898-03$
1.6737
11.106
11.186
1.7116
3.6865
21.987
23.196
24.705
2.1004
6.0699

$0.00000 E .00$

$0.00000 E+00$

$0.00000 E+00$
$0.00000 E+000$

$0.00000 E+00$

$0.000008+00$

$0.00000,00$

$0.00000 \varepsilon+00$

$0.00000 \times 00$

$0.00000 E+00$
$0.00000 E+00$

ABAQUS VERSION $5.2-1$ DATE O6-AUG-9 GOLDCROWN NONSTICK SLIDE AND WAY SYSTEM - MCUEL 2 - (MU = 0.02$)$

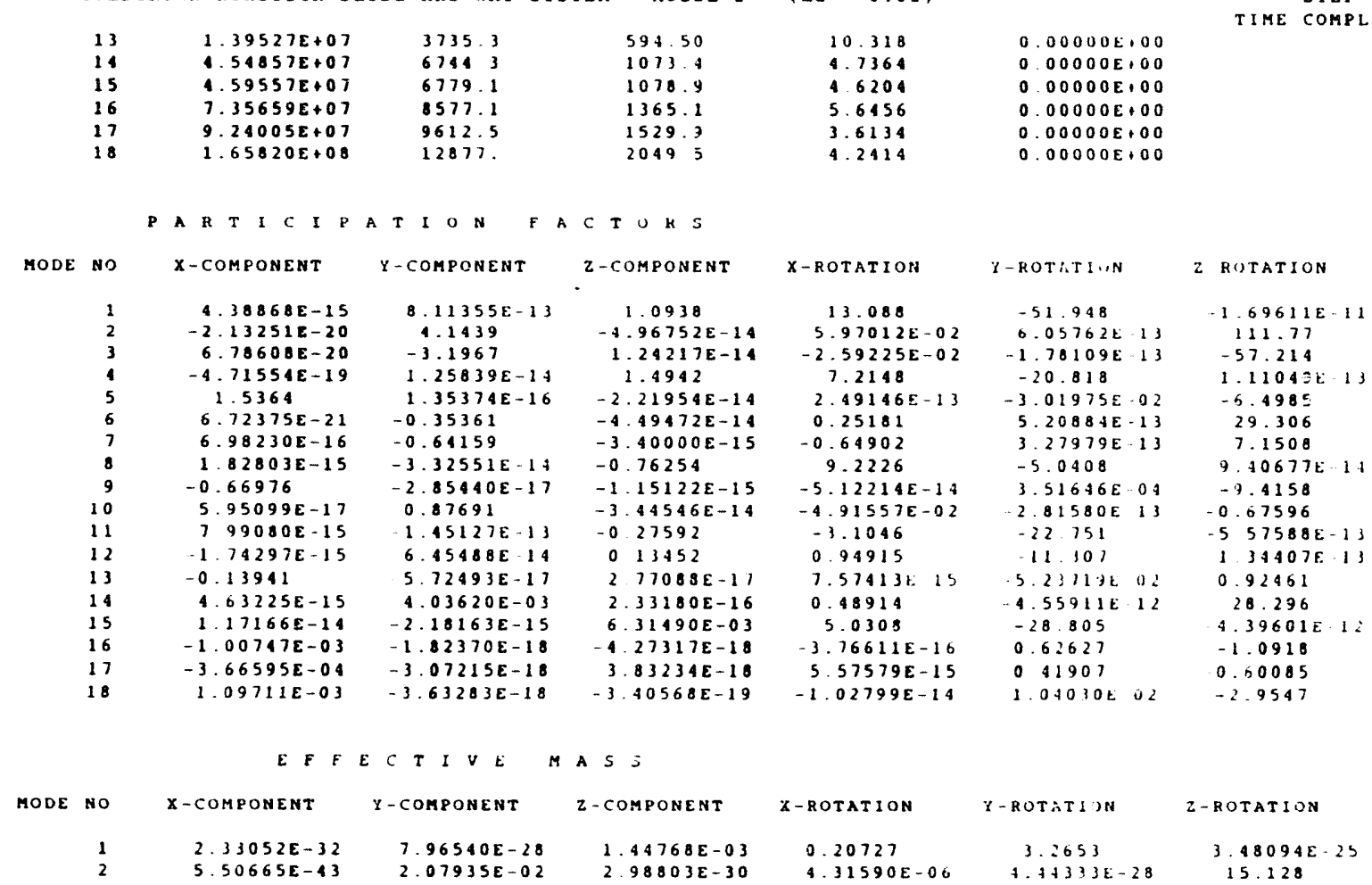


TABLE V, CONTINUED

EIGENVALUE OUTPUT FROM ABAQUS FOR THE COATED SLIDE MODEL

1

3
5
6
$?$
$?$
10
11

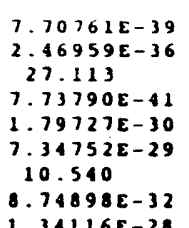

$1.12+70 E-03$

578.10
$7.12969 \varepsilon+25$

0.10833

1.5529
1870.2

$6.16455 E-26$

$9.969378-02$

20.245
30304962 4813 .
$1.0+718 E-02$ $1.64391 E-25$ $.96560 E-25$ 558.70
$2.90544 E-06$ $.958778-24$
1087.2
5478.9
$1.36956 E-25$
485.06
485.06
1469.9
188.50
$.94561 \mathrm{E}-25$
11.280
$.53020 E-25$

TIME 13:41:25

PAGE 1

ABAQUS VERSION 5.2-1 GOLDCROWN WONSTICK SLIDE AND WAY SYSTEA - MODEL 2 - (AU = 0.02 ;

$\begin{array}{ll}12 & 1.04401 E-29 \\ 13 & 0.20051 \\ 11 & 1.01633 E-28 \\ 15 & 6.34286 E-28 \\ 16 & 5.73025 E-06 \\ 17 & 1.85611 E-07\end{array}$

$17 \quad 1.85611 \mathrm{E}-07$ $5.10515 E-06$

TOTAL

37.853

\section{$2.52905 E-26$ \\ 0.10984}

5.4683

$5.91904 E-20$

1.1332

. $71605 E-05$

$19907 E-29$

. $410 j j E-35$

$5.59759 E-35$

37.853

$1.575335-31$

$2.57533 E-31$

$1.03088 E-34$

$1.306928-35$
$1.919492-37$

$1.00750 E-31$
$1.17338 E-28$

37.853

2594.0

776.09

$2.82998 E 0$
$9.84484 E^{2}$

0.63457

$4.59013 \mathrm{E}-0$

11075 
Although all of the nodal responses are available for analysis, the response of the center of mass of the upper housing was chosen to make comparisons for dynamic stiffness. The dynamic stiffness definition in the frequency domain used is actually the psuedo-dynamic stiffness defined by Eqs (1) and (2) in the Executive Summary.

\section{Results for the Low load level Comparison}

To carry out the low load level comparisons, the dynamic stiffness function for the center of mass of the upper housing was computed for each of the three models from the frequency response functions. In each case, the reference force was the $x$-direction force applied to the regulating wheel that houses the centerline node. Figures 30 through 38 show the directional dynamic stiffness functions for all three models calculated from 20 to $500 \mathrm{~Hz}$. The minimum dynamic stiffness (MDS) calculated for each case was also reported by the plotting algorithm. These results are presented in Table VII.

TABLE VI

APPLIED FORCES FOR "LIGHT"-CUT STUDY

$\begin{array}{lll}\text { Location } & \text { Force }(\text { lb) } & \text { Direction }\end{array}$

$\begin{array}{crc}\text { Regulating Wheel } & 25 & \mathrm{x} \\ \text { Housing } & 25 & \mathrm{y} \\ & 5 & \mathrm{z}\end{array}$

$\begin{array}{lcc}\text { Grinding Wheel } & -25 & \mathrm{x} \\ 25 & \mathrm{y} \\ 5 & \mathrm{z}\end{array}$

TABLE VII

LOW LOAD LEVEL DYNAMIC. STIFFNESS COMPARISON

Plane Slide

$\frac{\text { Static }}{\text { Magnitude (lb/in.) }} \quad \frac{\text { Dynamic }}{\text { Magnitude (lb/in.) }} \frac{\text { Dynamic }}{\text { Frequency } /(\mathrm{Hz})}$

$\begin{array}{lccc}\text { Longitudinal } & 16.2 \times 10^{9} & 739,900 & 177 . \\ \text { Vertical } & 508,120 & 139,500 & 117 . \\ \text { Transverse } & 58.3 \times 10^{9} & 1.61 \times 10^{6} & 162 .\end{array}$

INA Slide

$\begin{array}{lccr}\text { Longitudinal } & 14.6 \times 10^{9} & 27,540 & 93 . \\ \text { Vertical } & 249,000 & 144,000 & 113 . \\ \text { Transverse } & 54.8 \times 10^{9} & 1.93 \times 10^{6} & 159 .\end{array}$

Polymer Coated Slide

$\begin{array}{lccc}\text { Longitudinal } & 14.9 \times 10^{9} & 644,900 & 174 . \\ \text { Vertical } & 508,120 . & 139,800 & 117 . \\ \text { Transverse } & 58.3 \times 10^{9} & 1.59 \times 10^{6} & 162 .\end{array}$


Note that the responses of the models for this load level are predominantly in the linear or near-linear regime for the plane slide and coated slide model. This can be seen by comparing Figs. 30-38 and the frequency analysis results (Tables III-V). For example, Fig. 30 shows that the MDS value of $739,000 \mathrm{lb} / \mathrm{in}$. at $177 \mathrm{~Hz}$ corresponds to the undamped Mode 4 in Table III at $179.7 \mathrm{~Hz}$. The MDS value of $139,500 \mathrm{lb} / \mathrm{in}$. at $117 \mathrm{~Hz}$ in the $\mathrm{y}$ direction Fig. 31 corresponds to Mode 3 in Table III. The participation factors for this mode provide a large $y$-value of response for an $x$-excitation because of the rotational contributions. In effect, this mode is the "bending" of the machine in the $x-y$ plane. Most of the results for these two designs correspond to a mode in the linear modal analysis. However, the INA design, even at this low load level responds in a nonlinear fashion, which is reflected in the dynamic stiffness function shown in Figs. 36-38. For example, no amplifications of response or low values of dynamic stiffness can be correlated with a natural frequency from Table IV and Fig. 36 (the $x$-directional responses). The large values of damping supplied by the INA dampers and the lack of $x$-direction stiffness may be the reason that the $83.9-\mathrm{Hz}$ Mode 2 in Table IV does not appear to produce a low value of dynamic stiffness near this frequency. For the $y$ - and $z$-directional responses, however, there does appear to be some correspondence (Modes 4 and 5 in the $y$ - and z-directions, respectively).

\section{Nonlinear Response of the Models}

The nonlinear response of the models was performed to characterize the response of the designs when the load levels were large enough to cause the slides to have some motion during the grinding operations. Because the motion leads to a continual stick-slip response in the plane slide and coated slide designs, the machine would not be be likely to be operated at this load level, but the comparison might be useful in determining which design will show the best accuracy with the least control problems with the larger loads. Our goal was to simulate a random "part-chatter" condition.

Here, the load condition was to apply a relatively large random force with a power spectra density function that has energy in all frequencies from 30 to $250 \mathrm{~Hz}$. Because the friction effects are all in the $x-z$ plane of the model, this loading was applied to the $x$-direction only at the regulating wheel node centerline. The force level chosen was $250 \mathrm{lb}$. The timehistory of this input is shown in Fig. 39.

\section{E. Results of the Nonlinear Regime Comparisons}

The frequency response functions become more difficult to understand for this force level. The dynamic stiffness functions for the $x$-direction response of the upper housing is shown in Figs. 40-42 from 20 to $500 \mathrm{~Hz}$ for all three models. The functions are very "spiky" compared with those from the responses obtained in the linear regime. Our experience has shown that such results are characteristic of nonlinear systems of these types. Several problems show up when such functions are analyzed in a straight-forward manner. The first is illustrated in Table VIII, Columns 2 and 4. The MDS from Figs. 40-42 is reported in Column 2. The problem with the "spiky" behavior is illustrated in Figs. 43-45 and Column-4. The frequency step in computing the Fourier transform is too large to resolve the minimum values in Figs. 40-42. A "zoom" analysis in the frequency range of the spikes, gives the results from Figs. 43-45 and Column 4.

Another problem with nonlinear regime analysis can be seen in Figure 46, which shows the time-history of the response of the center of mass of the upper housing for the plane slide model. A study of this figure indicates that different frequency responses occur at different times, indicating nonstationarity. Thus, if the different time-windows are analyzed and the 
MDS is sought, the results found in Table VIII, Columns 6-8 are found. These values are reported in the tables shown in the executive summary. The nonlinear regime values in the INA slide design differ very little from the low load level values because the load path is the same in both cases, and it does not change with the larger load. The MDS value, however, is found at a lower frequency.

A different measure of overall dynamic stiffness for loads that cause the response to be nonlinear is the frequency-averaged value, defined as

$S_{\text {ave }}(w)=\frac{1}{w} \int_{0}^{500 H_{2}} S(w) d w$

These values are also reported in Table VIII for the nonlinear studies that were performed.

\begin{tabular}{|c|c|c|c|c|c|c|c|}
\hline \multirow[b]{2}{*}{ Model } & \multicolumn{7}{|c|}{$\begin{array}{c}\text { TABLE VIII } \\
\text { RESULT FROM NONLINEAR RAND }\end{array}$} \\
\hline & $\begin{array}{l}\text { MDS from } \\
20-500 \mathrm{~Hz} \\
(\mathrm{lb} / \mathrm{in} .) \\
(\mathrm{Hz})\end{array}$ & $\begin{array}{l}\text { Frequency } \\
\text { for MDS } \\
(\mathrm{Hz})\end{array}$ & $\begin{array}{l}\text { "Zoom" } \\
\text { Value } \\
\text { (lb/in.) }\end{array}$ & $\begin{array}{l}\text { Frequency } \\
\text { Averaged } \\
\text { (lb/in.) }\end{array}$ & $\begin{array}{l}\text { Minimum } \\
\text { MDS found } \\
\text { for various } \\
\text { time windows } \\
\text { (lb/in.) }\end{array}$ & $\begin{array}{l}\text { Frequency } \\
\quad(\mathrm{Hz})\end{array}$ & $\begin{array}{l}\text { Time } \\
\text { Window } \\
\text { (s) }\end{array}$ \\
\hline $\begin{array}{l}\text { Plane } \\
\text { slide }\end{array}$ & 192,000 & 168.5 & 183,300 & $14.4 \times 10^{6}$ & 10,160 & 61.2 & $0.6<t<0.8$ \\
\hline $\begin{array}{l}\text { INA } \\
\text { slide }\end{array}$ & 55,710 & 39.5 & 24,230 & $39.5 \times 10^{6}$ & 24,140 & 39.2 & $0.1<\mathrm{t}<1.0$ \\
\hline $\begin{array}{l}\text { Coated } \\
\text { slide }\end{array}$ & 12,080 & 79.1 & 2,202 & $17.1 \times 10^{6}$ & 5,853 & 54.5 & $0.6<t<1$ \\
\hline
\end{tabular}

The rms values of dynamic stiffness over the $500-\mathrm{Hz}$ range are as follows.

$\begin{array}{lll}\text { Plane slide } & 29.4 \times 10^{6} & \mathrm{lb} / \mathrm{in} . \\ \text { INA slide } & 67.9 \times 10^{6} & \mathrm{lb} / \mathrm{in} . \\ \text { Coated slide } & 33.8 \times 10^{6} & \mathrm{lb} / \mathrm{in} .\end{array}$




\section{CONCLUSIONS}

The plane slide design has the larger values of dynamic stiffness in the slide directions. However, the INA slide design is intriguing because there is no deterioration of performance for larger loads in terms of stiffness. Both the value and the frequency at which the MDS occurs can, potentially, be improved by stiffening the components in the load path to the swivel plate.

On the basis of the rms values of dynamic stiffness over the $500-\mathrm{Hz}$ range and the "spiky" dynamic stiffness functions for the coated slide, we conclude that control and accuracy with the coated design will likely be more difficult to achieve. Overall performance might improve, however, if some additional damping mechanism is included in this design. 


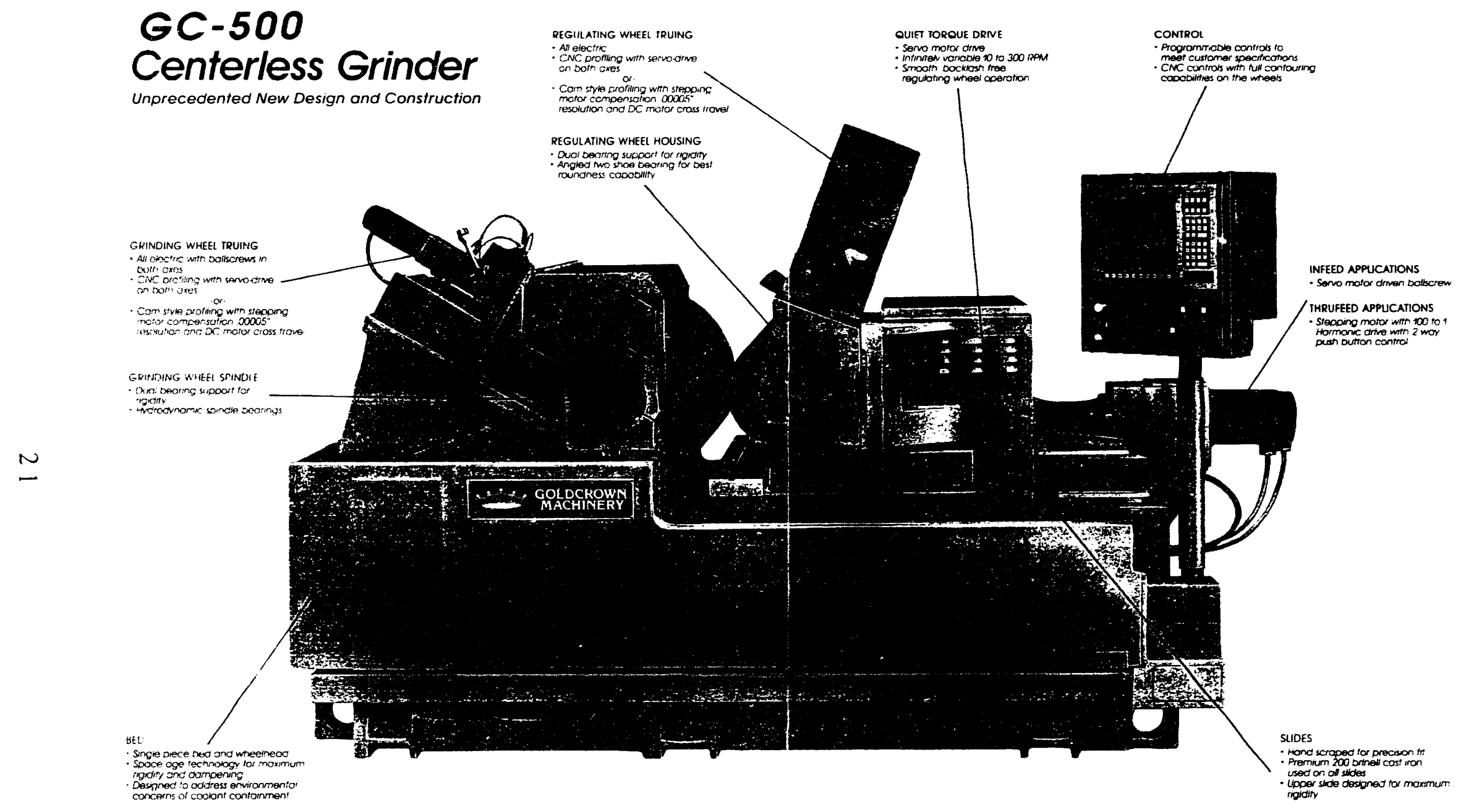

Fig. 1. Frontpiece from the GOLDCROWN GC-500 advertising brochure. 


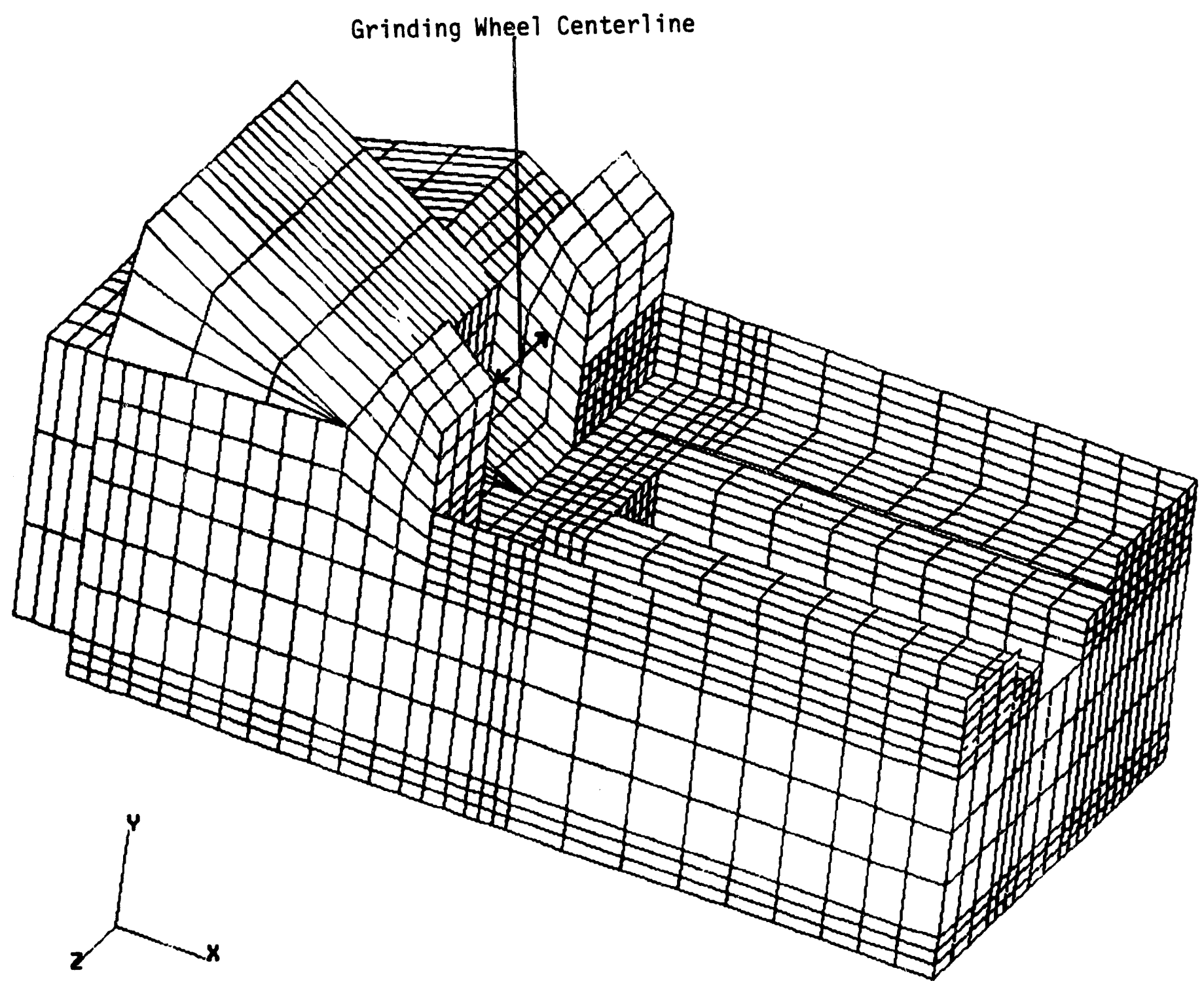

Fig. 2. Finite element model of the base for the GC-500. This view shows the swivel pin location and the approximate location of the grinding wheel centerline. 


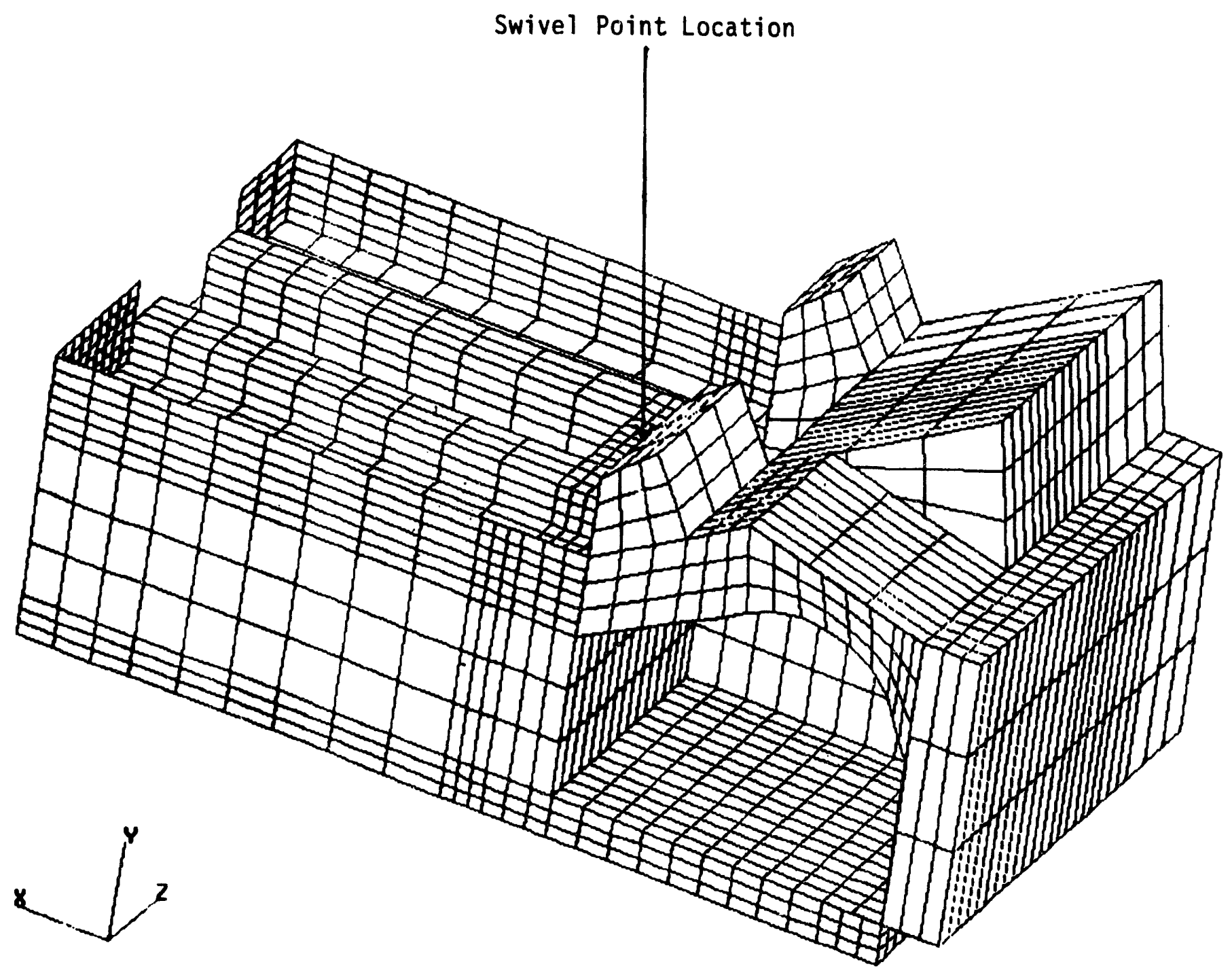

Fig. 3. Opposite side view of the base model of Fig. 1 showing the 40 HP drive motor cavity. 


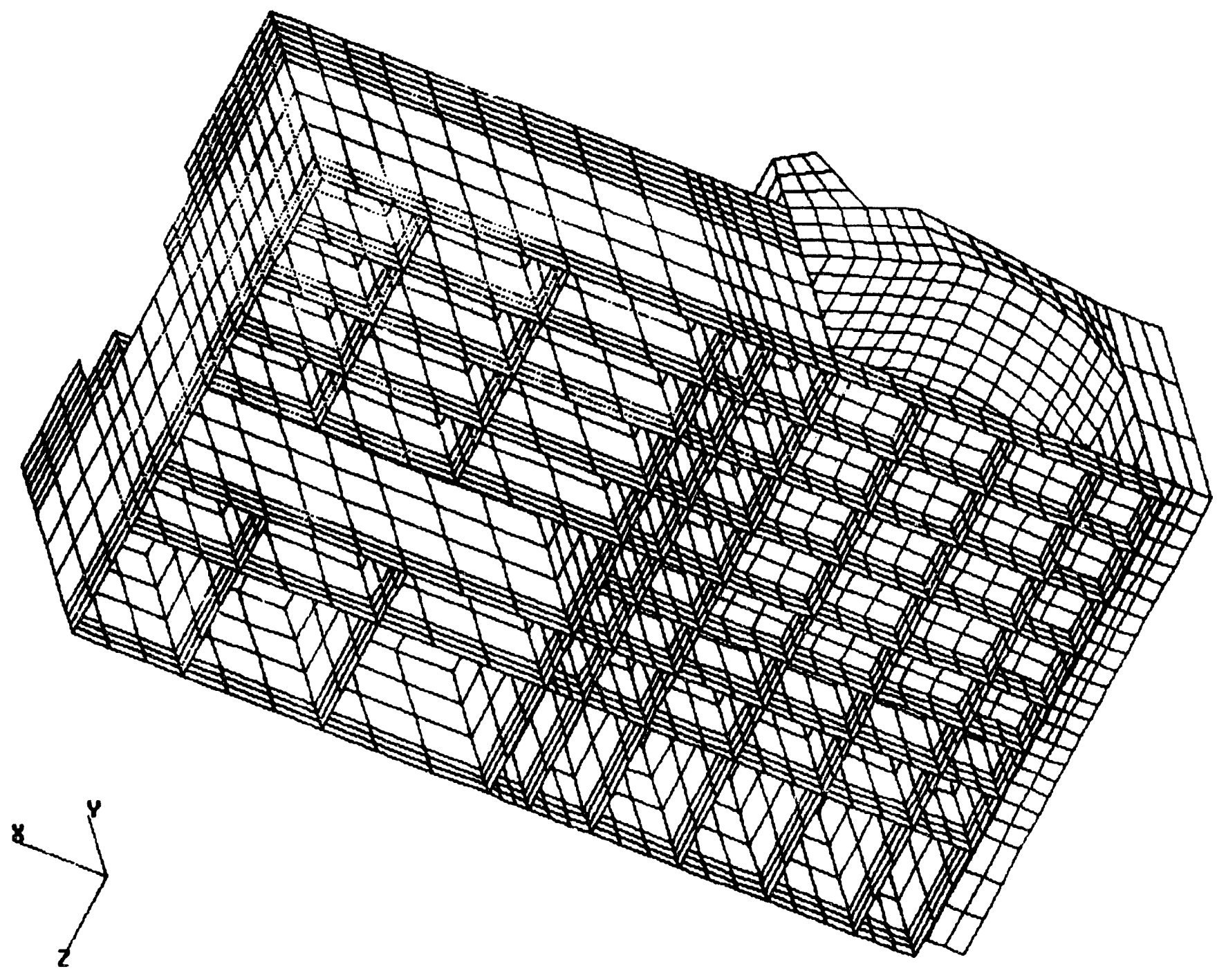

Fig. 4. Bottom view of the base model showing the ribbed construction of the base. 


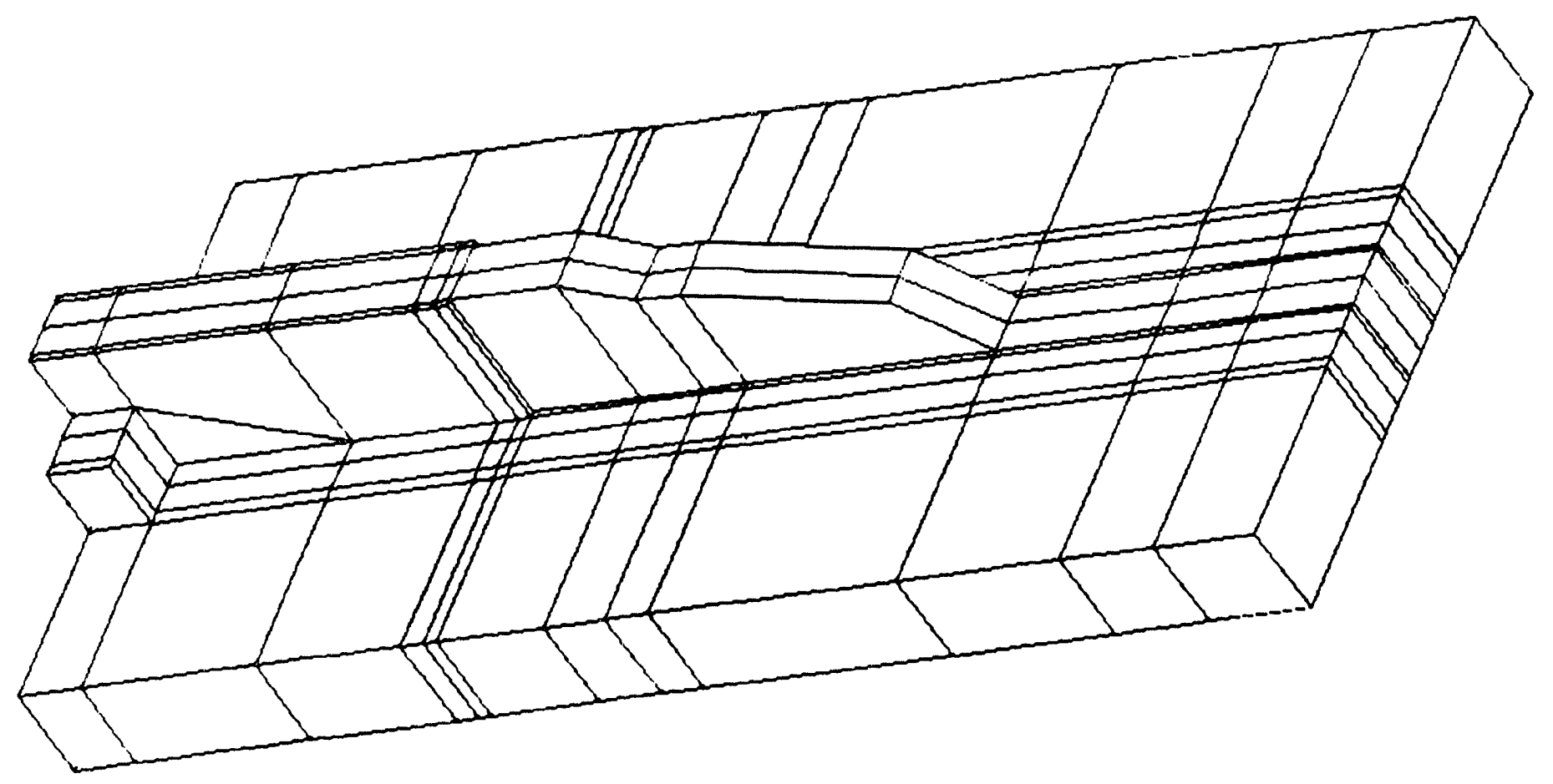

$x$
$z$

Fig. 5. Bottom view of the finite element model of the swivel plate with the location of the swivel pin centerline designated. 


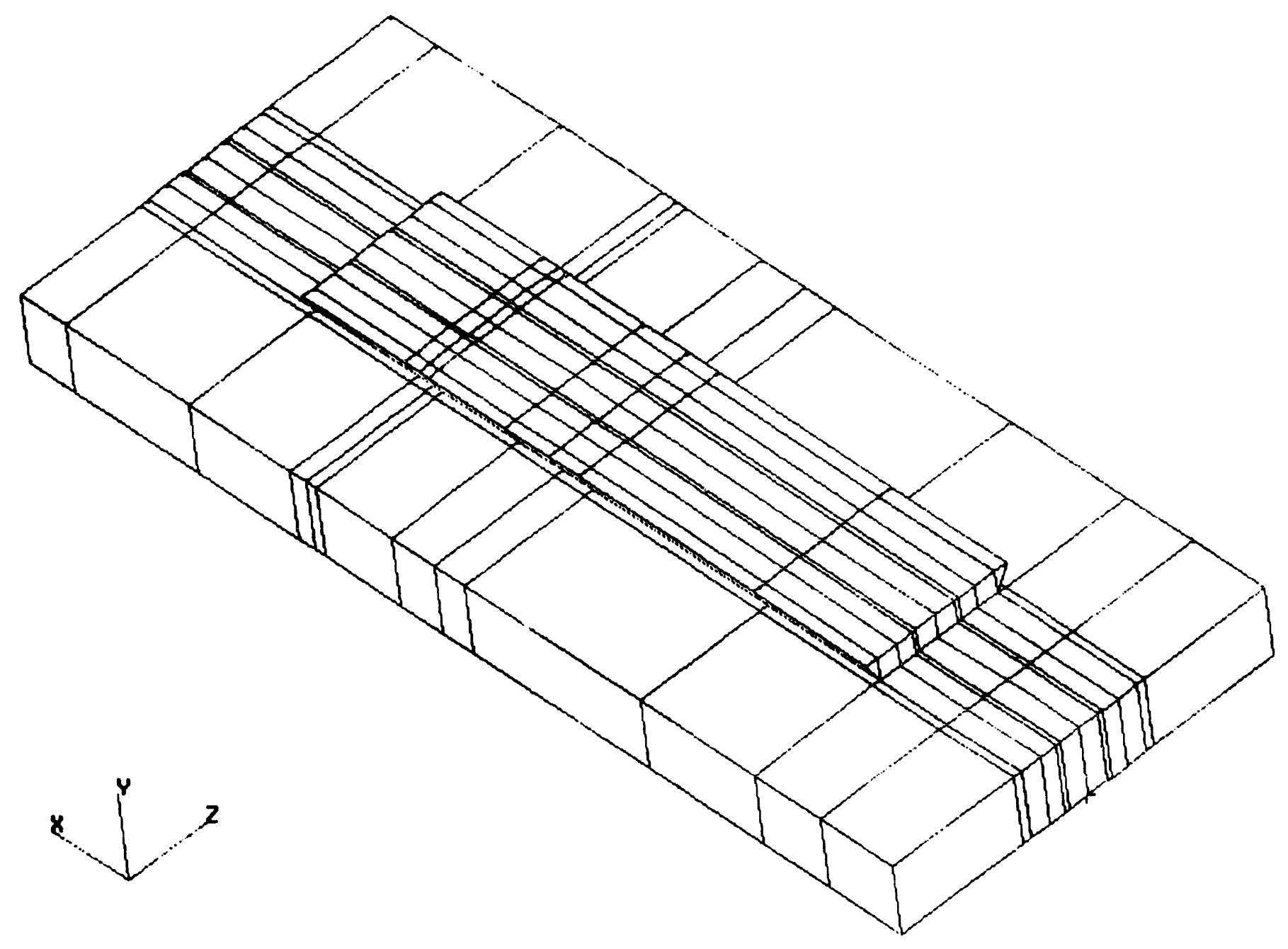

Fig. 6. Top view of the swivel plate for the plane slide model showing the dovetail way for the lower slide. 


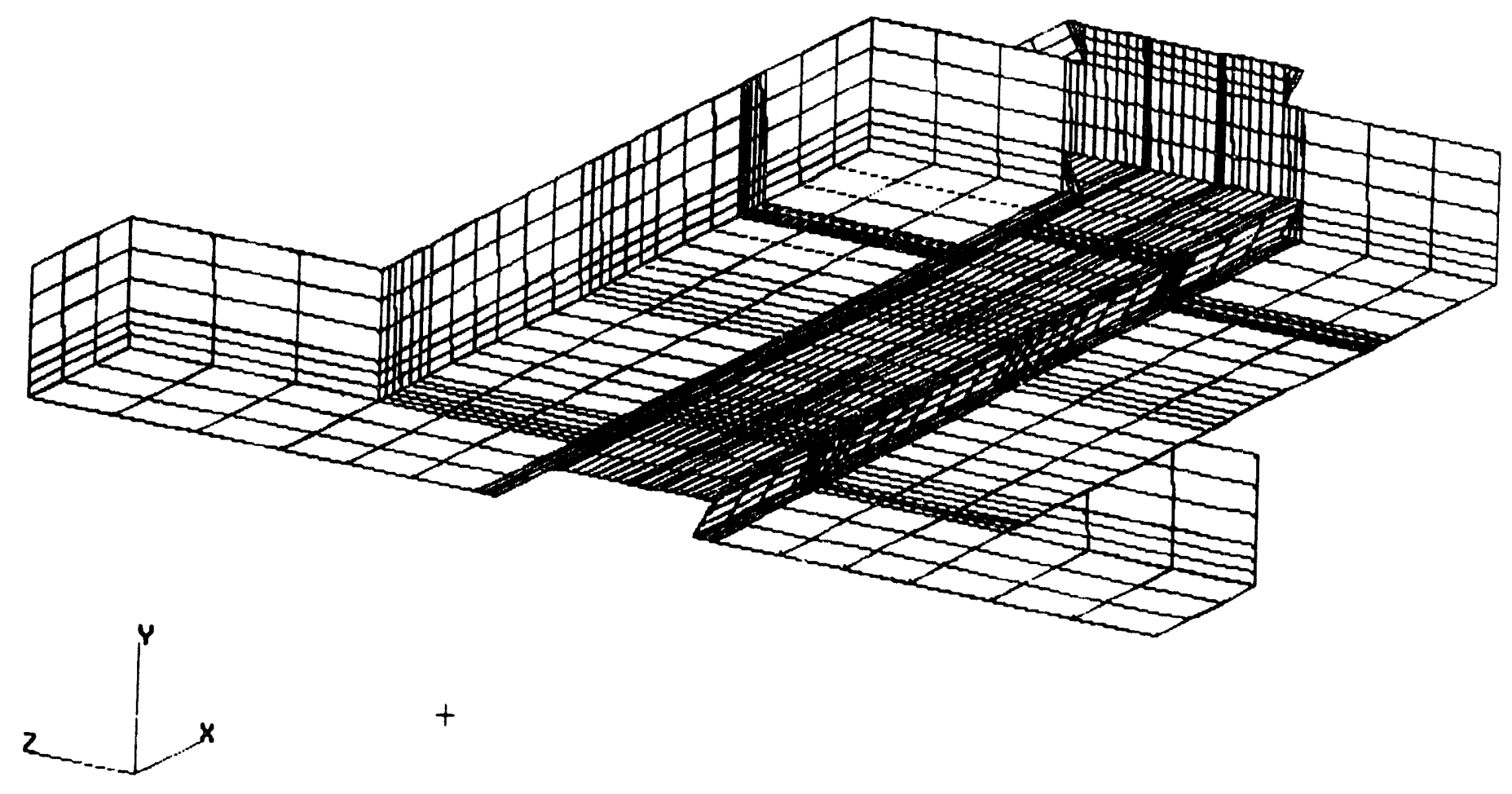

Fig. 7. Finite element model of the lower slide with the upper dovetail way visible on the top surface. The "ear" structure on the far end is a representation of the piurt that supports the feedthrough for the work rest structure. 

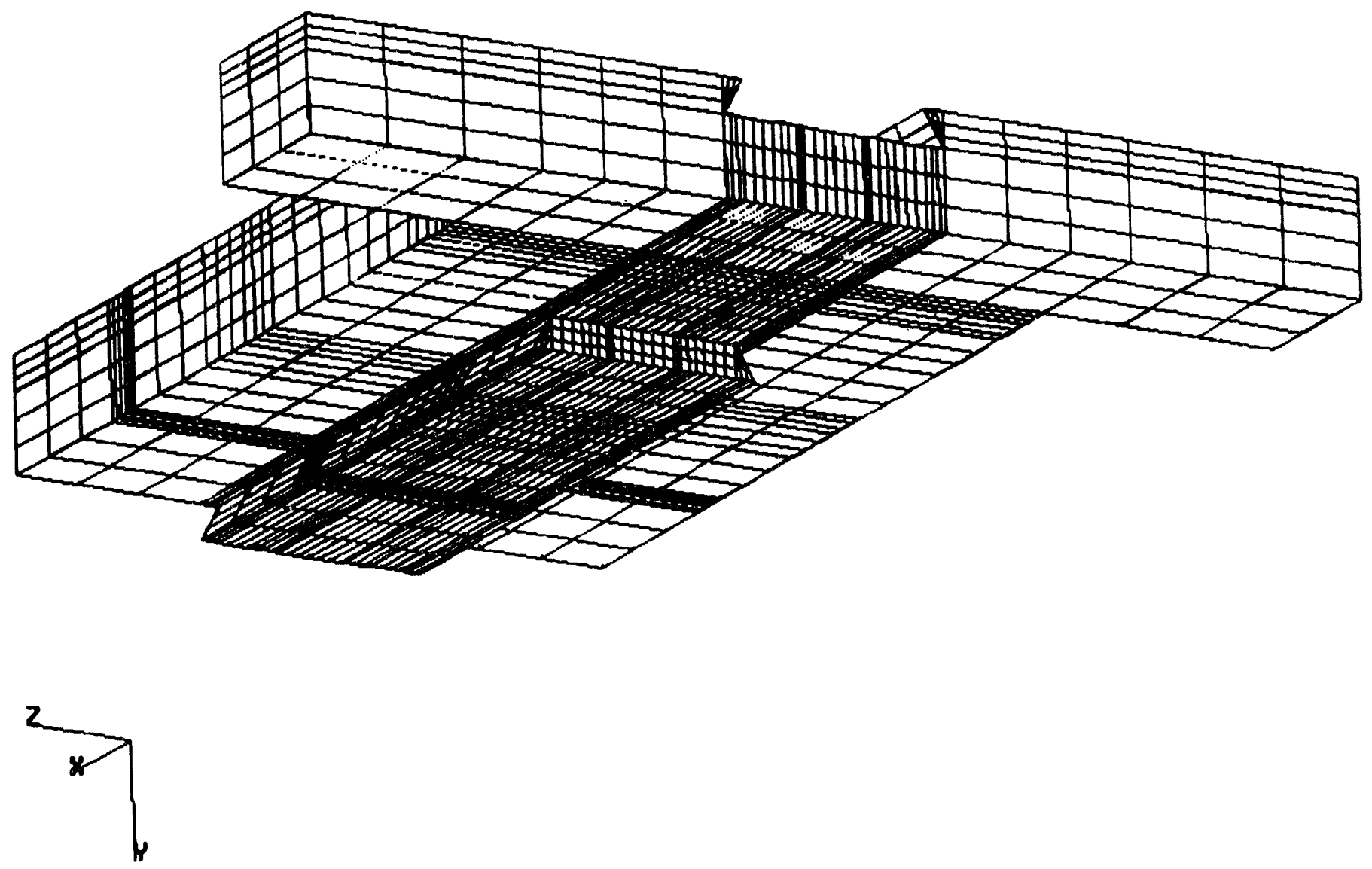

Fig. 8. Top view of the lower slide model showing the upper slide way. 


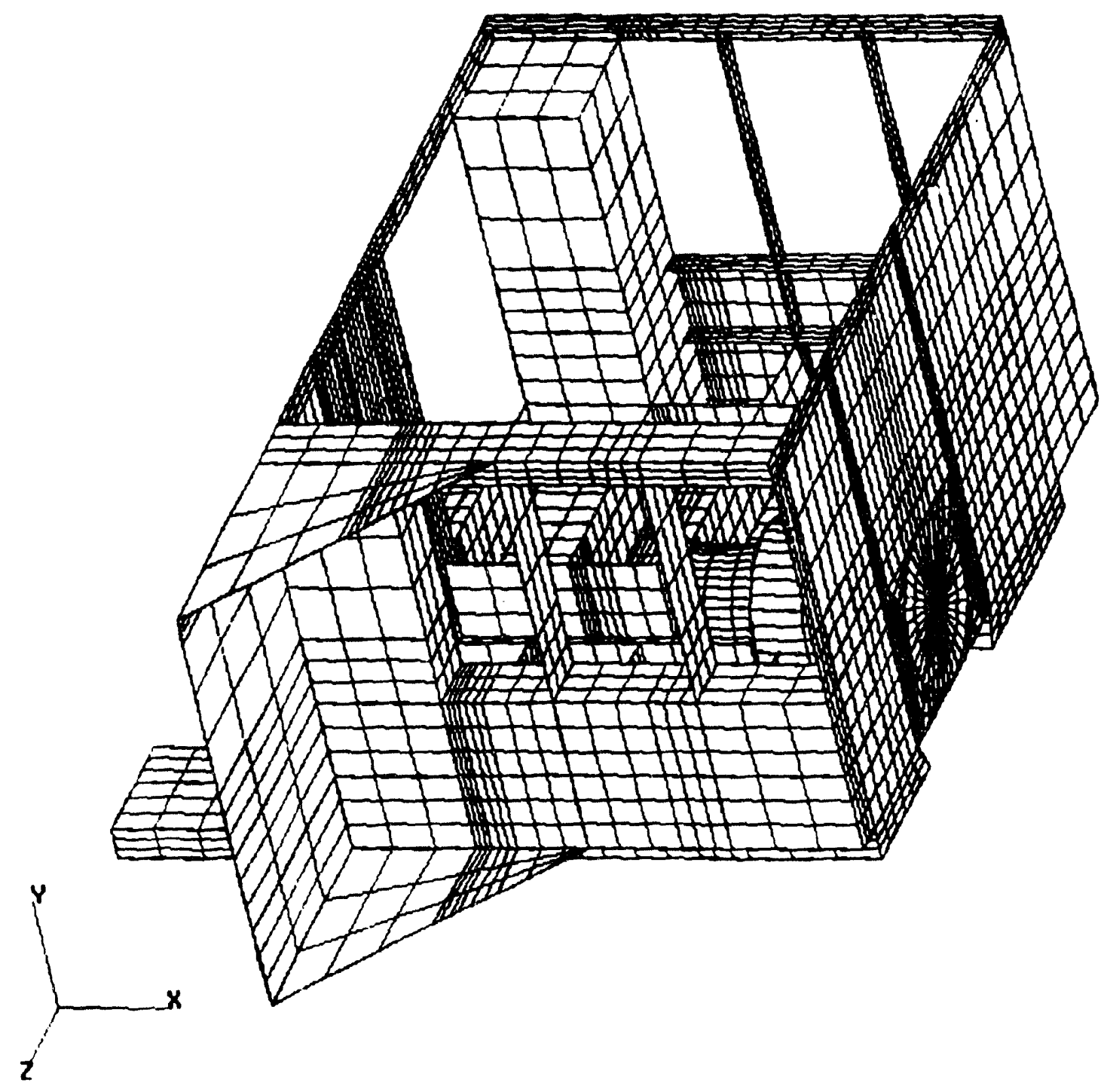

Fig. 9. Top oblique of the upper housing model with the ball screw housing visible along with the upper slide. 


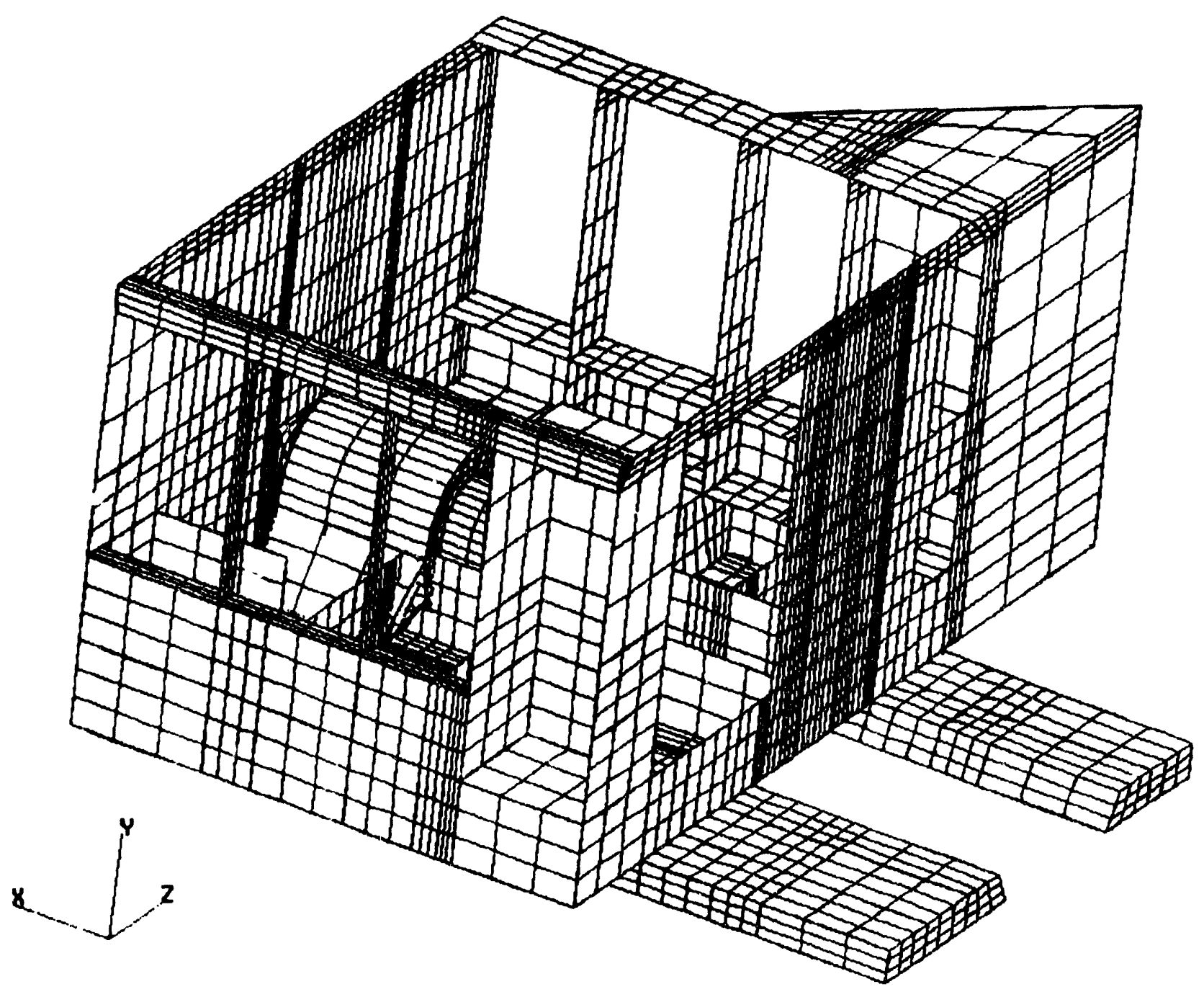

Fig. 10. The upper housing model from the opposite side of Fig. 9. (nonstructural cover plates have not been modeled). 


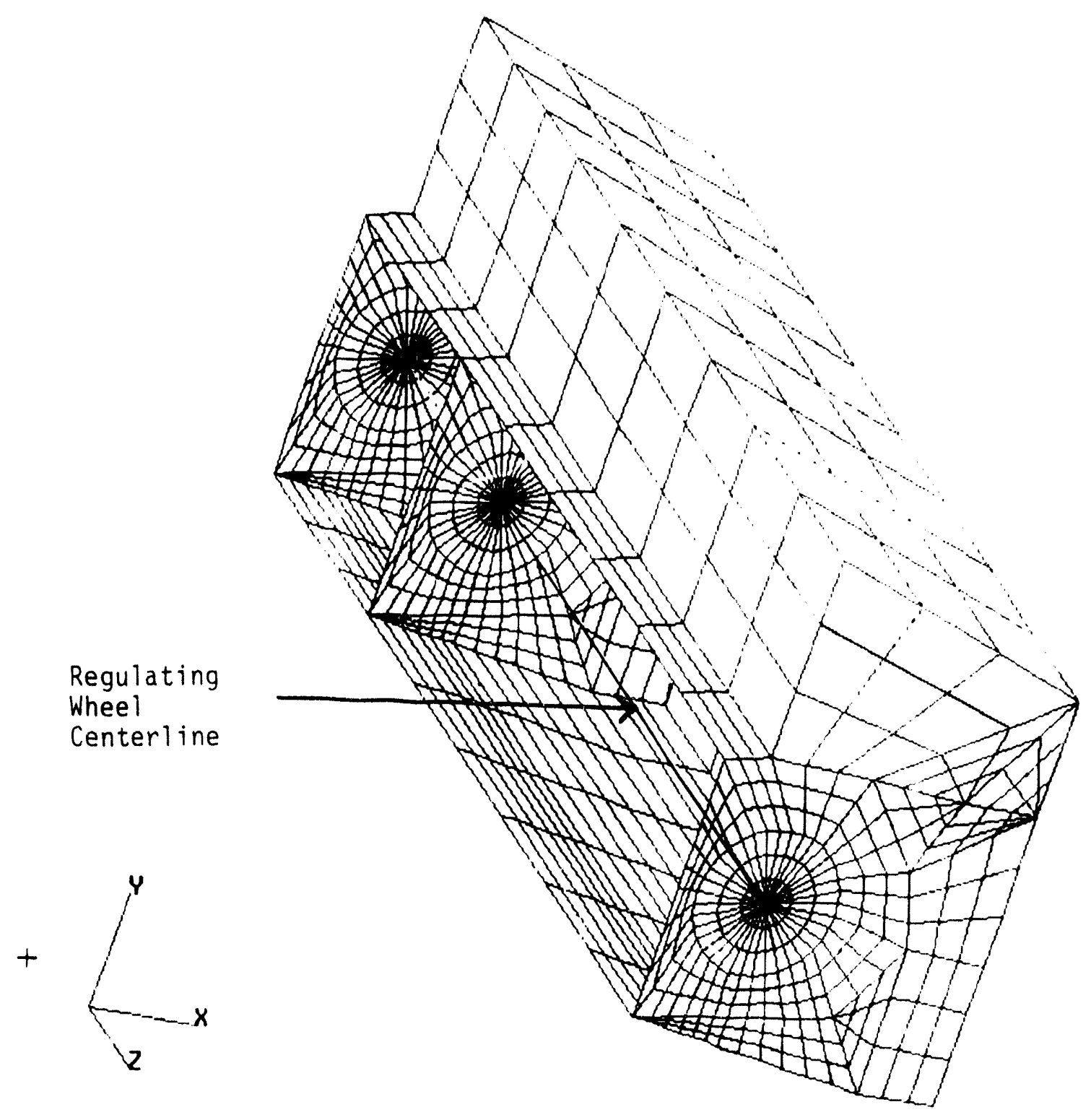

Fig. 11. The regulating wheel housing with the regulating wheel centerline shown. 


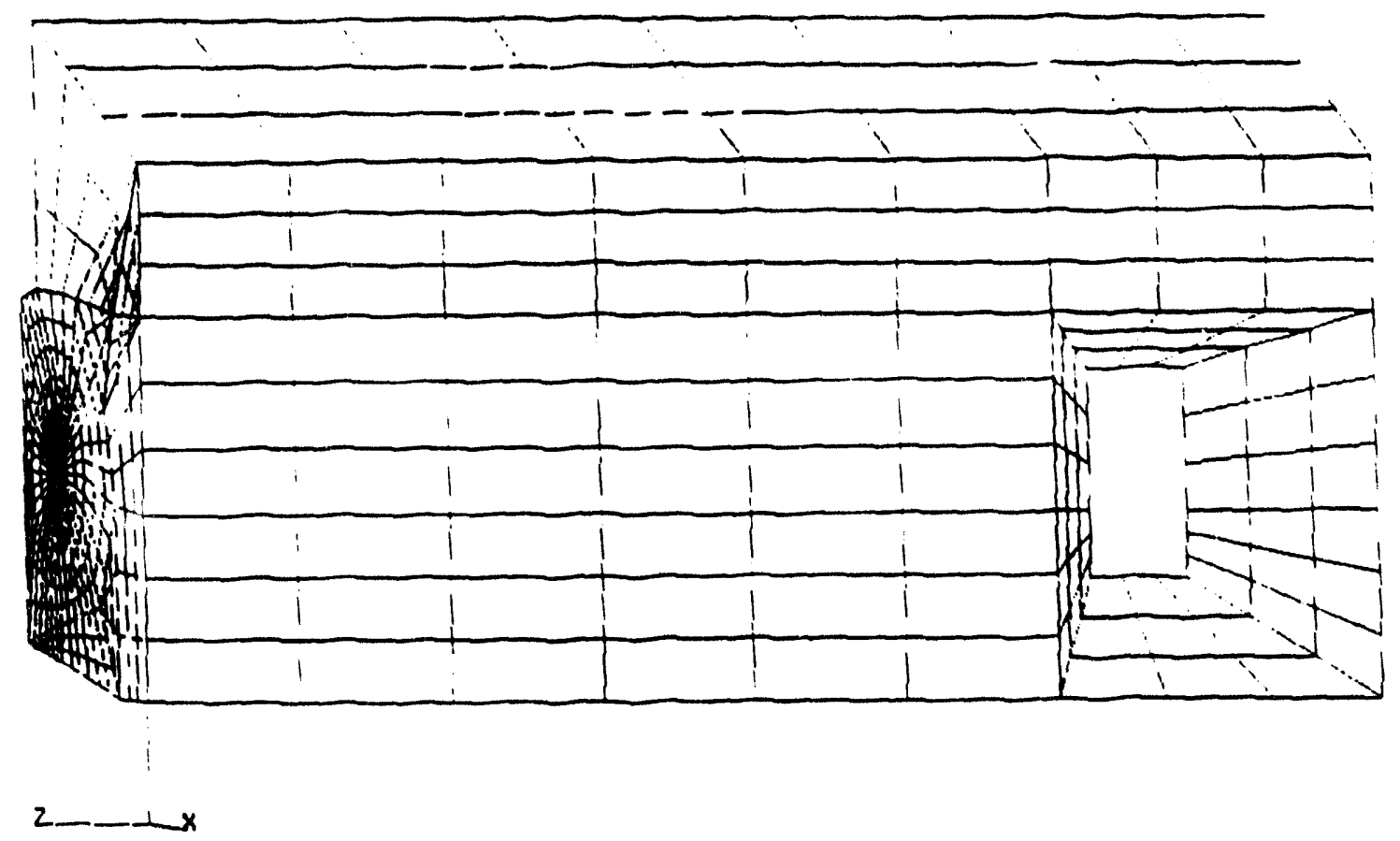

Fig. 12. The back of the regulating wheel housing with the opening for the drive motor visible. 

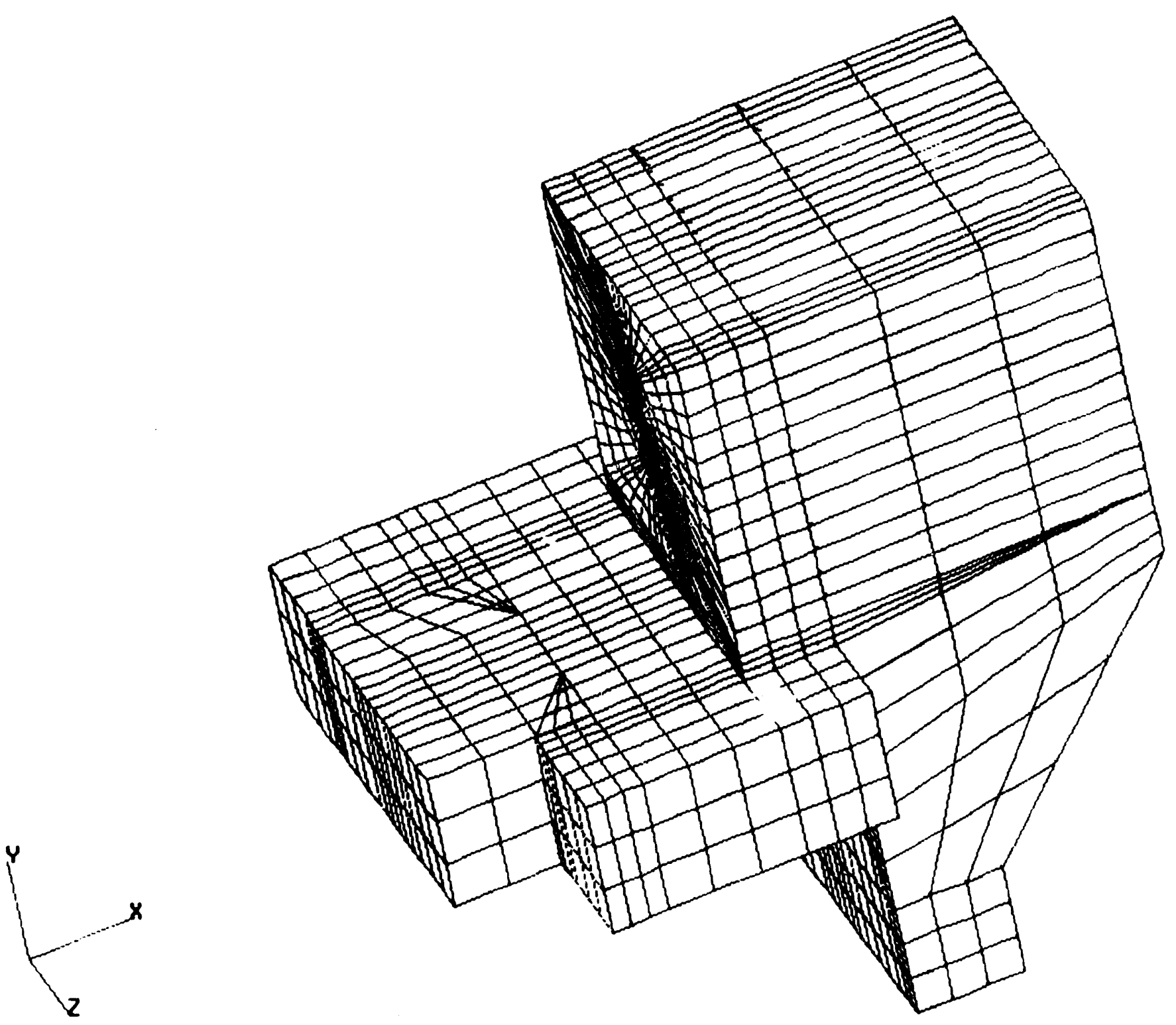

Fig. 13. Oblique top view of infeed body model. 


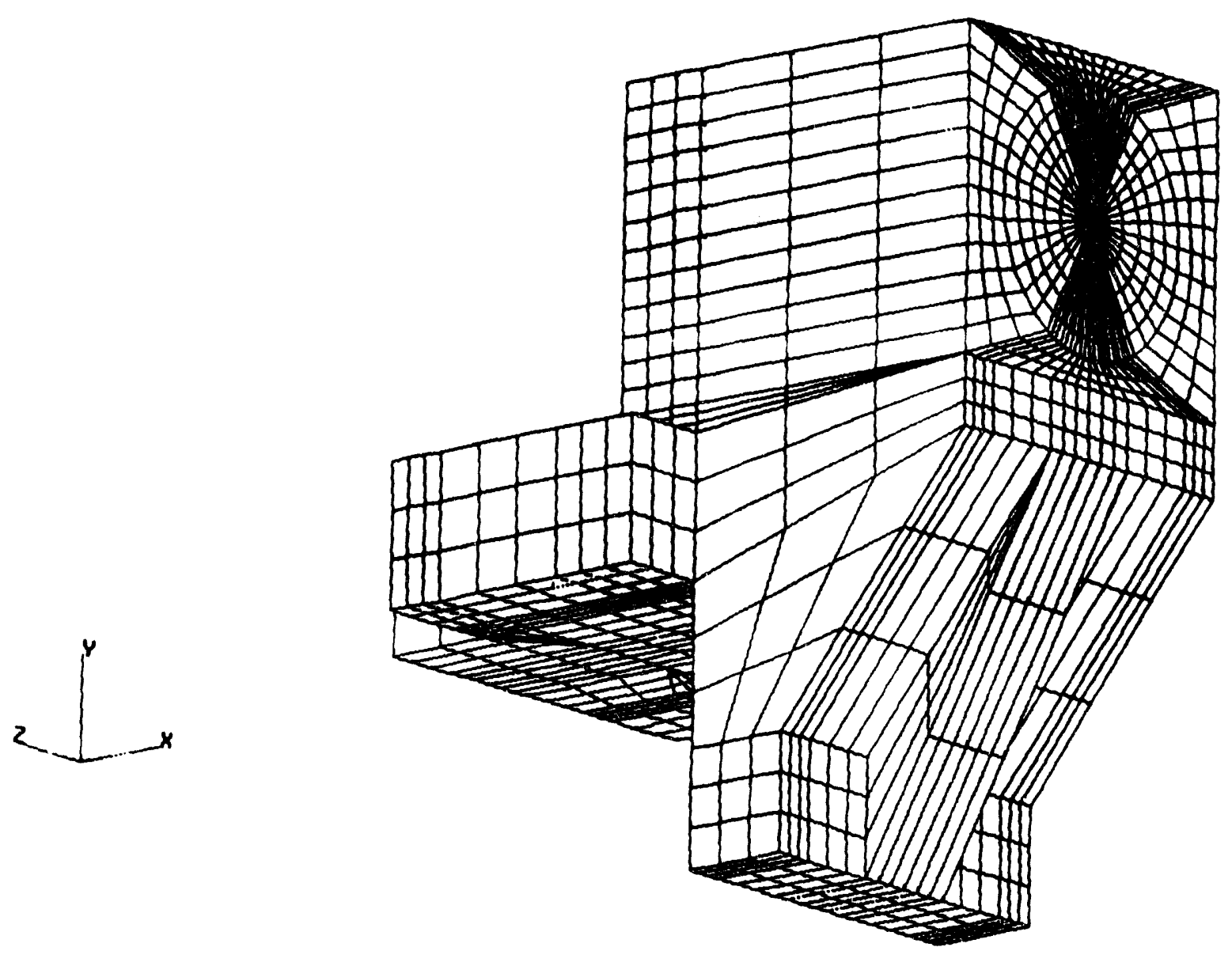

Fig. 14. Oblique bottom view of infeed body model. 


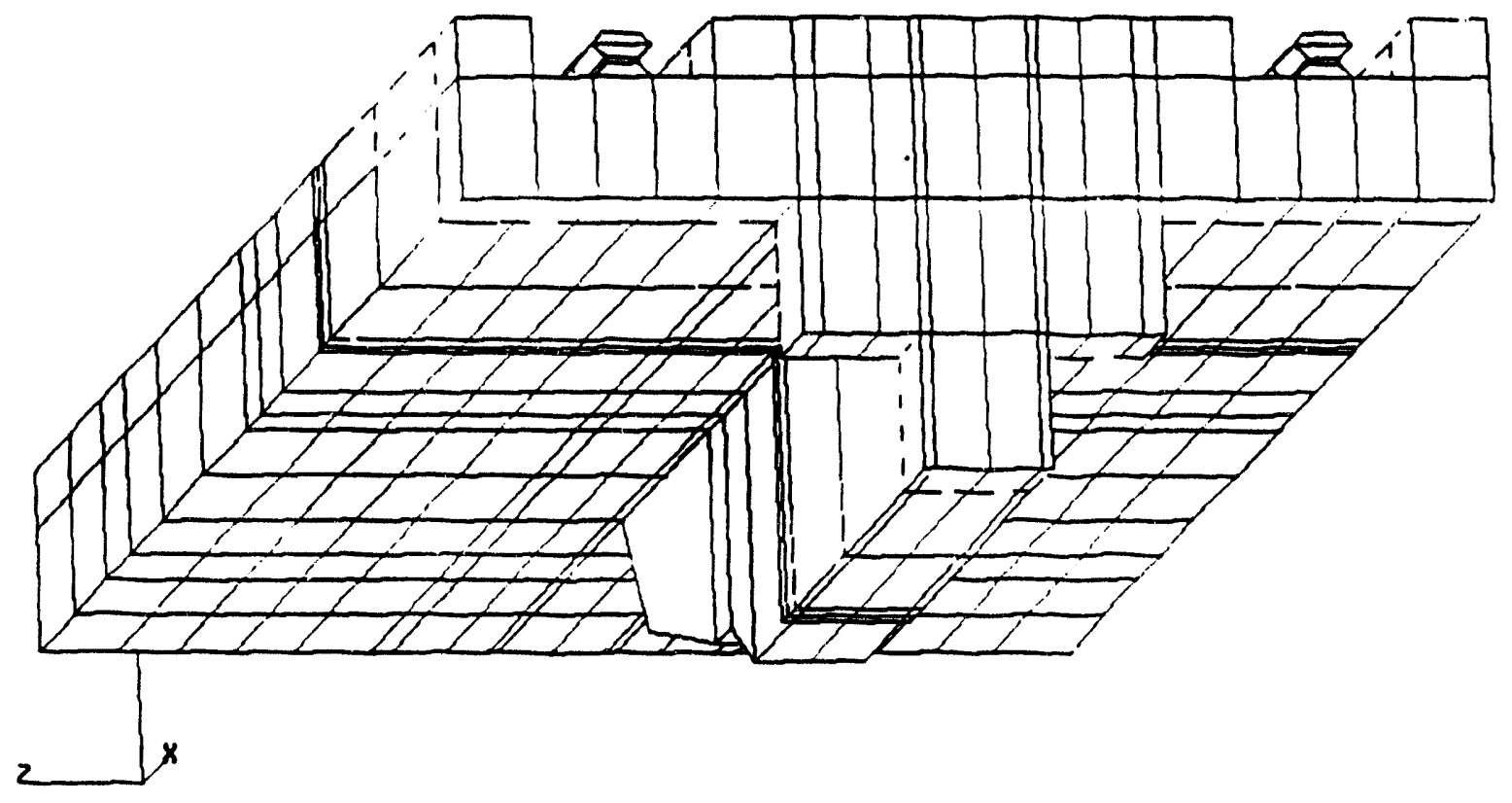

Fig. 15. Bottom end view of the INA model swivel plate showing the modifed swivel plate structure and the INA bearing rails. 


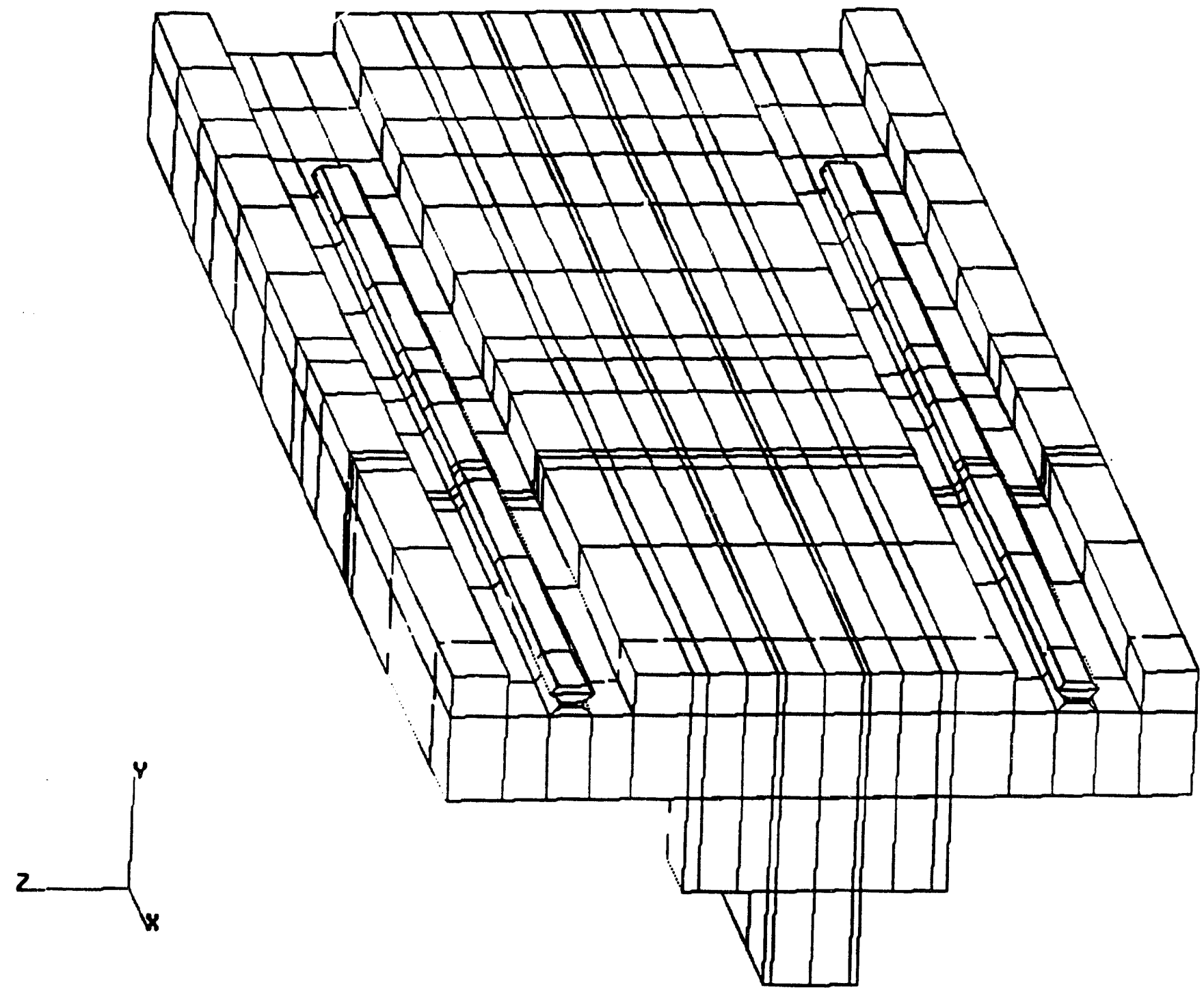

Fig. 16. Top view of the INA model swivel plate with full view of rails. 


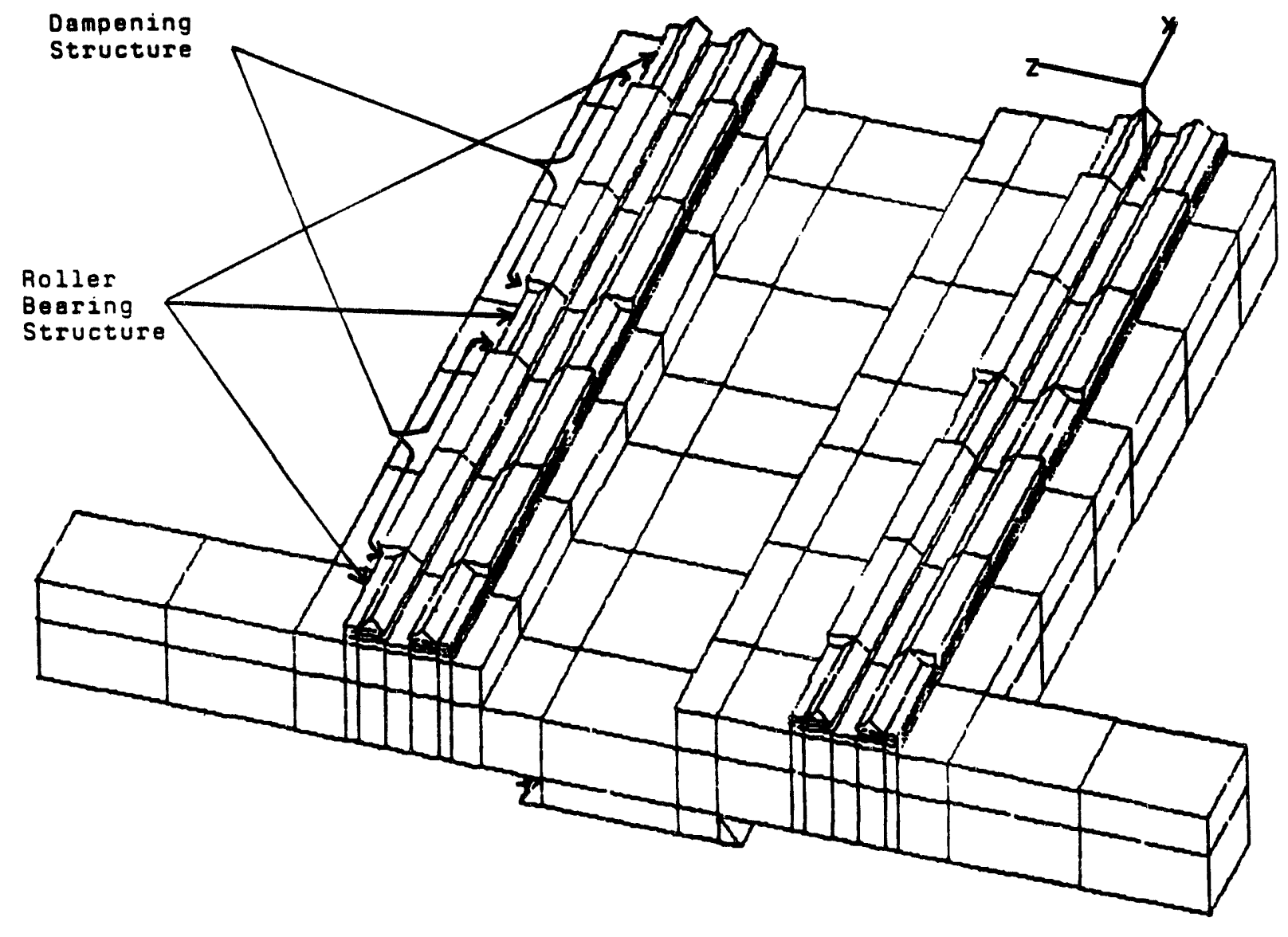

Fig. 17. Bottom view of the INA model lower slide with the recirculating rollerbearing structure and the damper structure called out. 


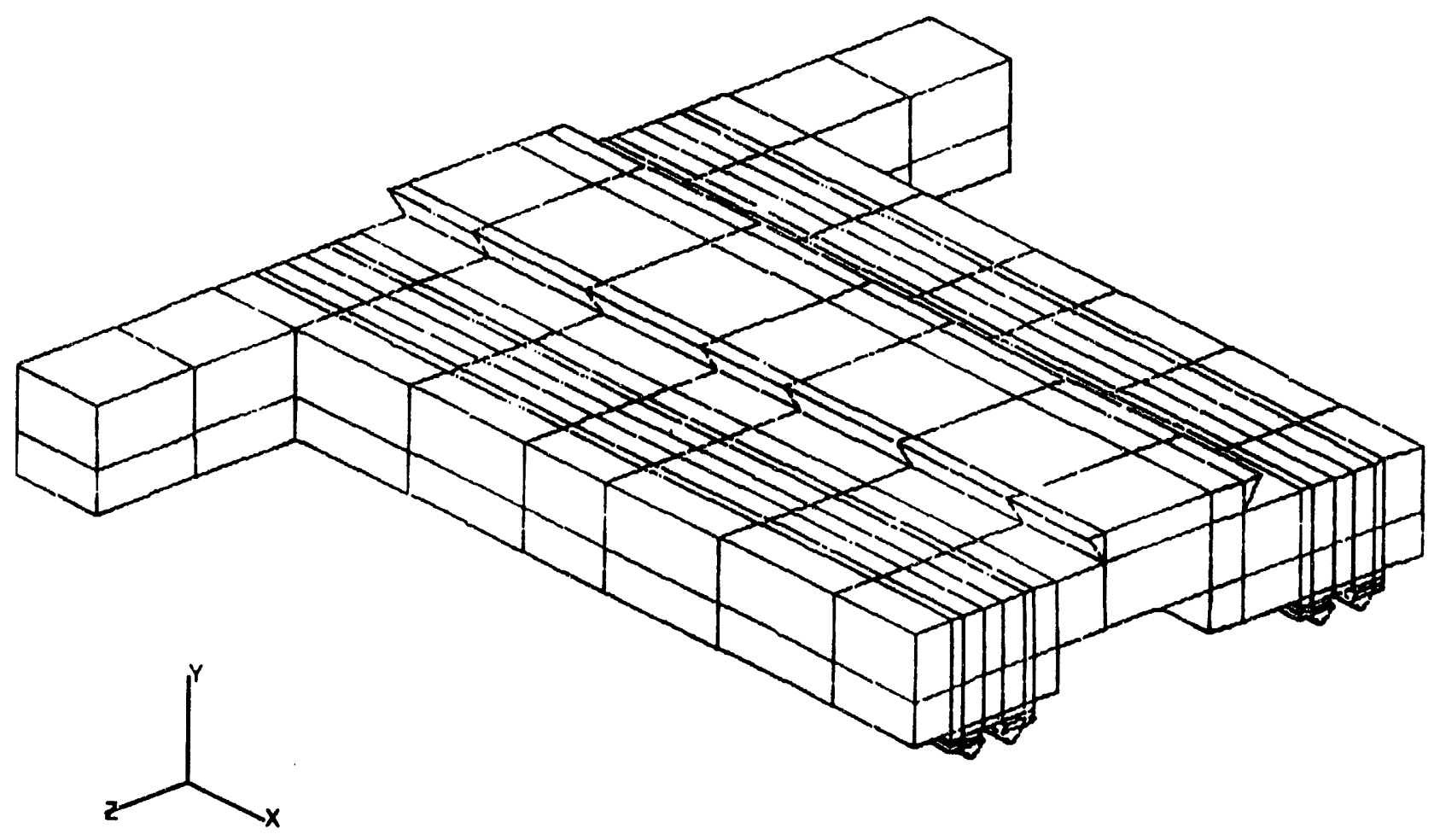

Fig. 18. Top view of the INA model lower slide structure. 


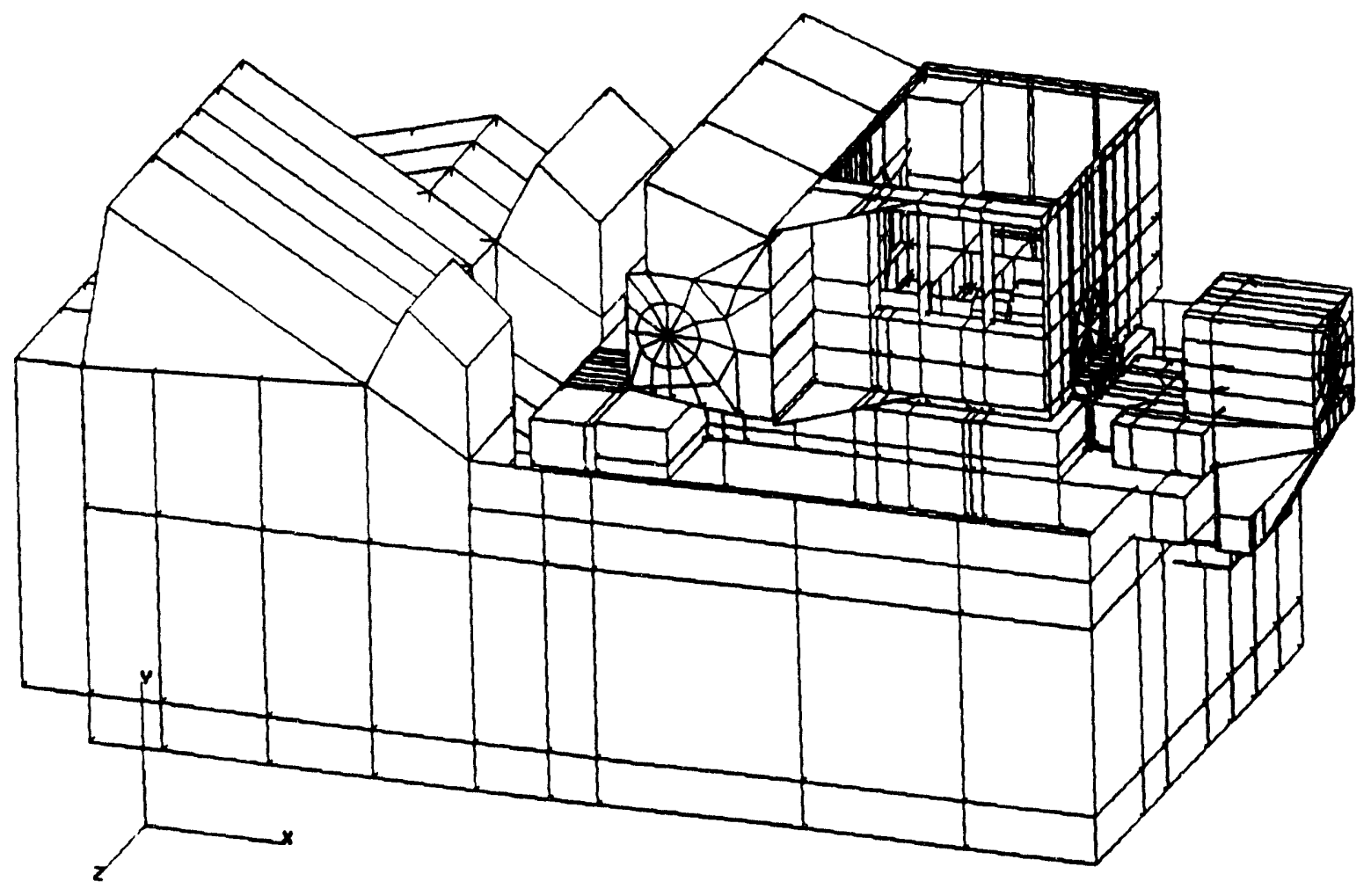

Fig. 19. Overall view of the finite element model structures of the GC-500 with all structure models assembled. 


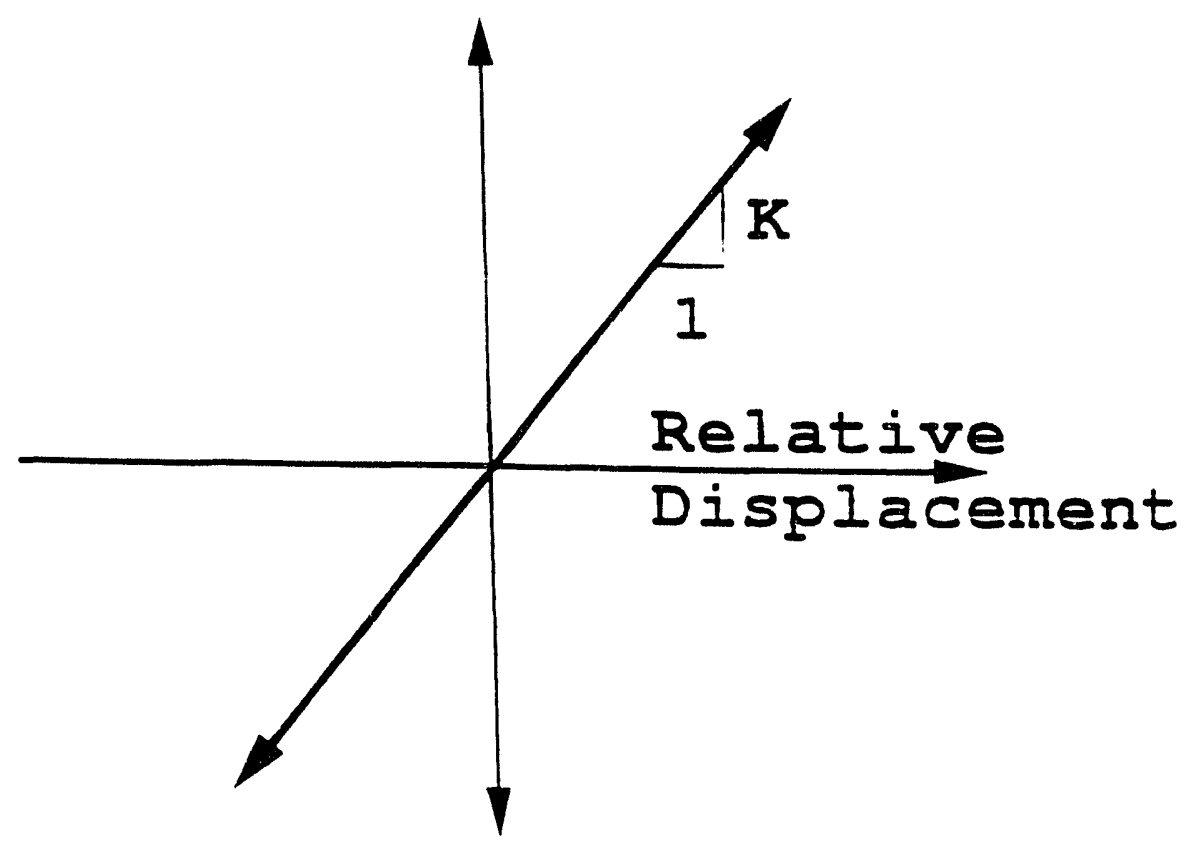

Fig. 20. ABAQUS linear spring-relative displacement relationship. Only $\mathrm{K}$ needs to be called out along with the nodal connectivity.

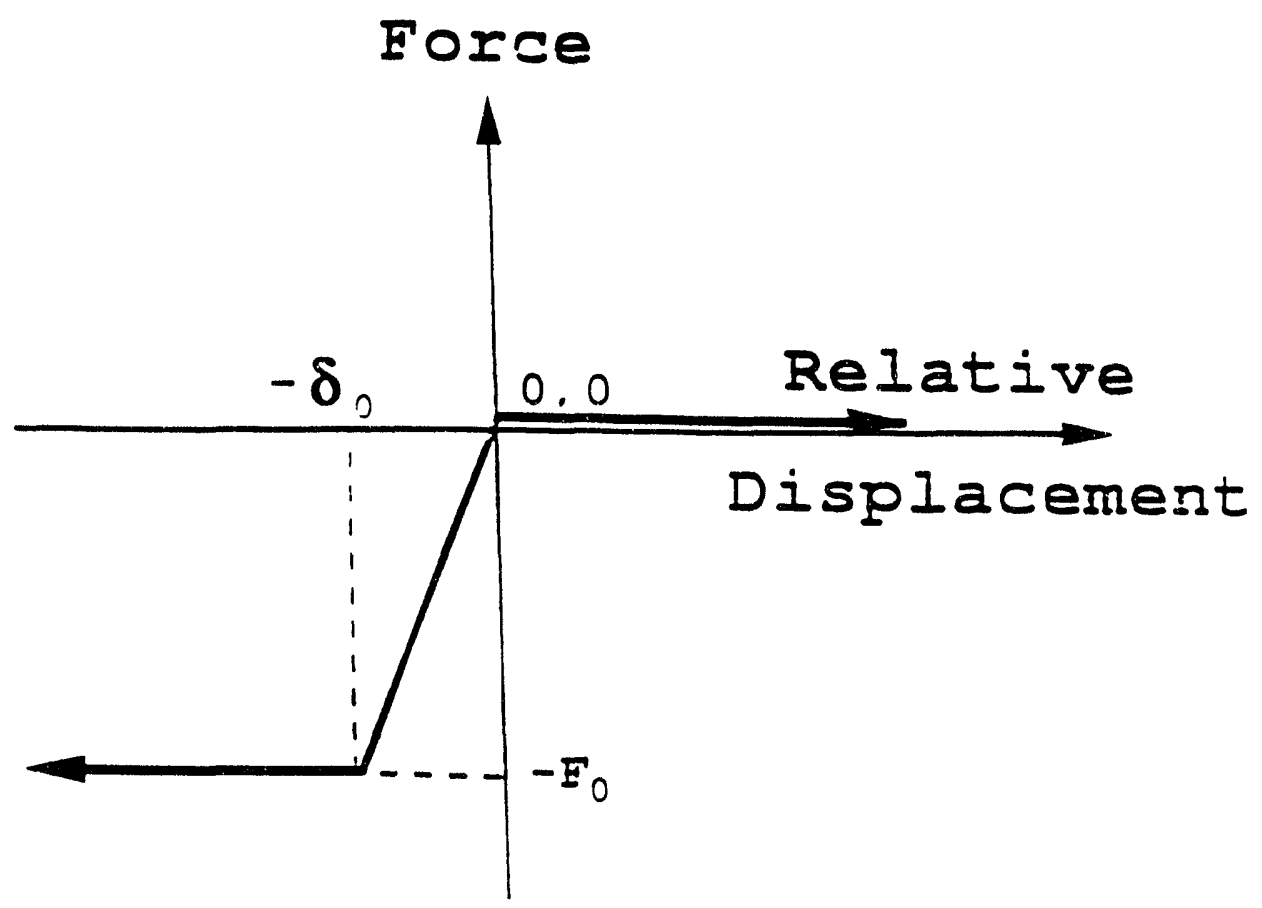

Fig. 21. Compressive-only spring representation for surfaces that can separate. 


\section{Force}

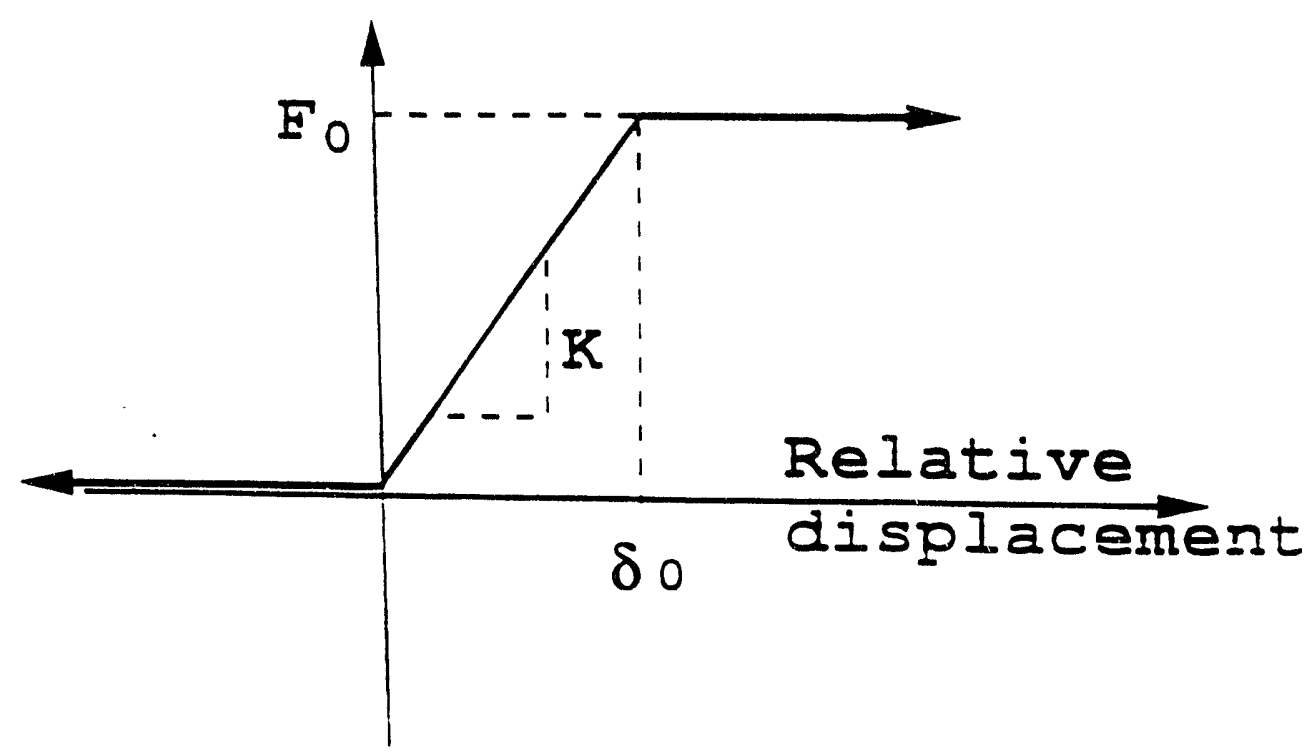

Fig. 22. Tension-only spring used for way representations in the vertical directions.

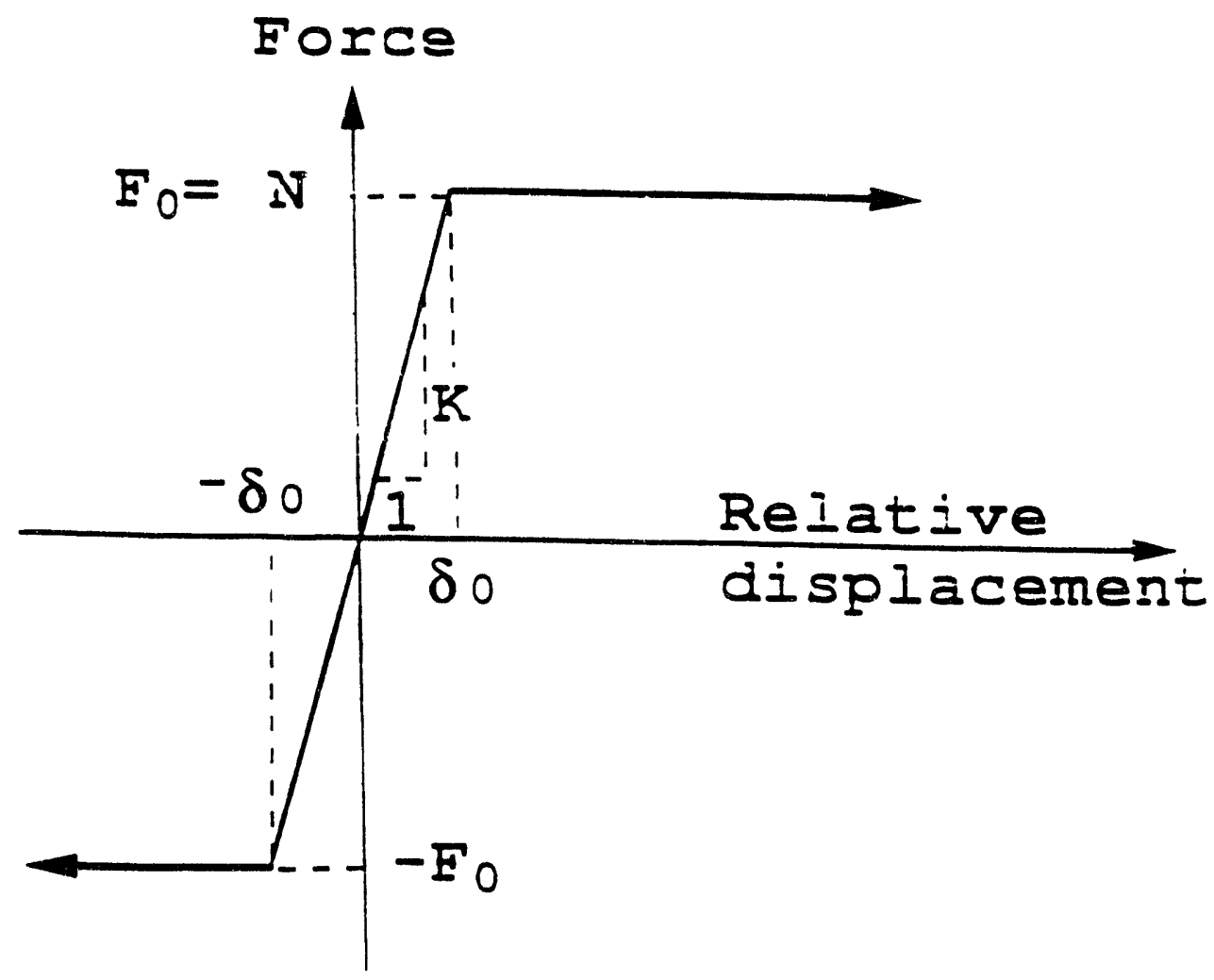

Fig. 23. Friction spring representation for contacting surfaces that can exhibit stickslip behavior. 


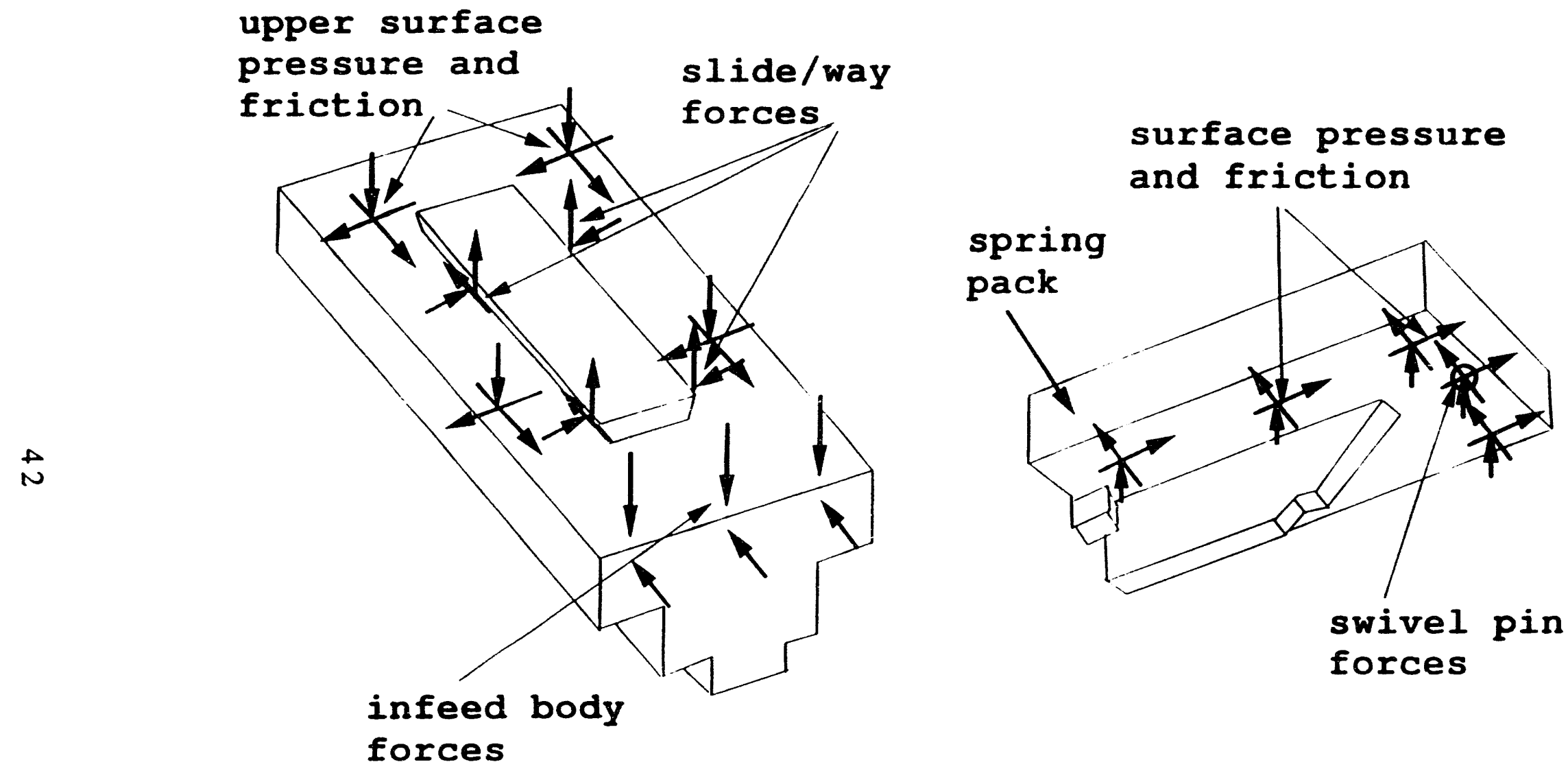

Fig. 24. Conceptual free-body diagram of the swivel plate for the plane slide and coated slide models. 


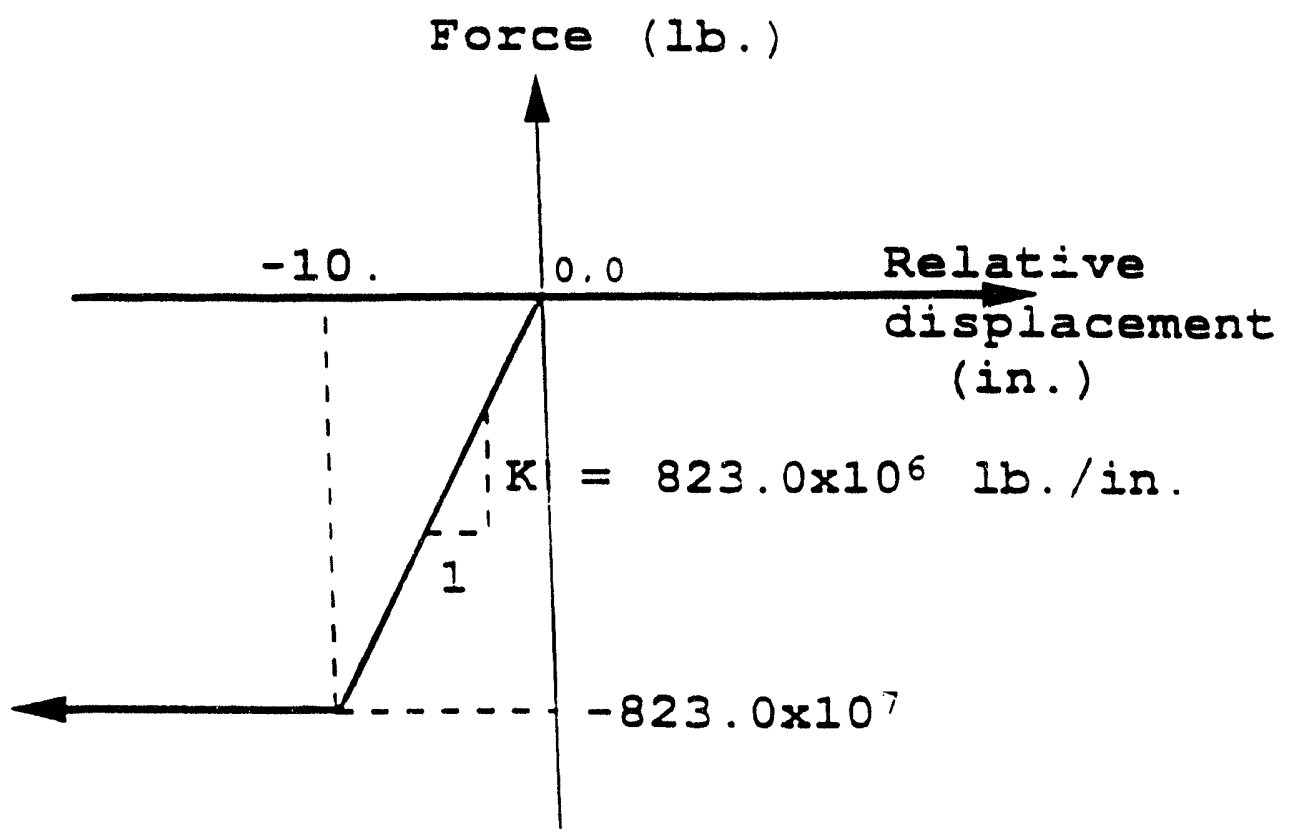

Fig. 25. The KCBYY spring of Table I for the swivel plate model.

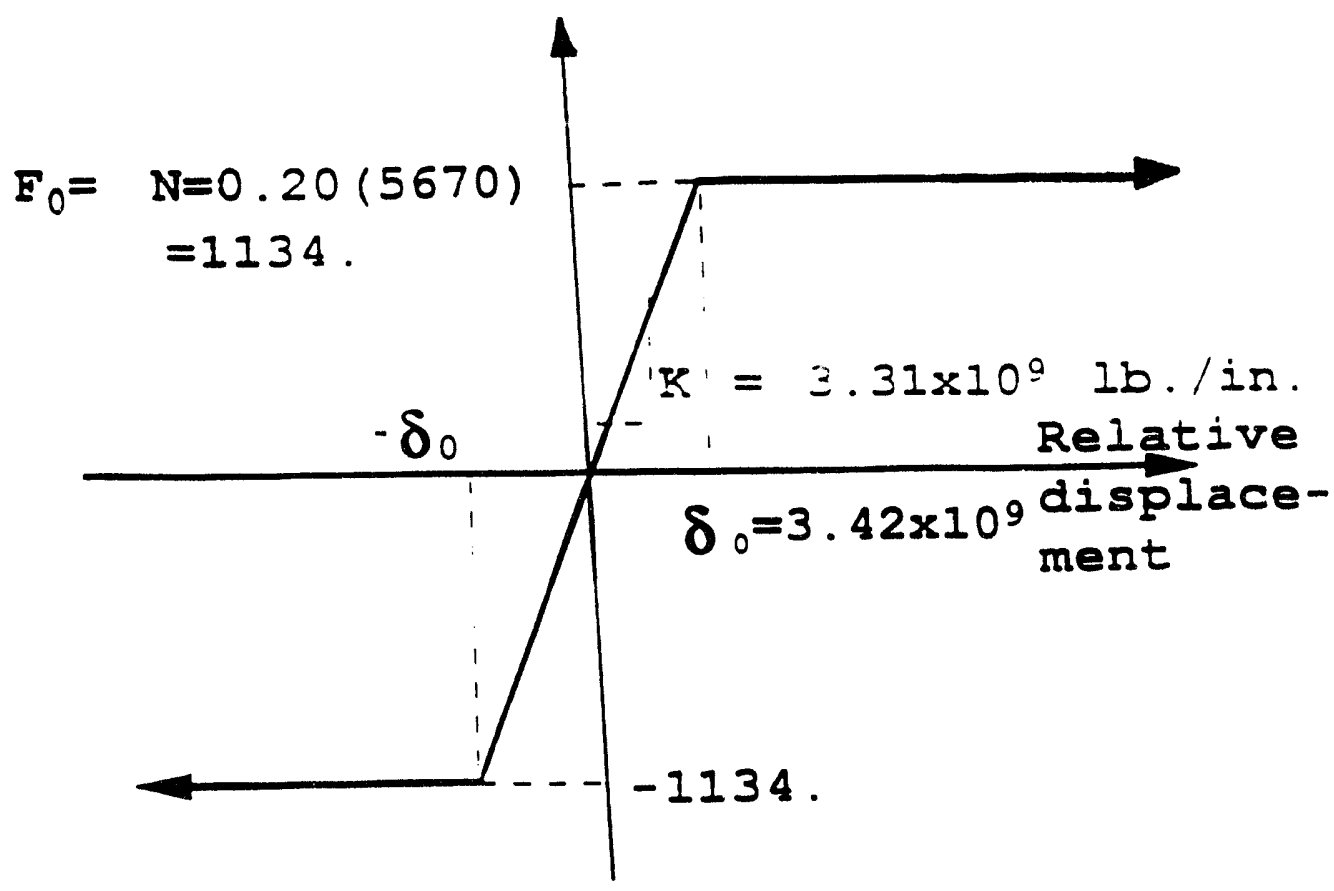

Fig. 26. The friction spring KFBXX of Table I for the swivel plate model. 


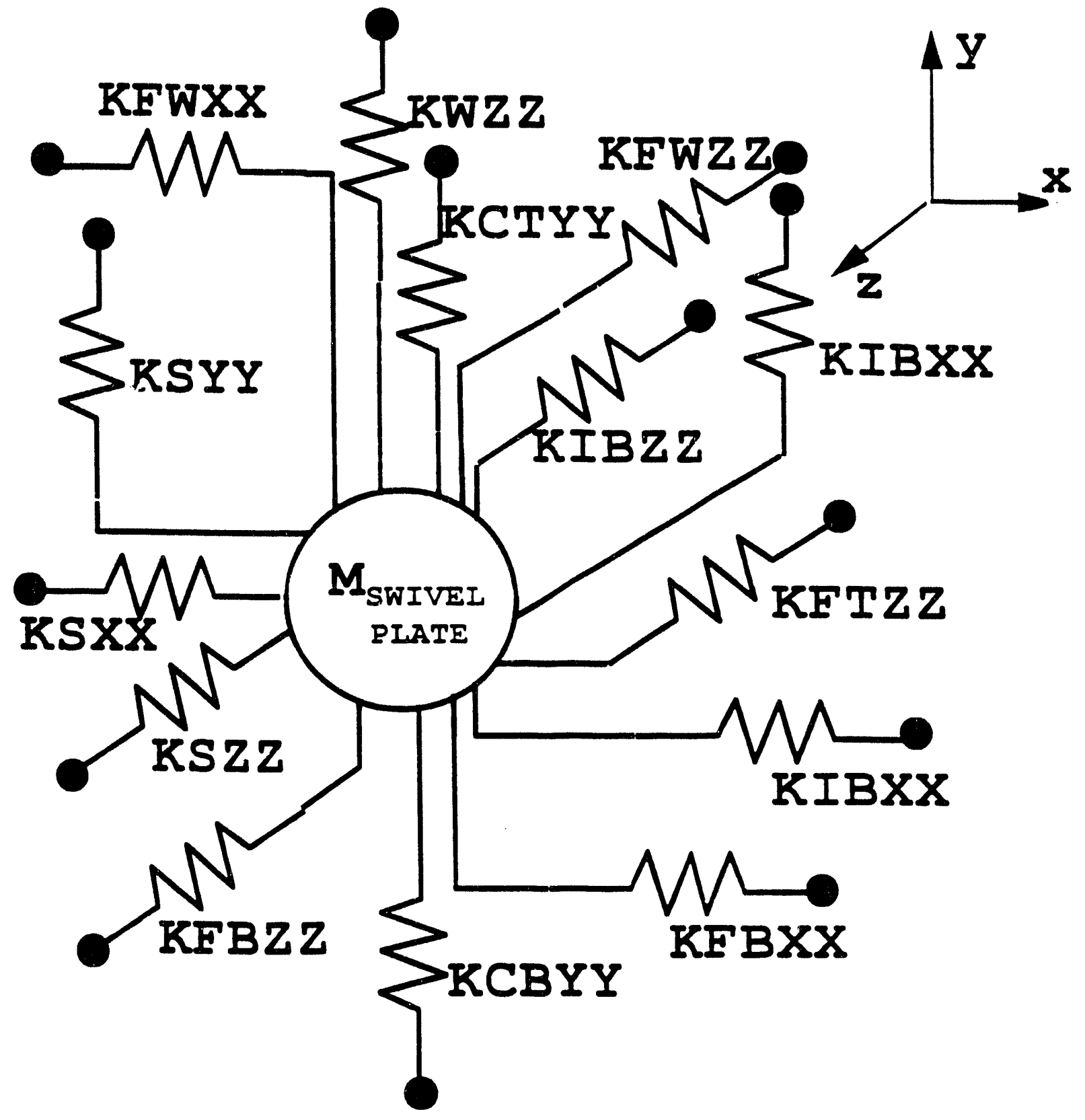

Fig. 27. The equivalent spring mass model of the swivel plate derived from the finite element model of Figs. 5 and 6. 


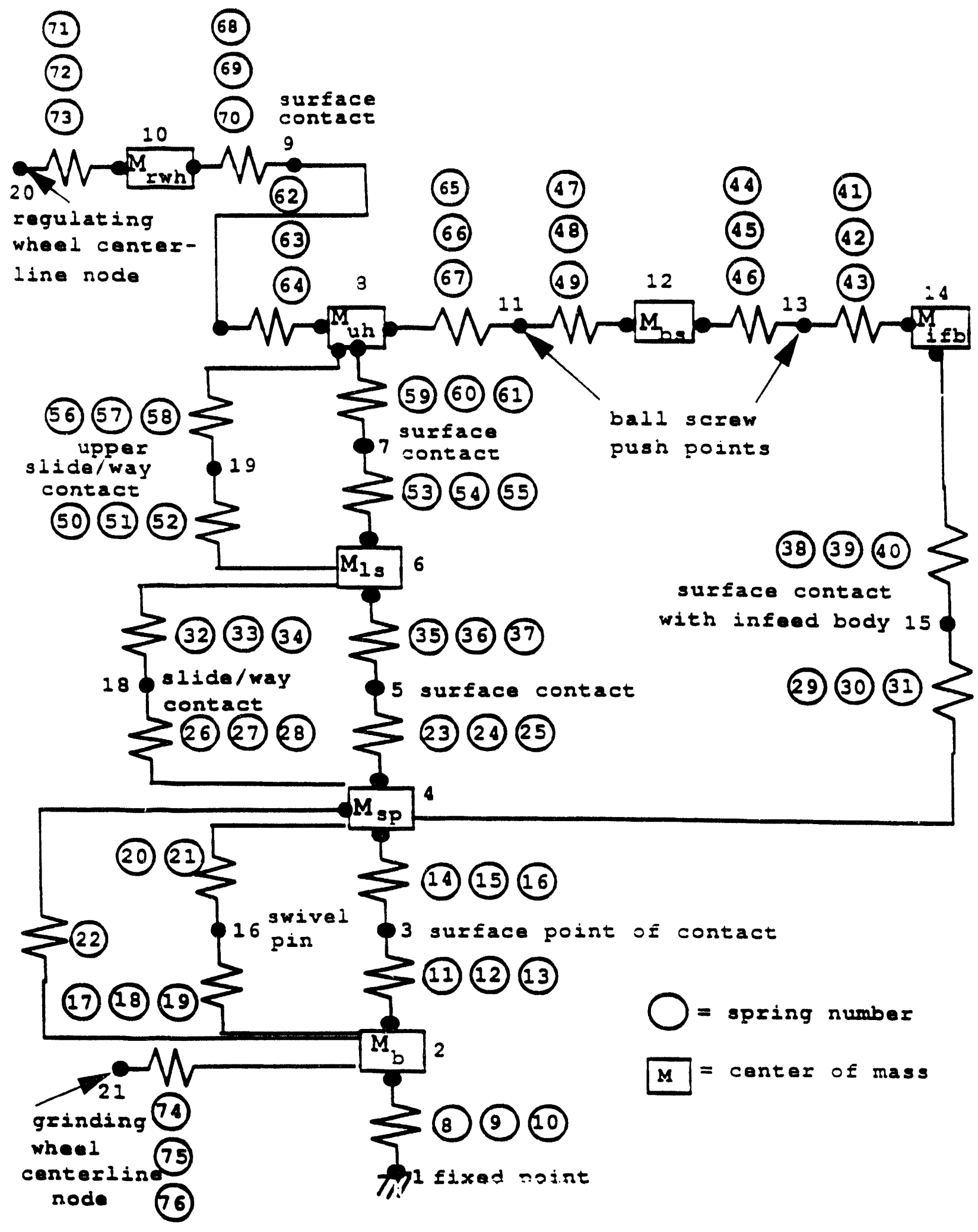

Fig. 28. The overall models used to represent the GC-500. 


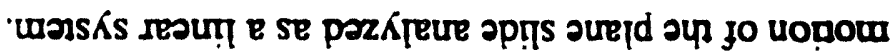

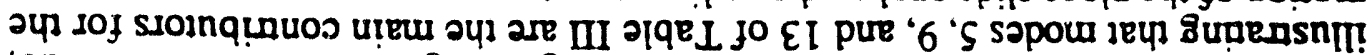

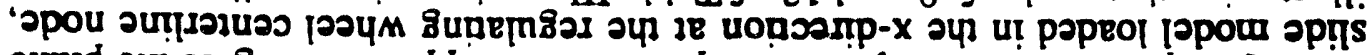

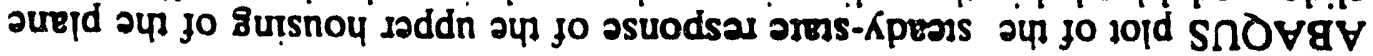

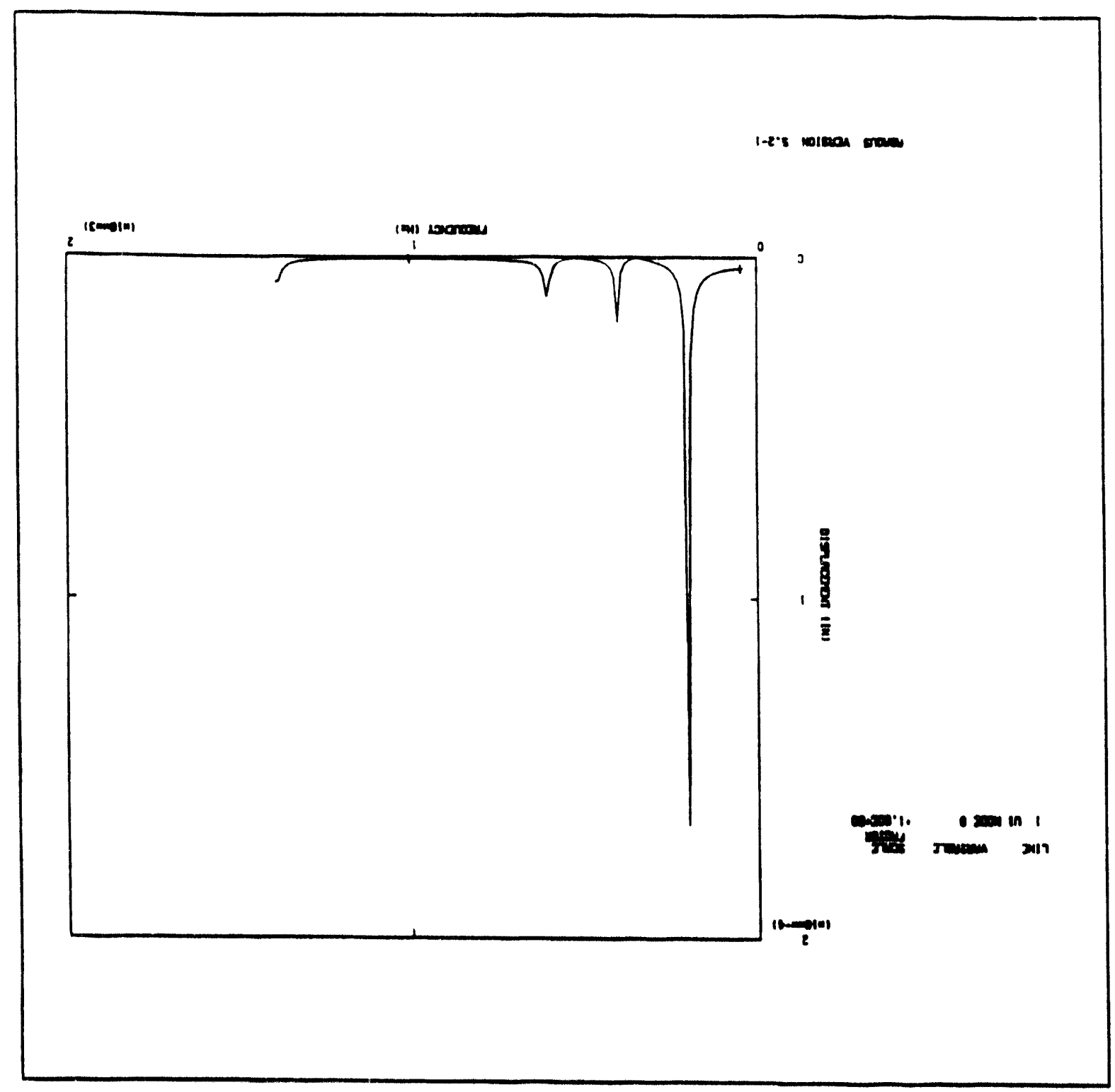


PSEUDO DYNAMIC STIFFNESS

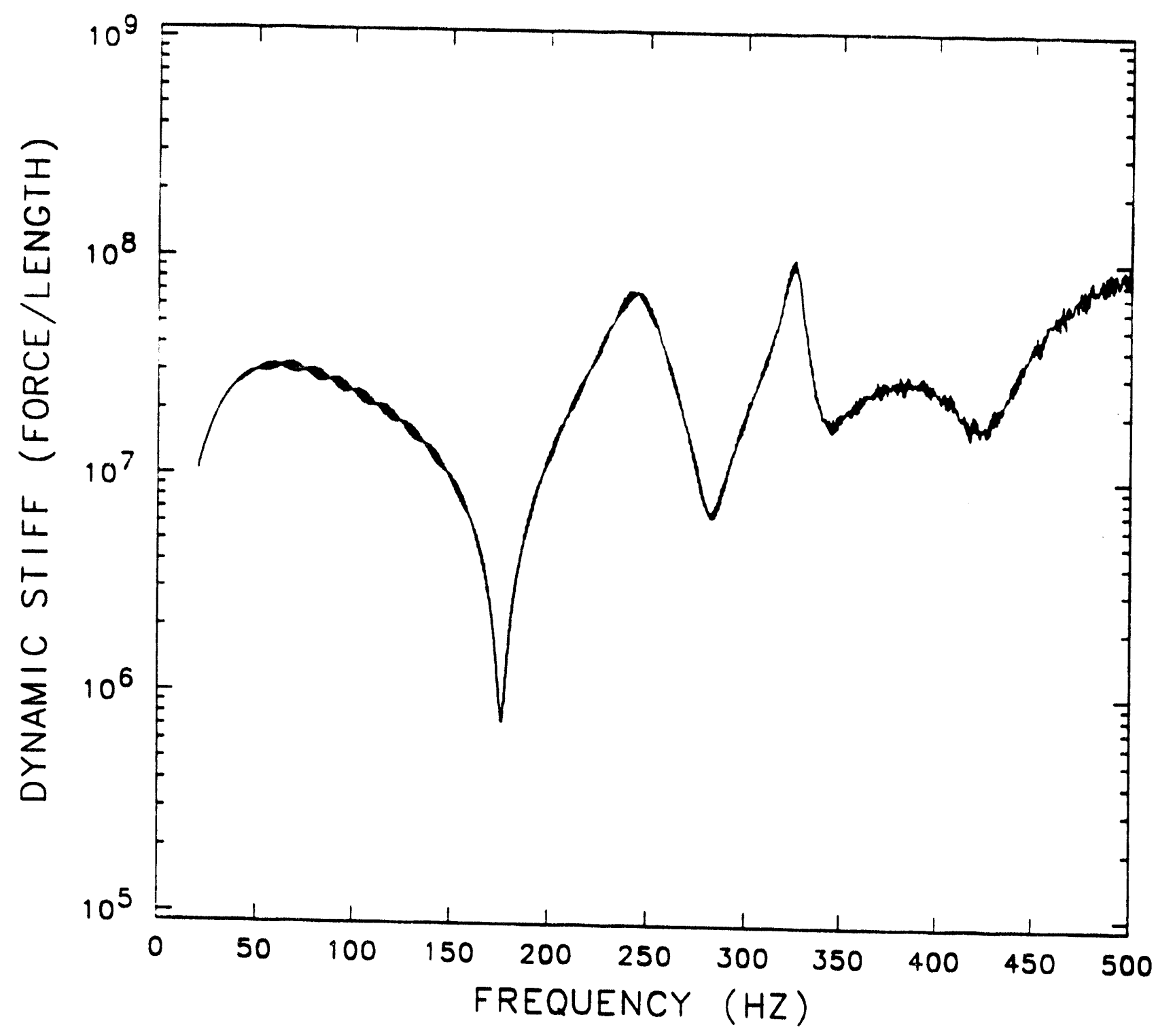

Fig. 30. Dynamic stiffness function for the plane slide model derived from analyzing the motion in the $x$-direction of the center of mass of the upper housing $\left(A_{x}(w) / F_{x}\right.$ $(w))$ for the low load level case, as defined in the text. 


\section{PSEUDO DYNAMIC STIFFNESS}

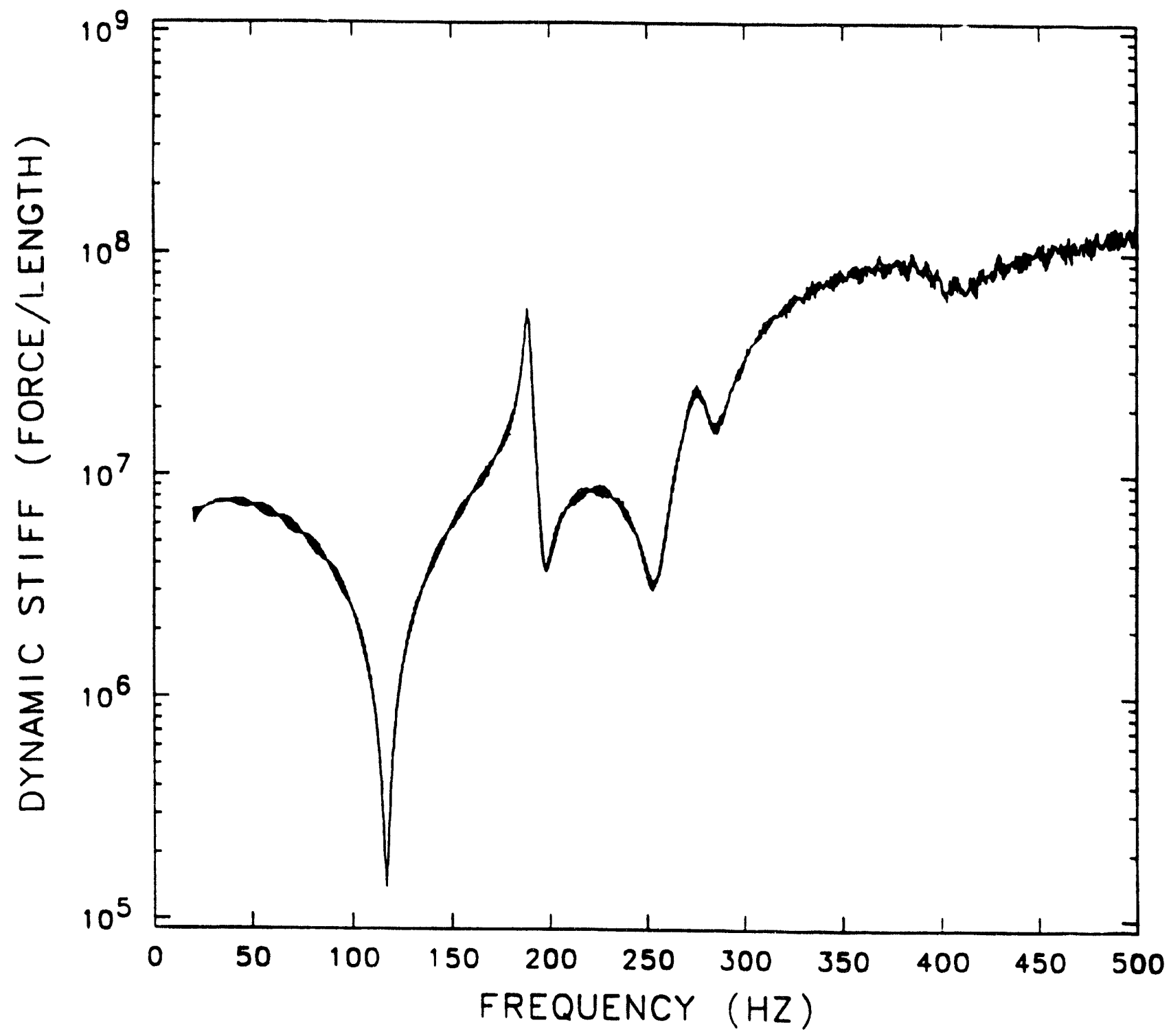

Fig. 31. Dynamic stiffness function for the plane slide model derived from analyzing the motion in the $y$-direction of the center of mass of the upper housing $A_{y}(w) / F_{x}$ $(w))$ for the low load level case, as defined in the text. 


\section{PSEUDO DYNAMIC STIFFNESS}

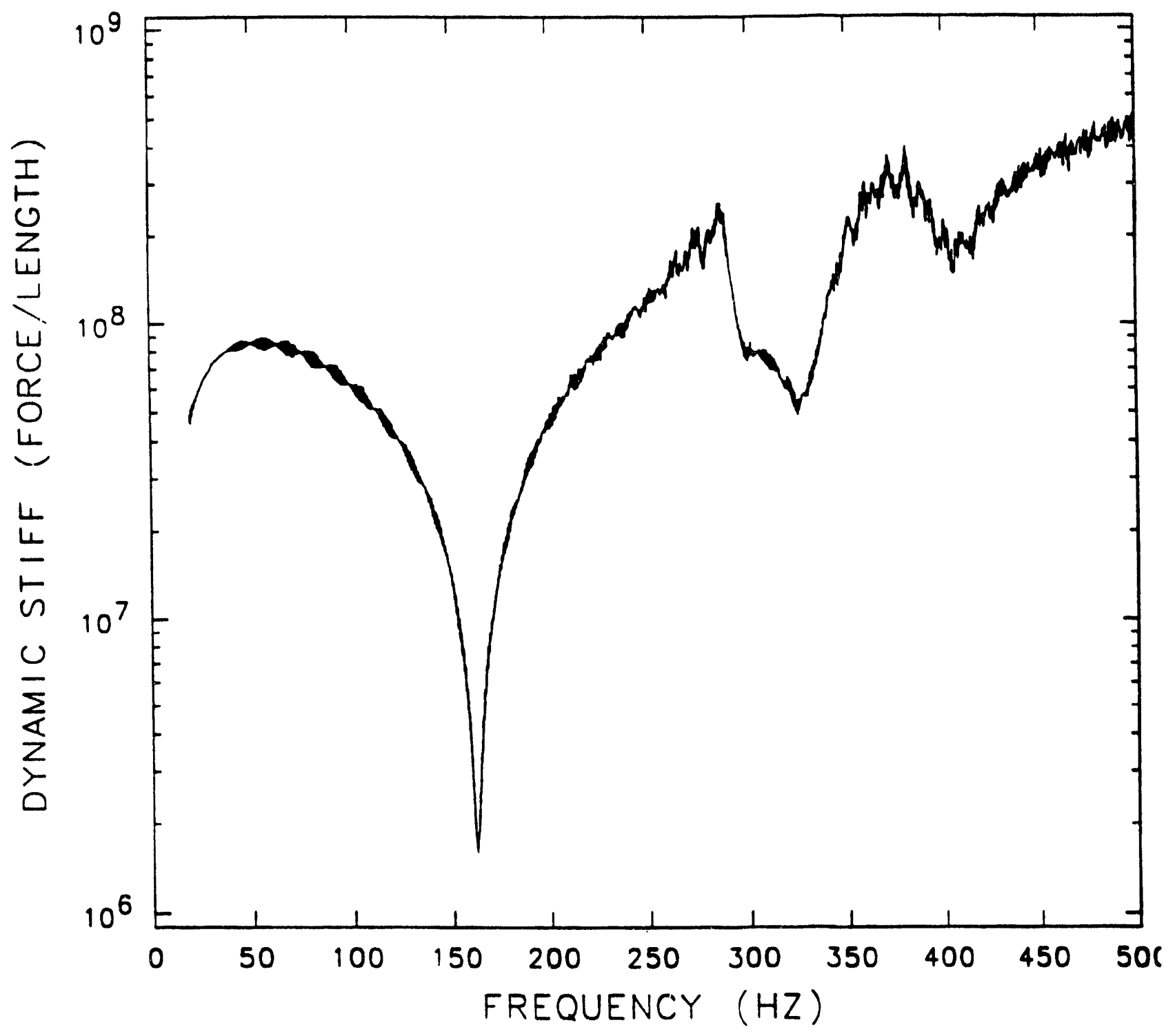

Fig. 32. Dynamic stiffness function for the plane slide model derived from analyzing the motion in the z-direction of the center of mass of the upper housing $A_{z}(w) / F_{x}$ (w)) for the low load level case, as defined in the text. 
PSEUDO DYNAMIC STIFFNESS

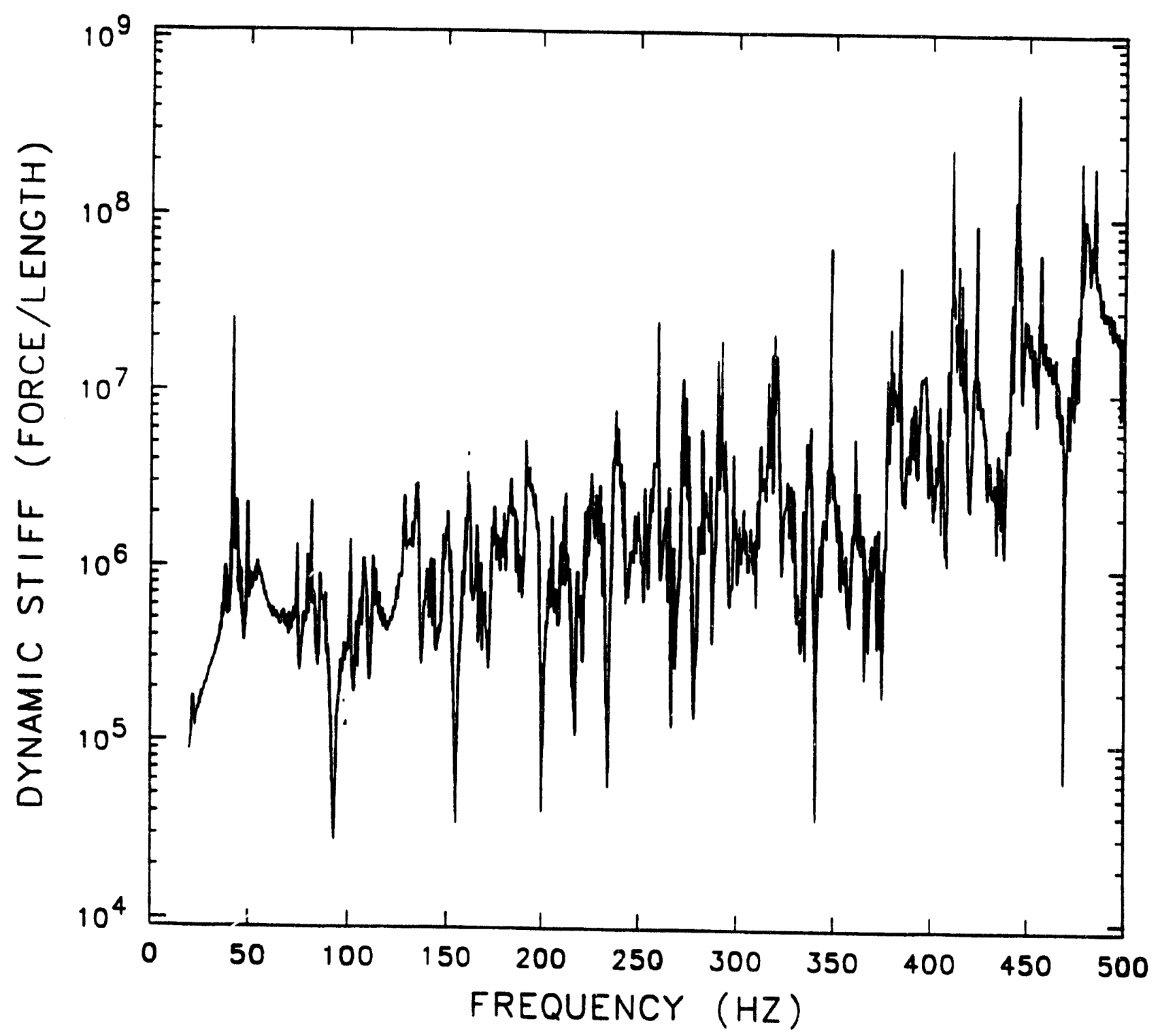

Fig. 33. Dynamic stiffness function for the INA slide model derived from analyzing the motion in the $x$-direction of the center of mass of the upper housing $A_{x}(w) / F_{x}$ $(w))$ for the low load level case, as defined in the text. 
PSEUDO DYNAMIC STIFFNESS

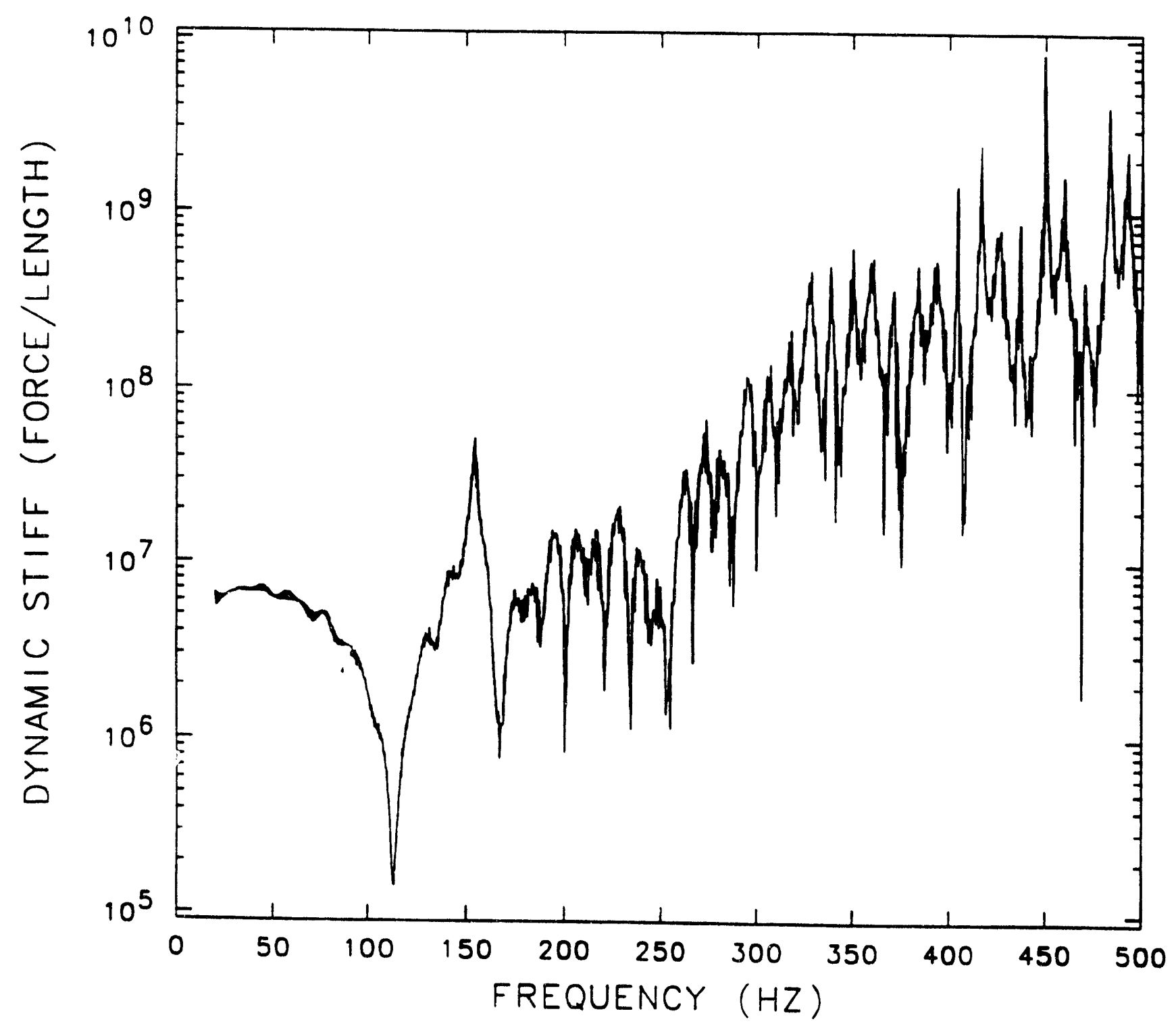

Fig. 34. Dynamic stiffness function for the INA slide model derived from analyzing the motion in the $y$-direction of the enter of mass of the upper housing $A_{y}(w) / F_{x}$ (w)) for the low load level case, as defined in the text. 
PSEUDO DYNAMIC STIFFNESS

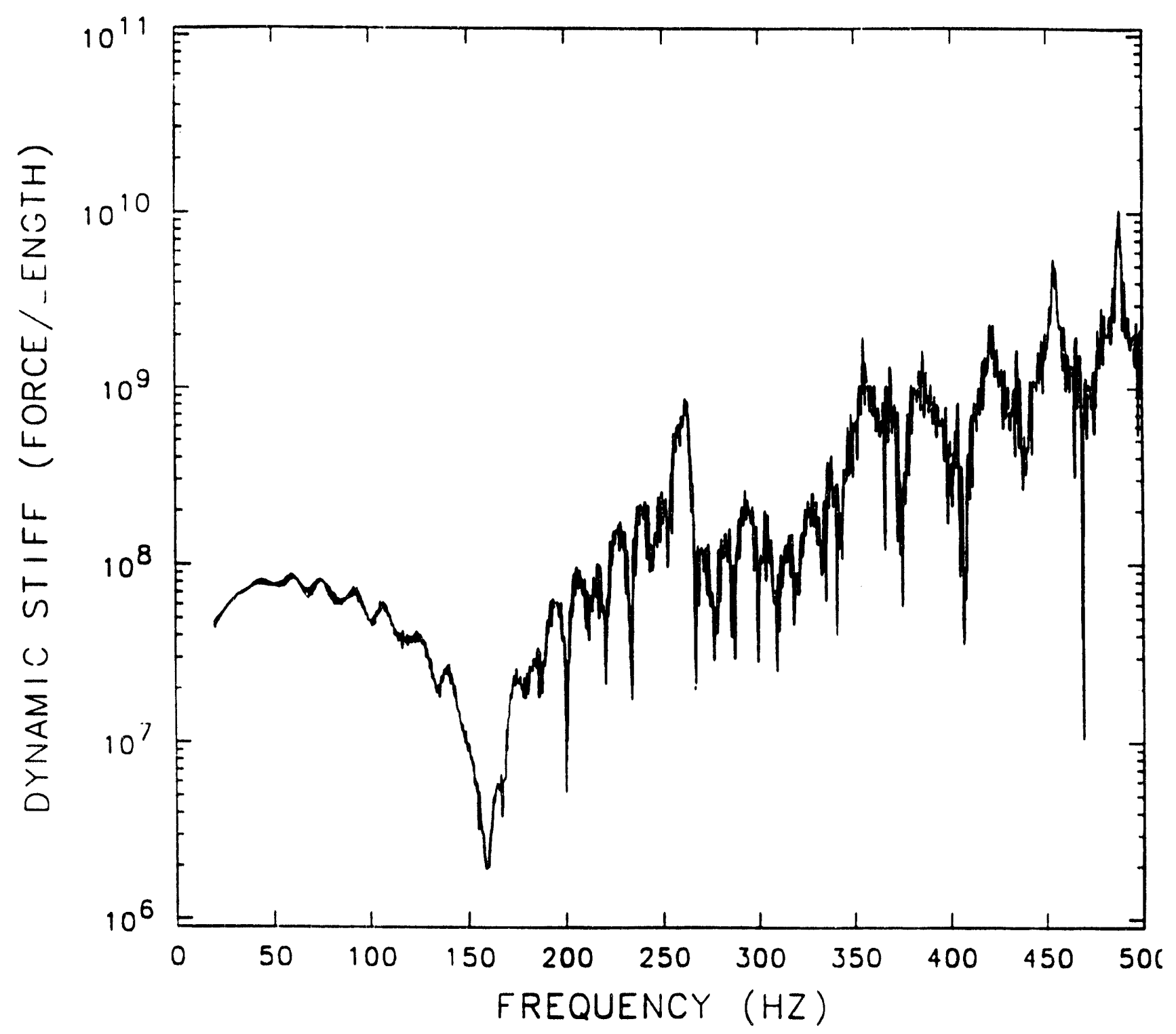

Fig. 35. Dynamic stiffness function for the INA slide model derived from analyzing the motion in the z-direction of the center of mass of the upper housing $A_{z}(w) / F_{x}$ $(w))$ for the low load level case, as defined in the text. 
PSEUDO DYNAMIC STIFFNESS

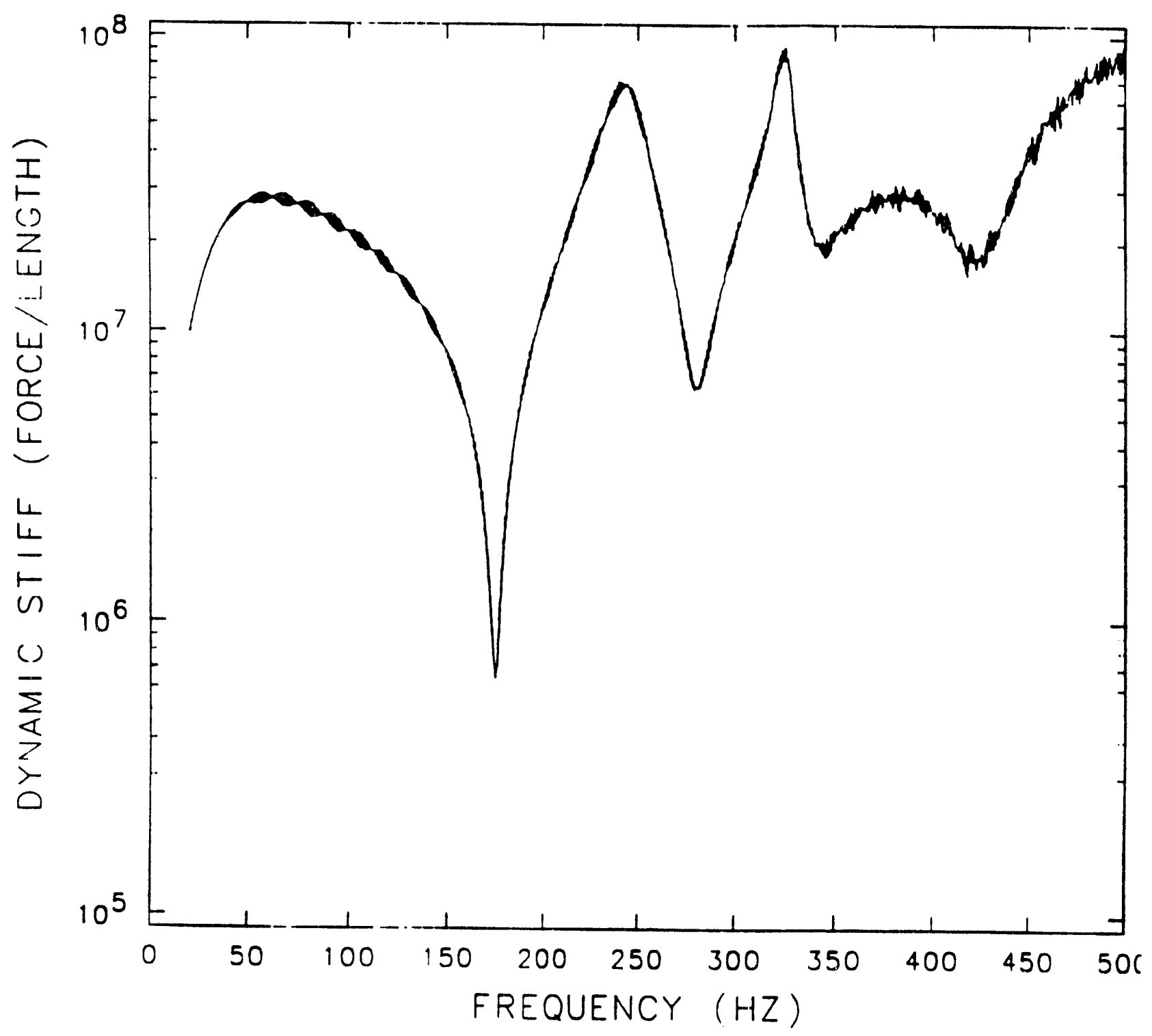

Fig. 36. Dynamic stiffness function for the coated slide model derived from analyzing the motion in the $x$-direction of the center of mass of the upper housing $A_{x}(w) / F_{x}$ (w)) for the low load level case, as defined in the text. 
PSEUDO DYNAMIC STIFFNESS

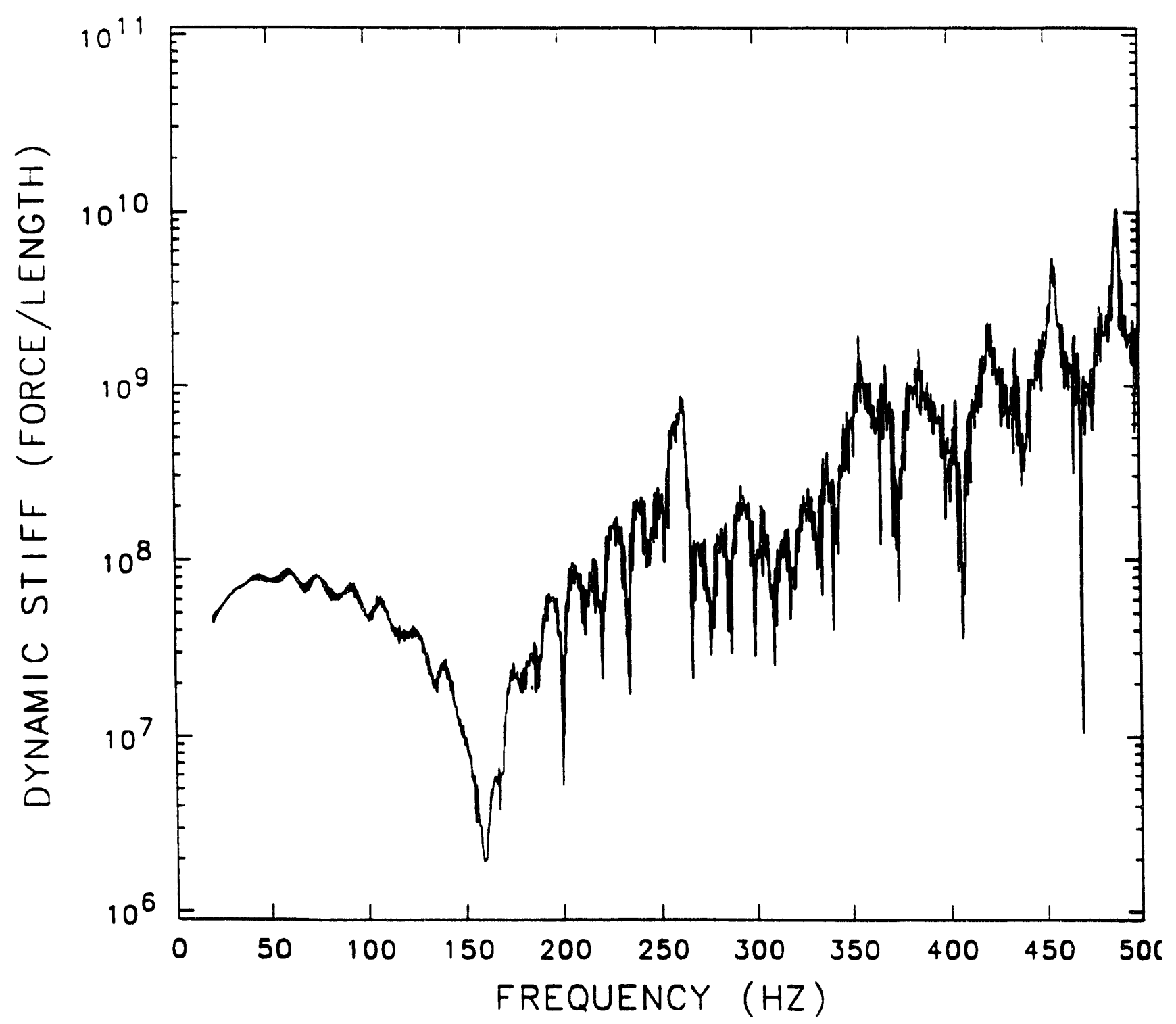

Fig. 37. Dynamic stiffness function for the coated slide model derived from analyzing the motion in the $y$-direction of the center of mass of the upper housing $A_{y}(w) / F_{x}$ $(w))$ for the low load level case as defined in the text. 
PSEUDO DYNAMIC. STIFFNESS

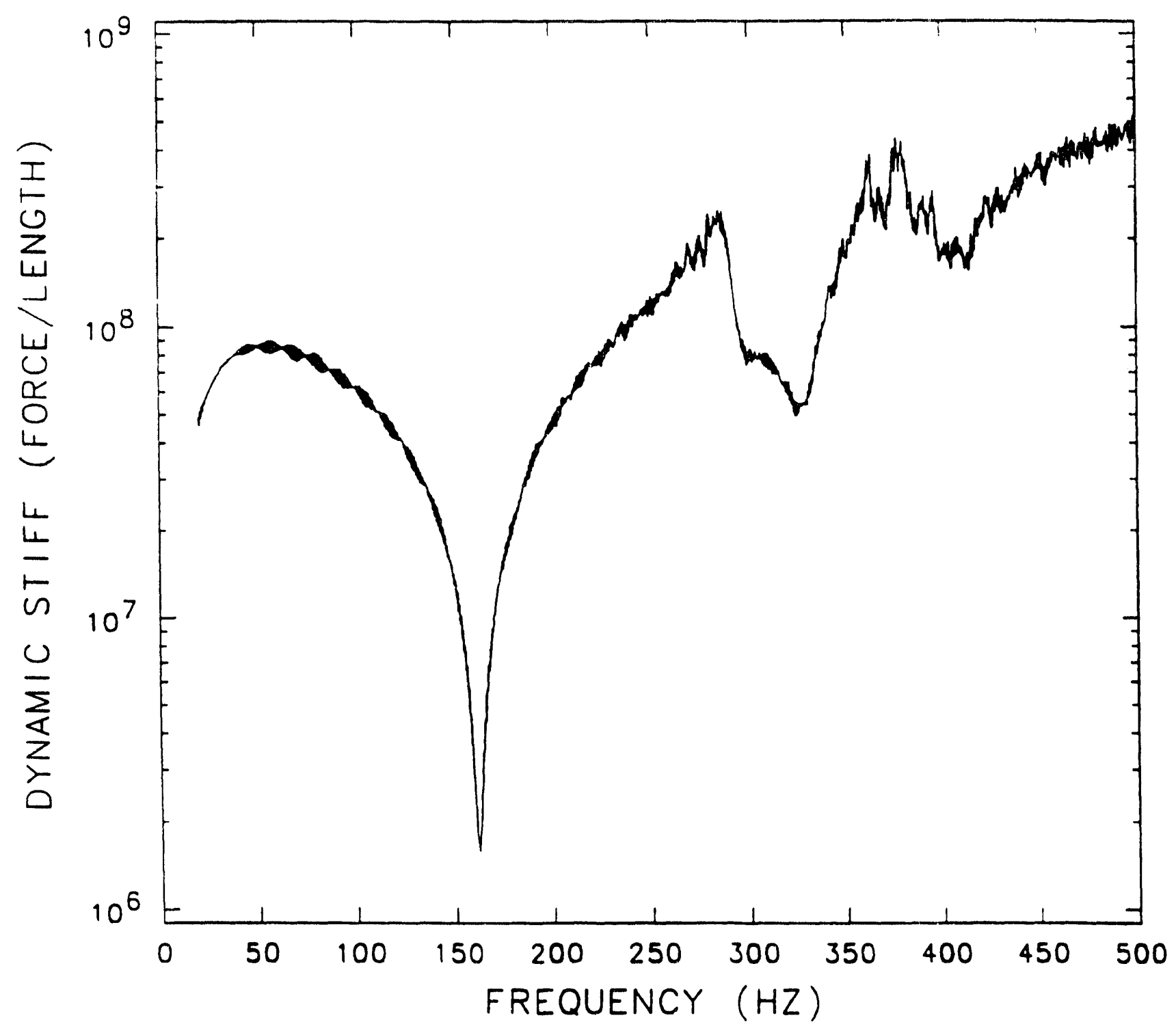

Fig. 38. Dynamic stiffness function for the coated slide model deriver from analyzing the motion in the z-direction of the center of mass of the upper housing $A_{z}(w) / F_{x}$ $(w))$ for the low load level case as defined in the text. 


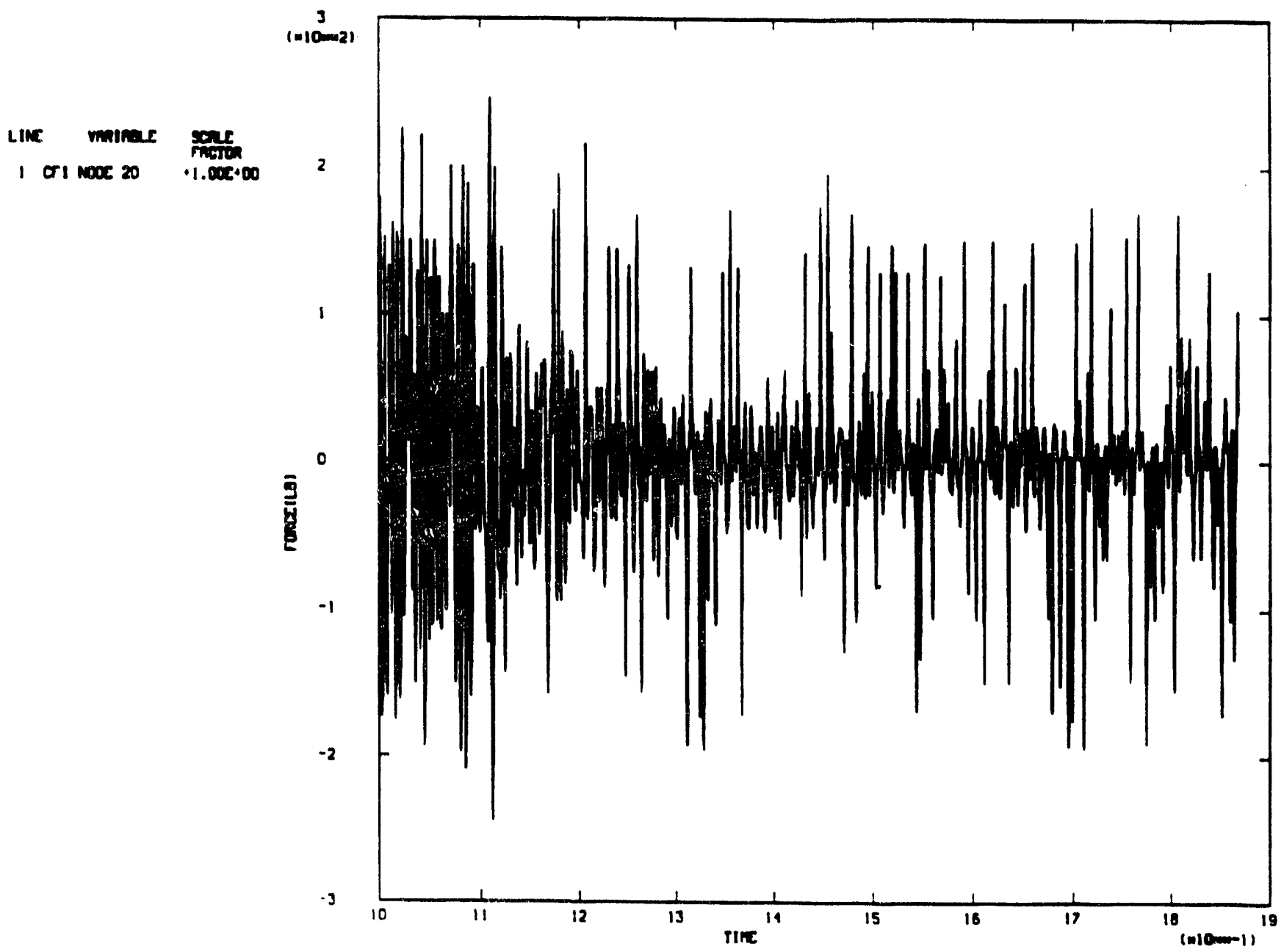

noms version $5.2-1$

Fig. 39. Force time-history applied to the regulating wheel centerline node of the model of Fig. 28 for the random load case discussed in the text. 
PSEUDO DYNAMIC STIFFNESS

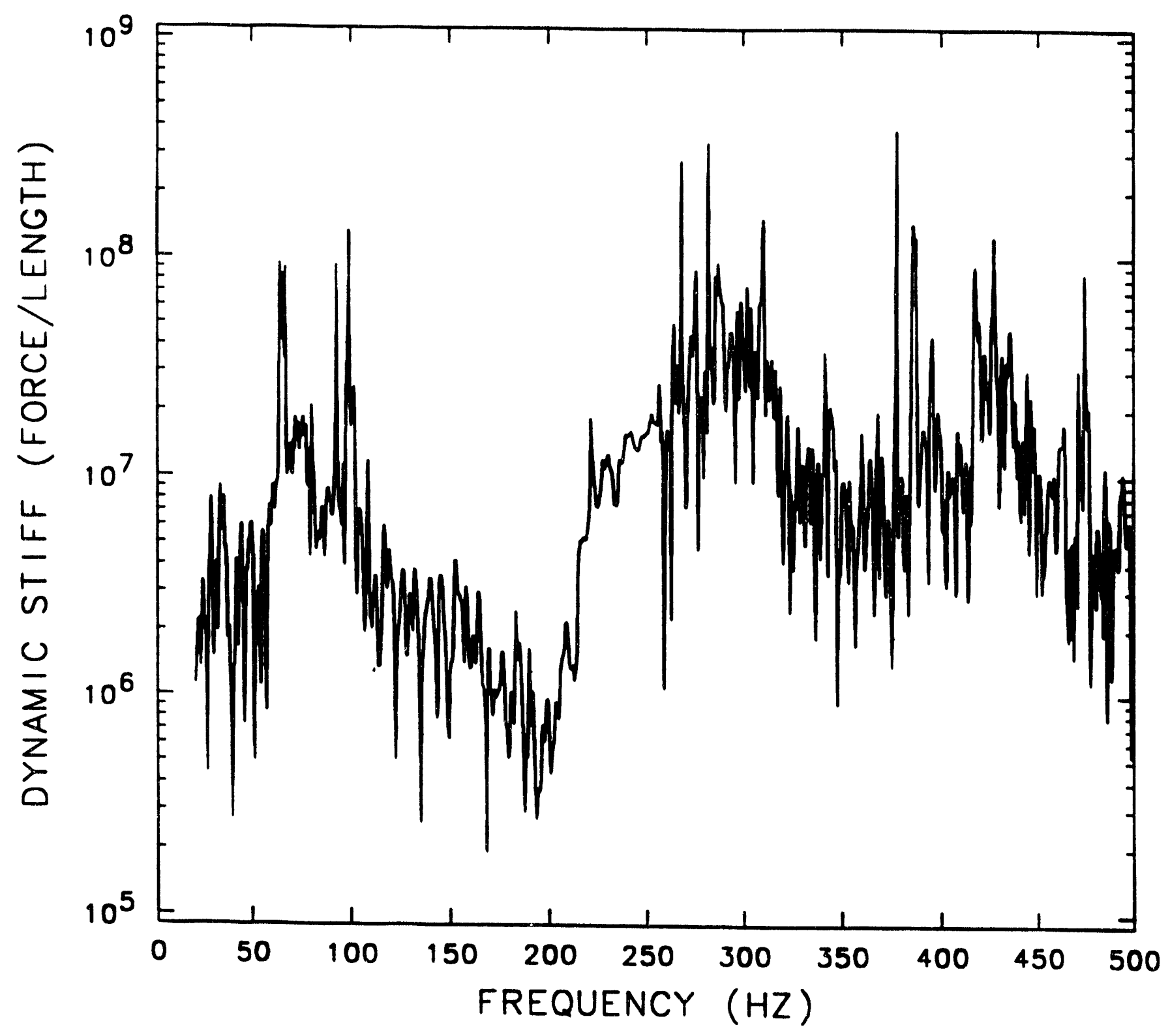

Fig. 40. Dynamic stiffness function for the plane slide model derived from analyzing the motion in the $x$-direction of the center of mass of the upper housing $\left.A_{x}(w) / F_{x}(w)\right)$ for the random-load level, case as defined in the text. 
PSEUDO DYNAMIC STIFFNESS

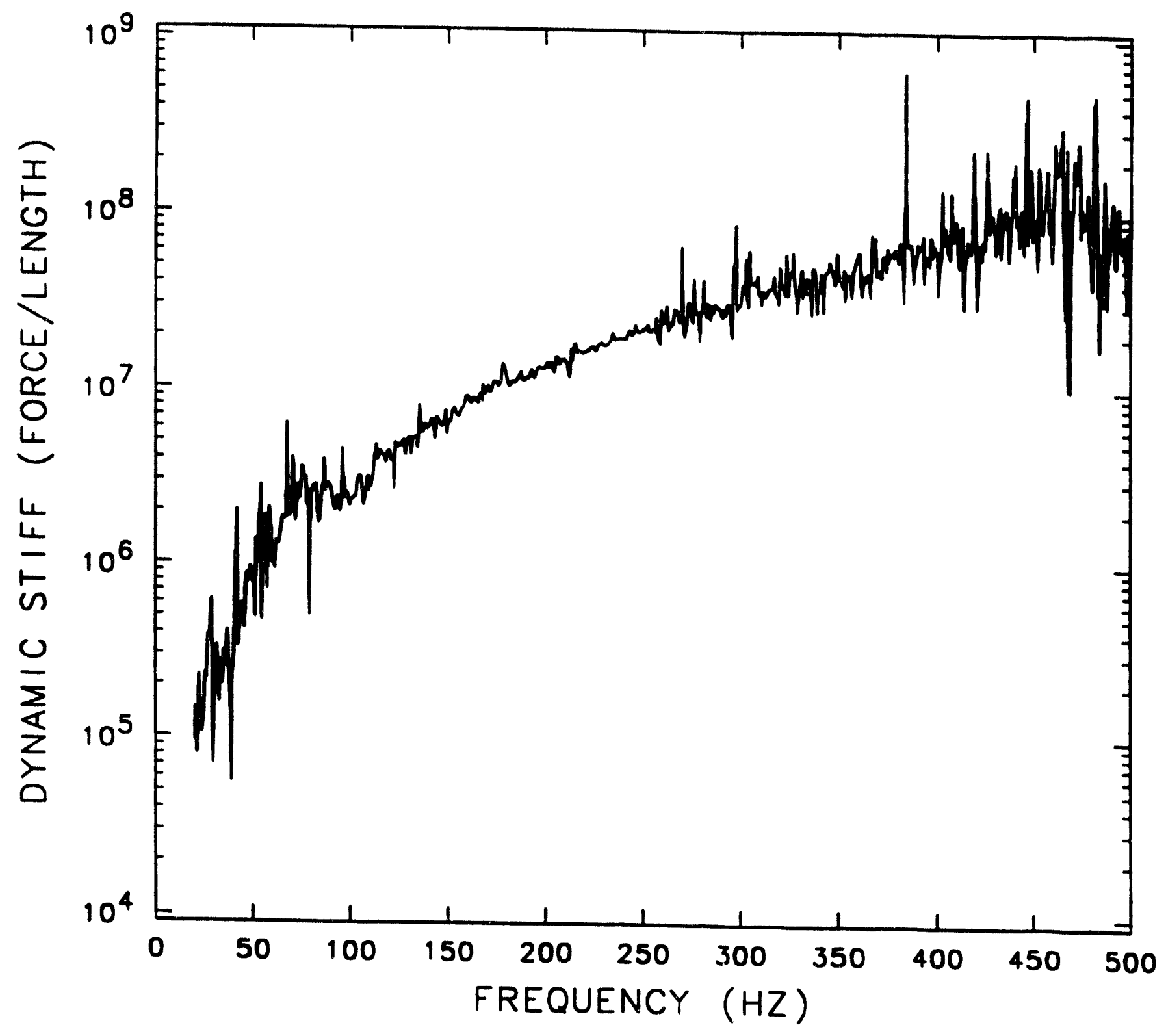

Fig. 41. Dynamic stiffness function for the INA slide model derived from analyzing the motion in the $x$-direction of the center of mass of the upper housing $A_{x}(w) / F_{x}$ $(w))$ or the random-load level case, as defined in the text. 


\section{PSEUDO DYNAMIC STIFFNESS}

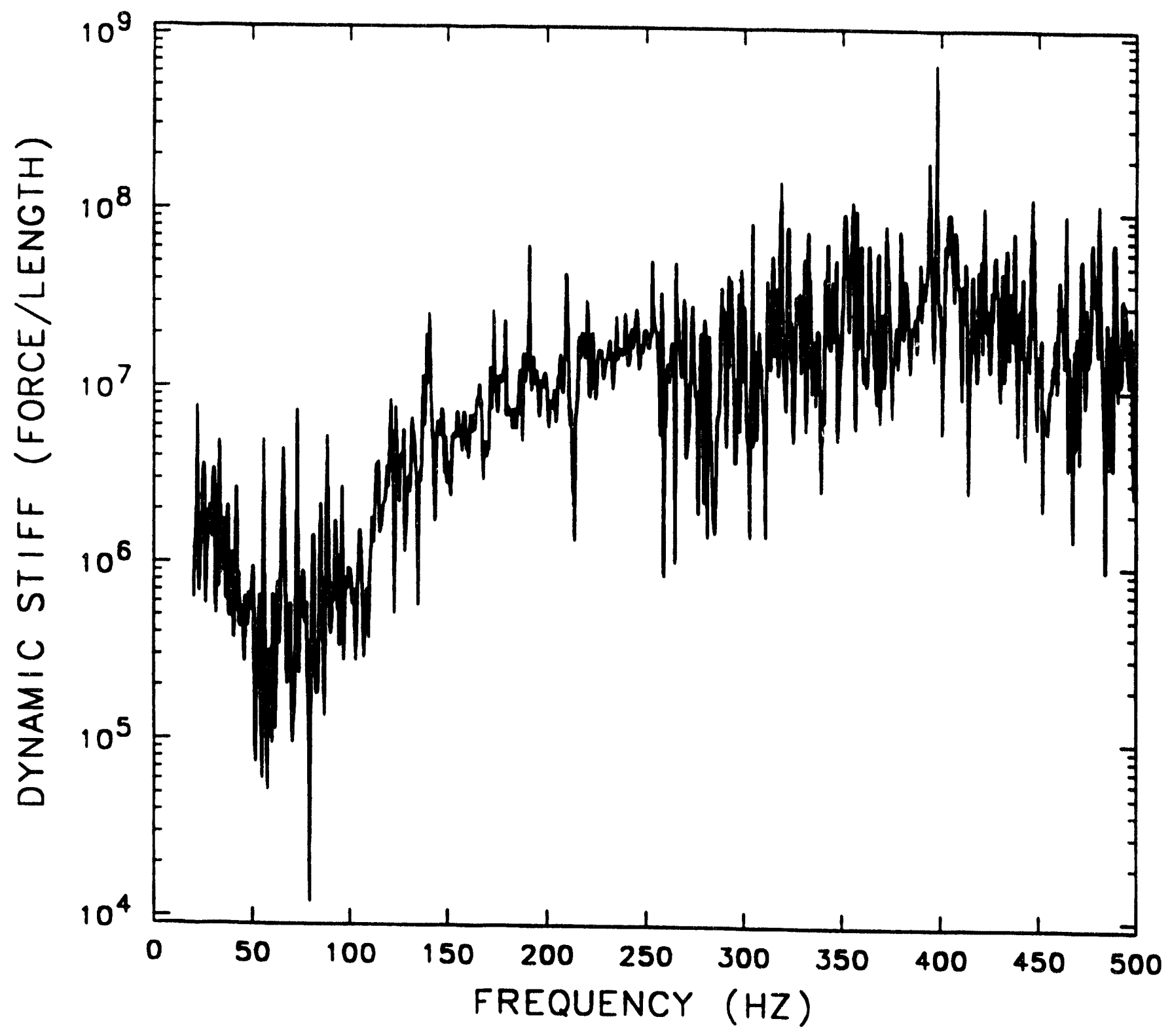

Fig. 42. Dynamic stiffness function for th coated slide model derived from analyzing the motion in the $x$-direction of the center of mass of the upper housing $A_{x}(w) / F_{x}$ $(w))$ for the random-load level case, as defined in the text. 
PSEUDO DYNAMIC STIFFNESS

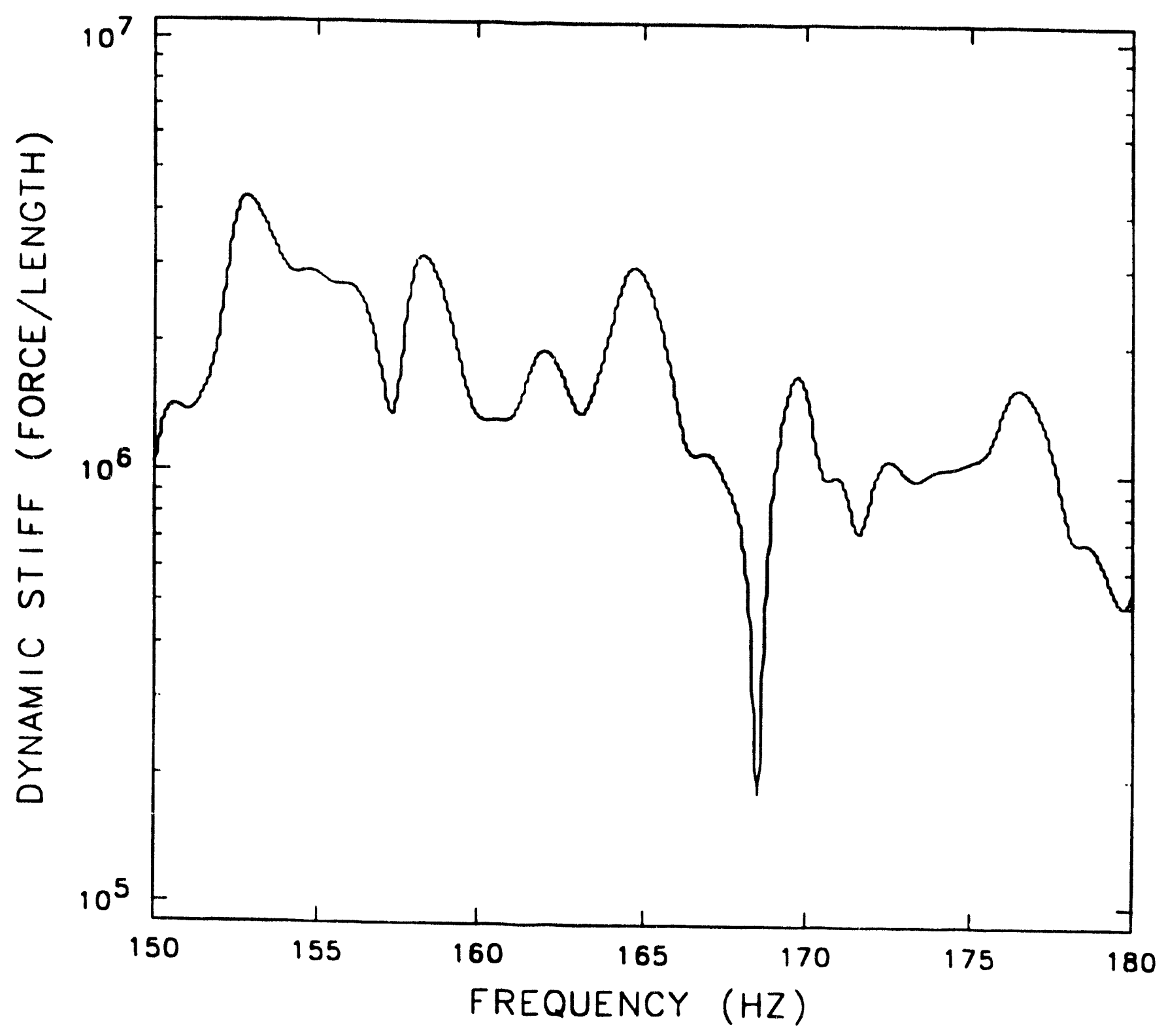

Fig. 43. "Zoom" on the dynamic stiffness function with a finer frequency step for the plane slide model in the frequency range from $150-180 \mathrm{~Hz}$. The MDS value at $168 \mathrm{~Hz}$ is shown to be $183,300 \mathrm{lb} / \mathrm{in}$. 
PSEUDO DYNAMIC STIFFNESS

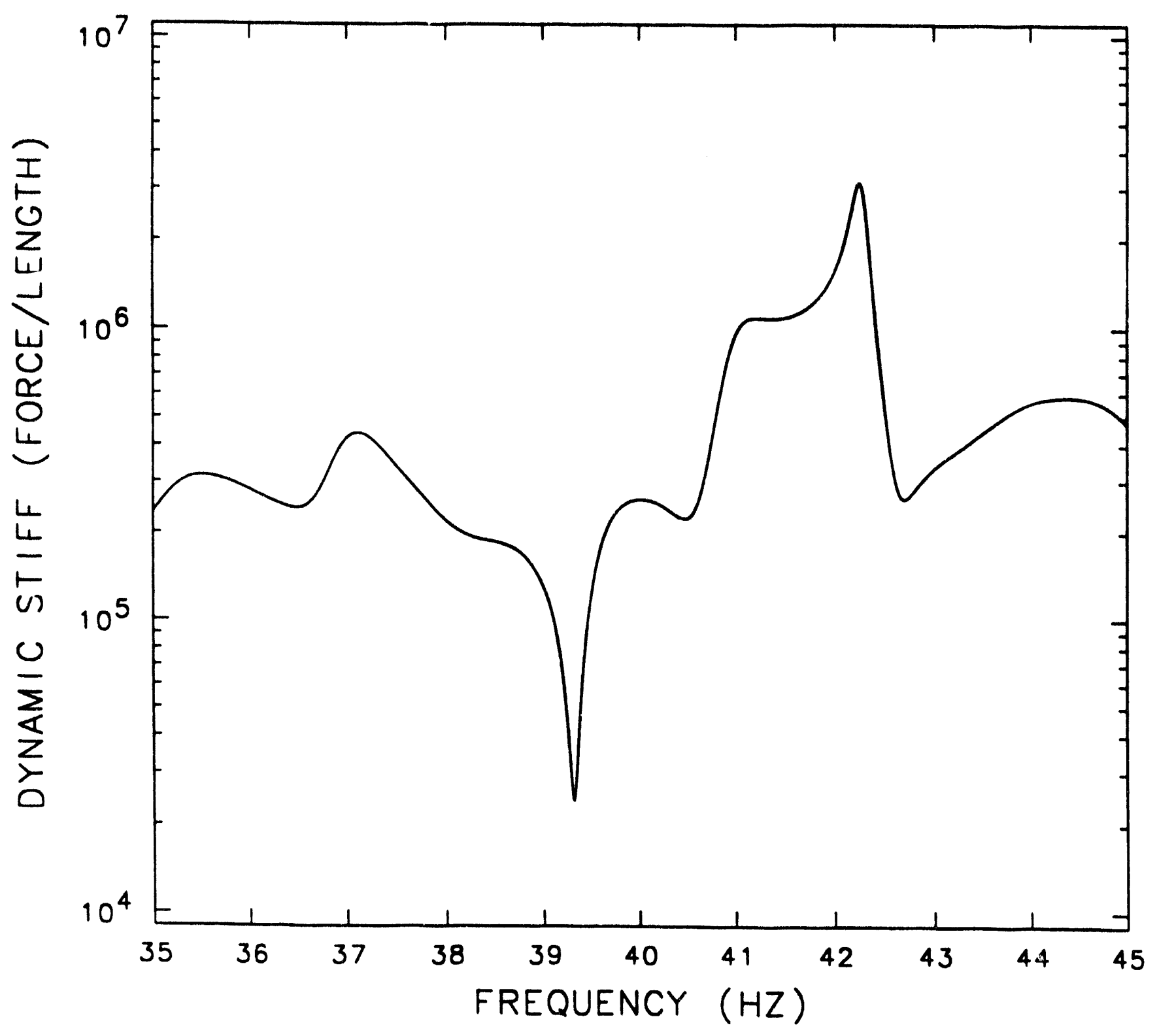

Fig. 44. "Zoom" on the dynamic stiffness function with a finer frequency step for the INA slide model in the frequency range from $35-45 \mathrm{~Hz}$. The MDS value at 39.5 $\mathrm{Hz}$ is shown to be $24,230 \mathrm{lb} / \mathrm{in}$. 
PSEUDO DYNAMIC STIFFNESS

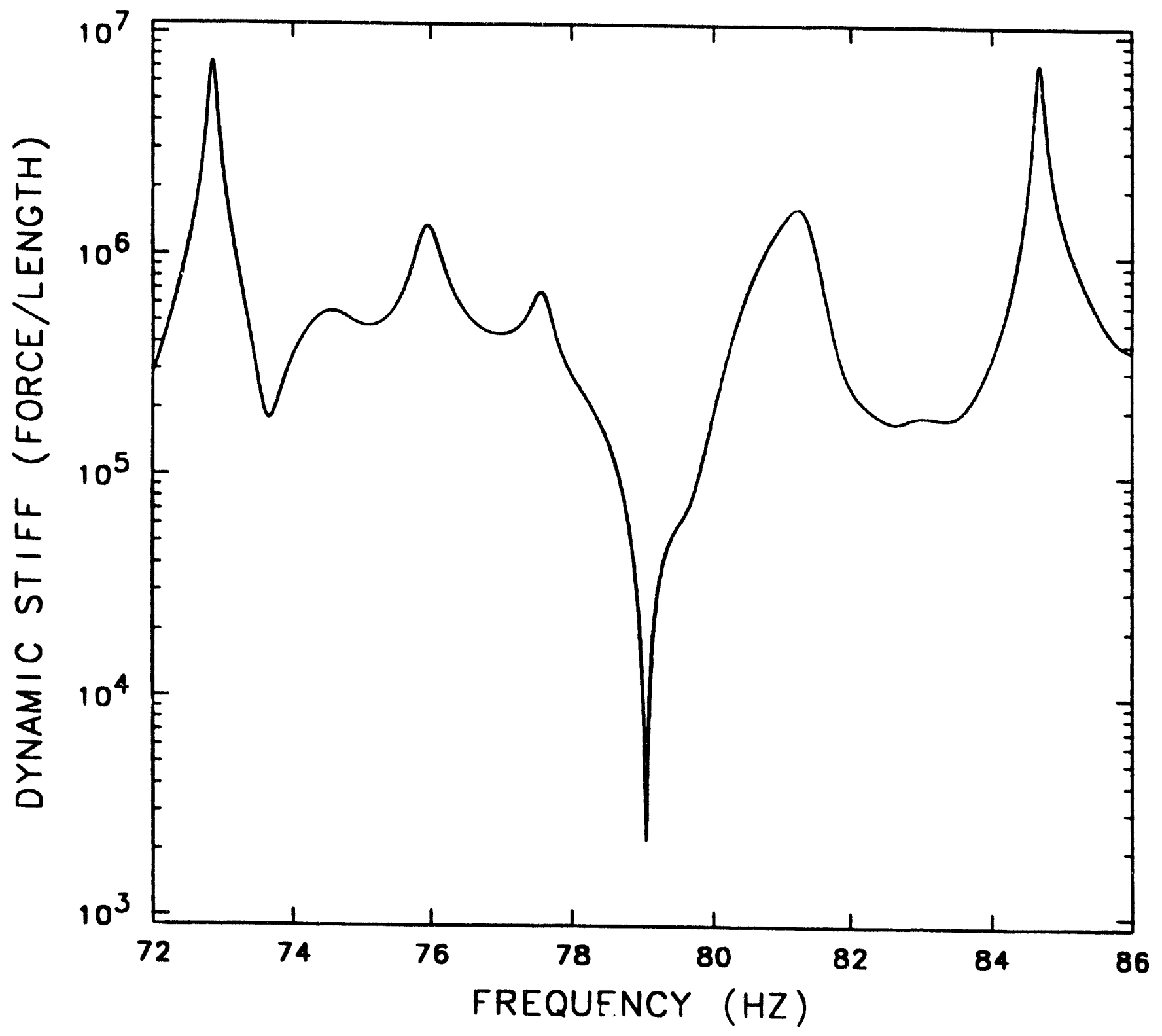

Fig. 45. "Zoom" on the dynamic stiffness function with a finer frequency step for the coated slide model in the frequency range from $72-86 \mathrm{~Hz}$. The MDS value at $79.1 \mathrm{~Hz}$ drops dramatically to $2,202 \mathrm{lb} / \mathrm{in}$. 


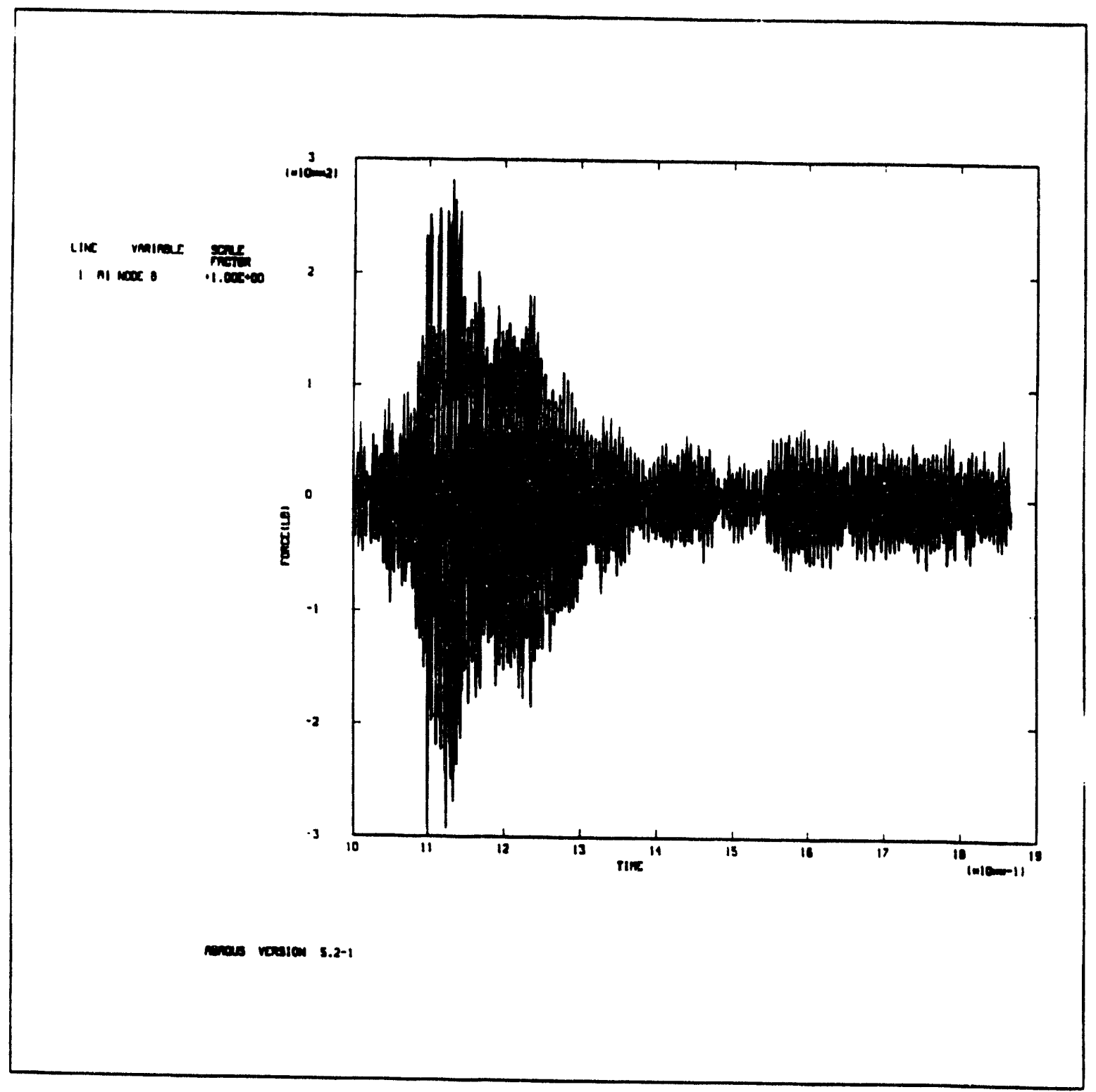

Fig. 46. Response time-history of the center of mass of the upper housing for the random force case. Observe that there appear to be time windows where the frequency response may change. These changes are the width of the "dark" regions along the zero ordinate. 
APPENDIX

A

64 


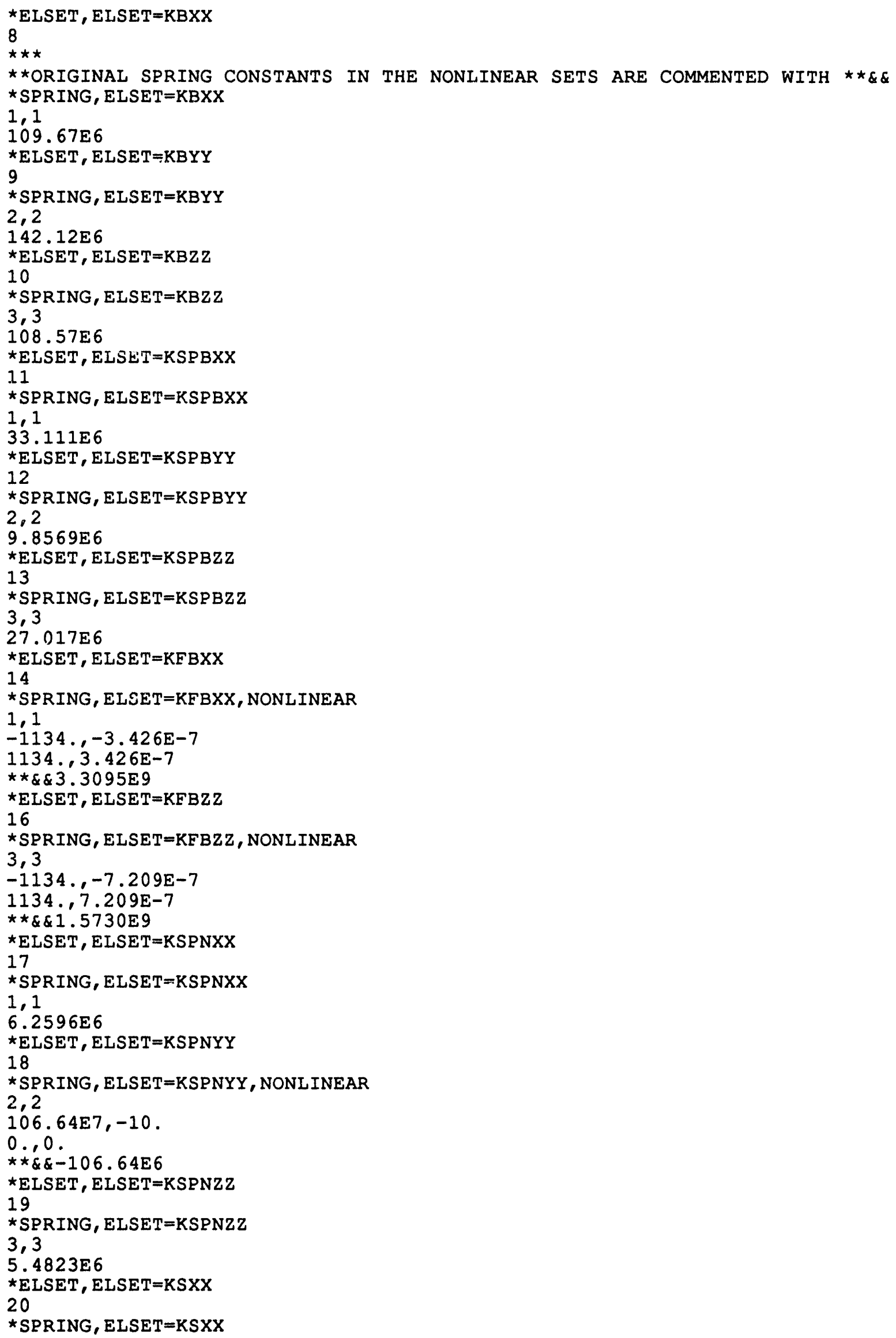




\section{1,1}

$25.980 \mathrm{E} 6$

*ELSET, ELSET $=$ KSYY

21

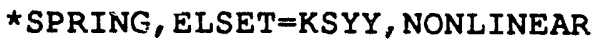

2,2

$-700.21 E 7,-10$.

$0.0,0$.

$\star \star \& \& 700.21 \mathrm{E}-6$

*ELSET, ELSET $=\mathrm{KSZZ}$

22

*SPRING, ELSET $=K S Z Z$

3,3

7387.600

*ELSET, ELSET $=$ KFTXX

23

*SPRING, ELSET $=$ KFTXX, NONLINEAR

1,1

$-661.6,-5.139 E-7$

$+661.6,+5.139 \mathrm{E}-7$

$\star \star \& \& 1.2873 E 9$

$\star$ ELSET, ELSET $=$ KCTYY

24

*SPRING, ELSET $=$ KCTYY, NONLINEAR

2,2

$-478.80 E 7,-10$.

$0 ., 0$.

$\star \star \& \& 478.80 \mathrm{E} 6$

*ELSET, ELSET $=$ KFTZZ

25

*SPRING, ELSET $=$ KFTZZ, NONLINEAR

3,3

$-661.6,-4.666 \mathrm{E}-7$

$+661.6,+4.666 \mathrm{E}-7$

$\star \star \& \& 1.418 \mathrm{E} 9$

*ELSET, ELSET $=$ KFWXX

26

^SPRING, ELSET $=$ KFWXX, NONLINEAR

1,1

$-365.2,-4.178 \mathrm{E}-7$

$365.2,4.178 \mathrm{E}-7$

$\star \star \& \& 874.06 \mathrm{E} 6$

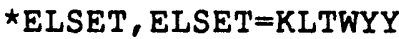

27

*SPRING, ELSET $=$ KLTWYY, NONLINEAR

2,2

$0 ., 0$.

$270.36 \mathrm{E} 7,10$.

$\star \star \& \& 270.36 \mathrm{E} 6$

*ELSET, ELSET $=$ KWZZ

28

*SPRING, ELSET $=\mathrm{KWZZ}$

3,3

$624.6 \mathrm{E} 6$

*ELSET, ELSET $=$ KIBXX

29

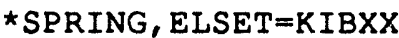

1,1

$259.56 \mathrm{E} 6$

*ELSET, ELSET $=$ KIBYY

30

* SPRING, ELSET =KIBYY

2,2

2. $6694 \mathrm{E} 6$

*ELSET, ELSET $=\mathrm{KIBZZ}$

31 


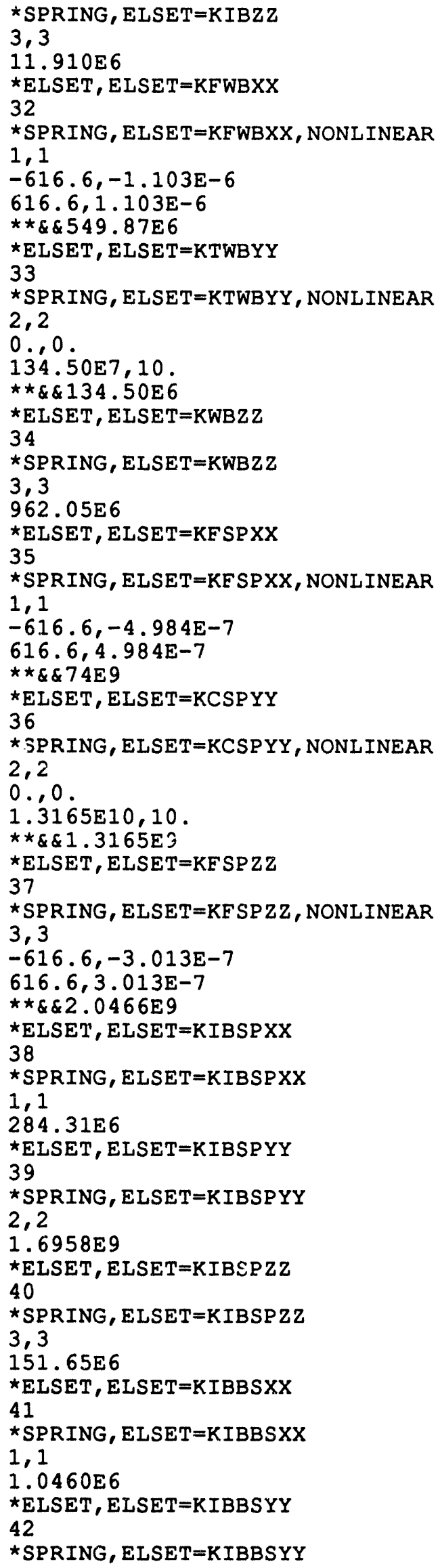


2,2

$-294.580$

*ELSET, ELSET $=$ KIBBSZZ

43

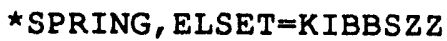

3,3

6.4256

^ELSET, ELSET $=$ KBALSXX

44,47

*SPRING, ELSET=KBALSXX

1,1

$4.1580 \mathrm{E} 6$

*ELSET, ELSET $=$ KBALSYY

45,48

*SPRING, ELSET $=$ KBALSYY

2,2

4.4000E5

*ELSET, ELSET=KBALSZZ

46,49

*SPRING, ELSET=KBALSZZ

3,3

4. 4000E5

*ELSET, ELSET $=$ KTWXX

50

*SPRING, ELSET $=K T W X X$

1,1

$597.97 \mathrm{E} 6$

*ELSET, ELSET $=K T W Y Y$

51

^SPRING, ELSET=KTWYY

2,2

$16.430 \mathrm{E} 6$

$\star$ ELSET, ELSET $=K T W Z Z$

52

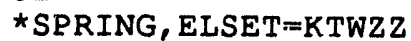

3,3

$116.19 \mathrm{E} 6$

$\star$ ELSET, ELSET $=$ KFUHXX

53

*SPRING, ELSET $=$ KFUHXX, NONLINEAR

1,1

$-430.7,-2.770 \mathrm{E}-7$

$430.7,2.770 \mathrm{E}-7$

$\star \star \& \& 1.5549 \mathrm{E} 9$

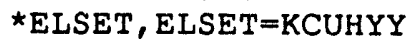

54

$\star$ SPRING, ELSET $=$ KCUHYY, NONLINEAR

2,2

$-699.01 E 7,-10$.

$0 ., 0$.

$\star \star \& \& 696.01 \mathrm{E} 6$

*ELSET, ELSET $=$ KFUHZZ

55

*SPRING, ELSET=KFUHZZ, NONLINEAR

3,3

$-430.7,-2.695 E-7$

$430.7,2.695 \mathrm{E}-7$

$\star \star \& \& 1.5985 \mathrm{E} 9$

*ELSET, ELSE $m=$ KUHWAYXX

56

*SPRING, ELSET $=$ KUHWAYXX

1,1

$19.530 \mathrm{E} 6$

^ELSET , ELSET $=$ KUHWAYYY

57

* SPRING, ELSET $=$ KUHWAYYY 
2,2

$34.035 \mathrm{E} 6$

^ELSET, ELSET $=$ KUHWAYZZ

58

*SPRING, ELSET =KUHWAYZZ

3,3

$37.295 \mathrm{E} 6$

*ELSET, ELSET $=$ KUHCXX

59

*SPRING, ELSET $=$ KUHCXX

1,1

$25.920 E 6$

„ELSET, ELSET $=$ KUHCYY

60

*SPRING, ELSET $=$ KUHCYY

2,2

$112.22 \mathrm{E} 6$

*ELSET, ELSET $=$ KUHCZZ

61

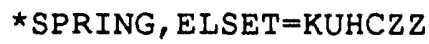

3,3

$62.008 \mathrm{E} 6$

*ELSET, ELSET $=$ KRWUHXX

62

*SPRING, ELSET $=$ KRWUHXX

1,1

$-967.91 E 6$

*ELSET, ELSET $=$ KRWUHYY

63

*SPRING, ELSET $=$ KRWUHYY

2,2

$9.4981 \mathrm{E} 6$

$\star$ ELSET , ELSET $=$ KRWUHZZ

64

$\star$ SPRING, ELSET $=$ KRWUHZZ

3,3

$24.8666 \mathrm{E} 6$

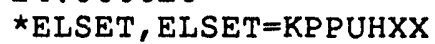

65

*SPRING, ELSET $=$ KP PUHXX

1,1

$0.91723 \mathrm{E} 6$

$\star$ ELSET, EISST $=$ KPPUHYY

66

*SPRING, ELSET $=$ KPPUHYY

2,2

229.22

*ELSET, ELSET $=$ KP PUHZZ

67

*SPRING, ELSET $=$ KPPUHZZ

3,3

103.41

*ELSET, ELSET $=$ KUHRWXX

68

*SPRING, ELSET $=$ KUHRWXX

1,1

$106.08 \mathrm{E} 6$

^ELSET, ELSET $=$ KUHRWYY

69

*SPRING, ELSET $=$ KUHRWYY

2,2

63.085E 6

^ELSET, ELSET $=$ KUHRWZZ

70

*SPRING , ELSET $=$ KUHRWZZ

3,3 
$115.92 \mathrm{E} 6$

*ELSET, ELSET=KRWSXX

71

*SPRING, ELSET $=$ KRWSXX

1,1

$-349.67$

*ELSET, ELSET=KRWSYY

72

*SPRING, ELSET =KRWSYY

2,2

261.98

*ELSET, ELSET=KRWSZZ

73

*SPRING, ELSET=KRWSZZ

3,3

$14.352 \mathrm{E} 6$

*ELEMENT , TYPE=DASHPOT2

$108,1,2$

$109,1,2$

$1010,1,2$

$1011,2,3$

$1012,2,3$

$1013,2,3$

$1014,3,4$

$1016,3,4$

$1017,2,16$

$1018,2,16$

$1019,2,16$

$1020,16,4$

$1021,16,4$

$1022,4,2$

$1023,4,5$

$1024,4,5$

$1025,4,5$

$1026,4,18$

$1027,4,18$

$1028,4,18$

$1029,4,15$

$1030,4,15$

$1031,4,15$

$1032,18,6$

$1033,18,6$

$1034,18,6$

$1035,5,6$

$1036,5,6$

$1037,5,6$

$1038,15,14$

$1039,15,14$

$1040,15,14$

$1041,14,13$

$1042,14,13$

$1043,14,13$

$1044,13,12$

$1045,13,12$

$1046,13,12$

$1047,12,11$

$1048,12,11$

$1049,12,11$

$1050,6,19$

$1051,6,19$

$1052,6,19$

$1053,6,7$

$1054,6,7$

$1055,6,7$

$1056,19,8$

$1057,19,8$ 


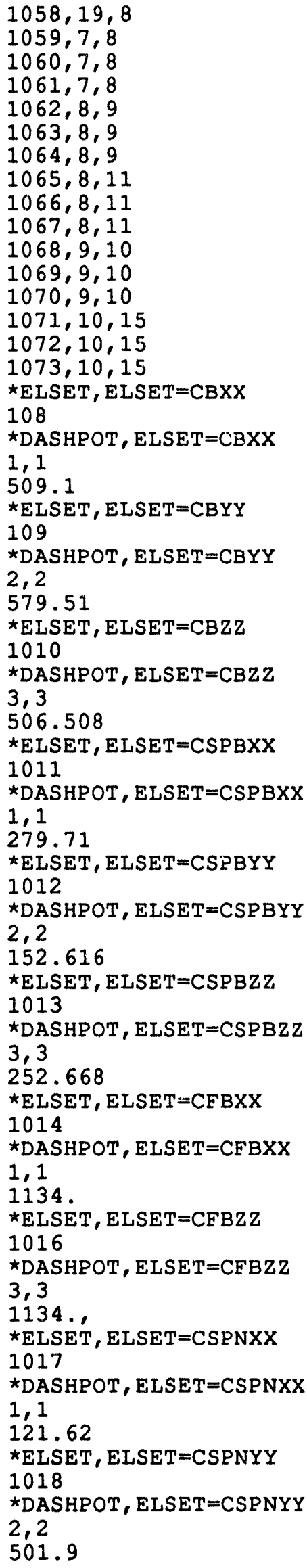


*ELSET, ELSET $=$ CSPNZZ

1019

^DASHPOT, ELSET=CSPNZZ

3,3

113.8186

*ELSET, ELSET $=$ CSXX

1020

$\star$ DASHPOT , ELSET $=\mathrm{CSXX}$

1,1

105.3994

$\star$ ELSET, ELSET $=$ CSYY

1021

*DASHPOT, ELSET $=$ CSYY

2,2

173.034

$\star$ ELSET, ELSET $=$ CSZZ

1022

*DASHPOT, ELSET $=\mathrm{CSZZ}$

3,3

1.777

*ELSET, ELSET=CFTXX

1023

^DASHPOT, ELSET $=$ CFTXX

1,1

$+661.6$

*ELSET, ELSET=CCTYY

1024

*DASHPOT, ELSET $=$ CCTYY

2,2

452.48

^ELSET, ELSET=CETZZ

1025

^DASHPOT, ELSET $=$ CFTZZ

3,3

$+661.6$

*ELSET, ELSE' $\perp^{\prime}=$ CEWXX

1026

$\star D A S H P O T, E L S E T=C F W X X$

1,1

365.2

*ELSET, ELSET=CLTWYY

1027

*DASHPOT , ELSET $=$ CLTWYY

2,2

340.009

*ELSET, ELSET $=$ CWZZ

1028

*DASHPOT , ELSET $=$ CWZZ

3,3

516.79

*ELSET, ELSET $=$ CIBXX

1029

*DASHPOT , ELSET $=$ CIBXX

1,1

333.148

*ELSET , ELSET $=$ CIBYY

1030

^DASHPOT, ELSET=CIBYY

2,2

33.785

*ELSET, ELSET $=$ CIBZZ

1031

*DASHPOT, ELSET $=$ CIBZZ

3,3

71.363

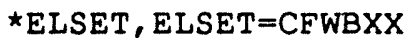


1032

*DASHPOT, ELSET $=$ CFWBXX

1,1

616.6

*ELSET, ELSET $=$ CTWBYY

1033

*DASHPOT, ELSET $=$ CTWBYY

2,2

200.5

^ELSET, ELSET $=$ CWBZZ

1034

*DASHPOT, ELSET $=$ CWBZZ

3,3

536.24

${ }^{\star}$ ELSET, ELSET $=$ CFSPXX

1035

^DASHPOT, ELSET $=$ CF SPXX

1,1

616.6

*ELSET, ELSET $=$ CCSPYY

1036

*DASHPOT, ELSET $=$ CCSPYY

2,2

627.30

^ELSET, ELSET $=$ CESPZZ

1037

ॠDASHPOT, ELSET $=$ CFSP ZZ

3,3

616.6

^ELSET, ELSET $=$ CIBSPXX

1038

*DASHPOT, ELSET $=$ CIBSPXX

1,1

198.364

*ELSET, ELSET=CIBSPYY

1039

*DASHPOT, ELSET $=$ CIBSPYY

2,2

484.46

^ELSET, ELSET $=$ CIBSP ZZ

1040

*DASHPOT, ELSET $=$ CIBSPZZ

3,3

144.87

*ELSET, ELSET $=$ CIBBSXX

1041

*DASHPOT, ELSET=CIBBSXX

1,1

12.0318

^ELSET, ELSET $=$ CIBBSYY

1042

*DASHPOT, ELSET $=$ CIBBSYY

2,2

0.2019

*ELSET, ELSET $=$ CIBBSZZ

1043

*DASHPOT , ELSET $=$ CIBBSZZ

3,3

2. $98 \mathrm{E}-2$

*ELSET, ELSET $=$ CBALSXX

1044,1047

*DASHPOT , ELSET $=$ CBALSXX

1,1

0.7093

*ELSET, ELSET $=$ CBALSYY

1045,1048 
^DASHPOT , ELSET $=$ CBALSYY

2,2

0.2307

*ELSET, ELSET $=$ CBALSZZ

1046,1049

$\star$ DASHPOT , ELSET $=$ CBALSZZ

3,3

.2307

*ELSET, ELSET $=$ CTWXX

1050

^DASHPOT , ELSET $=$ CTWXX

1,1

422.7685

*ELSET, ELSET=CTWYY

1051

^DASHPOT, ELSET=CTWYY

2,2

70.078

*ELSET, ELSET $=$ CTWZZ

1052

^DASHPOT , ELSET=CTWZZ

3,3

186.3576

*ELSET, ELSET $=$ CFUHXX

1053

*DASHPOT, ELSET $=$ CFUHXX

1,1

430.7

*ELSET, ELSET $=$ CCUHYY

1054

^DASHPOT, ELSET $=$ CCUHYY

2,2

457.093

^ELSET, ELSET $=$ CEUHZZ

1055

$\star$ DASHPOT , ELSET $=$ CFUHZZ

3,3

430.7

*ELSET, ELSET =CUHWAYXX

1056

*DASHPOT, ELSET=CUHWAYXX

1,1

79.04205

*ELSET, ELSET=CUHWAYYY

1057

*DASHPOT, ELSET $=$ CUHWAYYY

2,2

104.3446

*ELSET, ELSET=CUHWAYZZ

1058

^DASHPOT, ELSET=CUHWAYZZ

3,3

109.2276

*ELSET, ELSET=CUHCXX

1059

$\star$ DASHPOT , ELSET $=$ CUHCXX

1,1

91.05936

*ELSET, ELSET=CUHCYY

1060

*DASHPOT, ELSET $=$ CUHCYY

2,2

189.4707

*ELSET, ELSET $=$ CUHCZZ

1061

*DASHPOT, ELSET $=$ CUHCZZ 
3,3

140.8416

${ }^{\star}$ ELSET, ELSET $=$ CRWUHXX

1062

^DASHPOT, ELSET $=$ CRWUHXX

1,1

556.44802

*ELSET, ELSET $=$ CRWUHYY

1063

^DASHPOT, ELSET $=$ CRWUHYY

2,2

55.12206

$\star$ ELSET, ELSET $=$ CRWUHZZ

1064

*DASHPOT, ELSET $=$ CRWUHZZ

3,3

89.189827

*ELSET, ELSET $=$ CPPUHXX

1065

*DASHPOT, ELSET $=$ CPPUHXX

1,1

17.129561

*ELSET, ELSET $=$ CPPUHYY

1066

$\star$ DASHPOT, ELSET $=$ CPPUHYY

2,2

.27079

«ELSET, ELSET $=$ CPPUHZZ

1067

^DASHPOT, ELSET $=$ CPPUHZZ

3,3

0.18188

*ELSET, ELSET=CUHRWXX

1068

^DASHPOT, ELSET $=$ CUHRWXX

1,1

158.6927

*ELSET, ELSET=CUHRWYY

1069

*DASHPOT , ELSEI'=CUHRWYY

2,2

122.3780

*ELSET, ELSET $=$ CUHRWZZ

1070

*DASHPOT, ELSET $=$ CUHRWZZ

3,3

165.8897

*ELSET, ELSET $=$ CRWSXX

1071

*DASHPOT, ELSET $=$ CRWSXX

1,1

0.28811

$\star$ ELSET, ELSET $=$ CRWSYY

1072

*DASHPOT, ELSET $=$ CRWSYY

2,2

0.24939

*ELSET, ELSET $=$ CRWSZZ

1073

^DASHPOT, ELSET $=$ CRWSZZ

3,3

58.37 


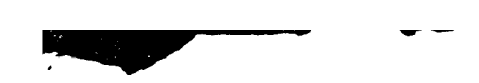 \\ -}

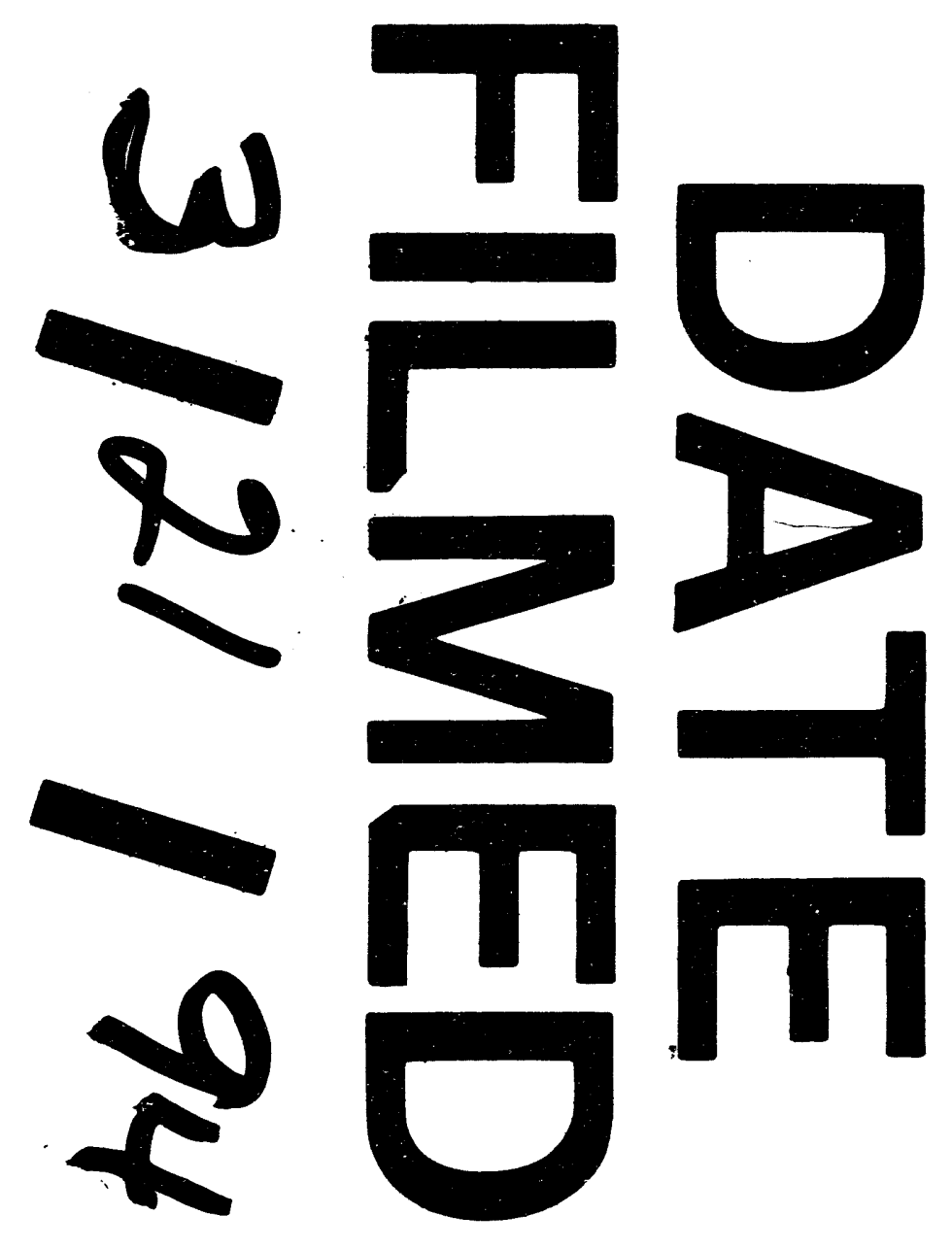

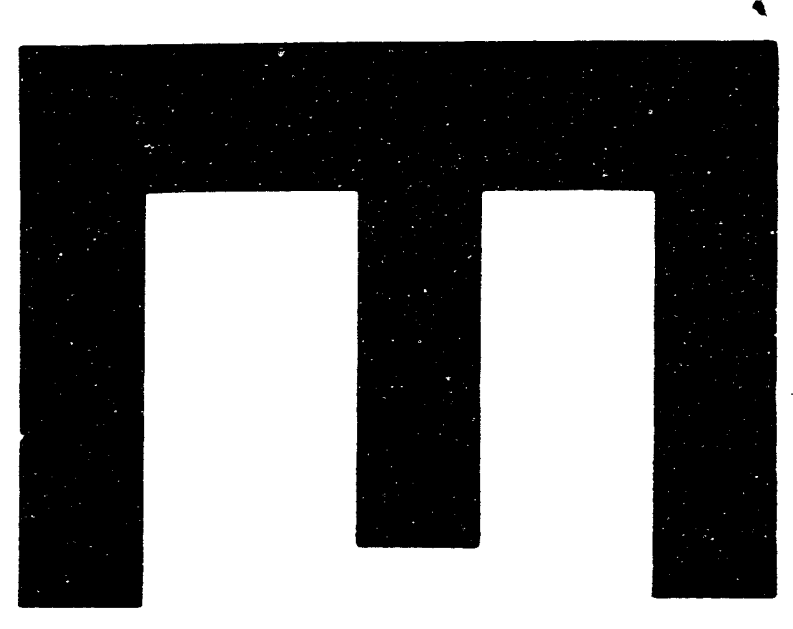
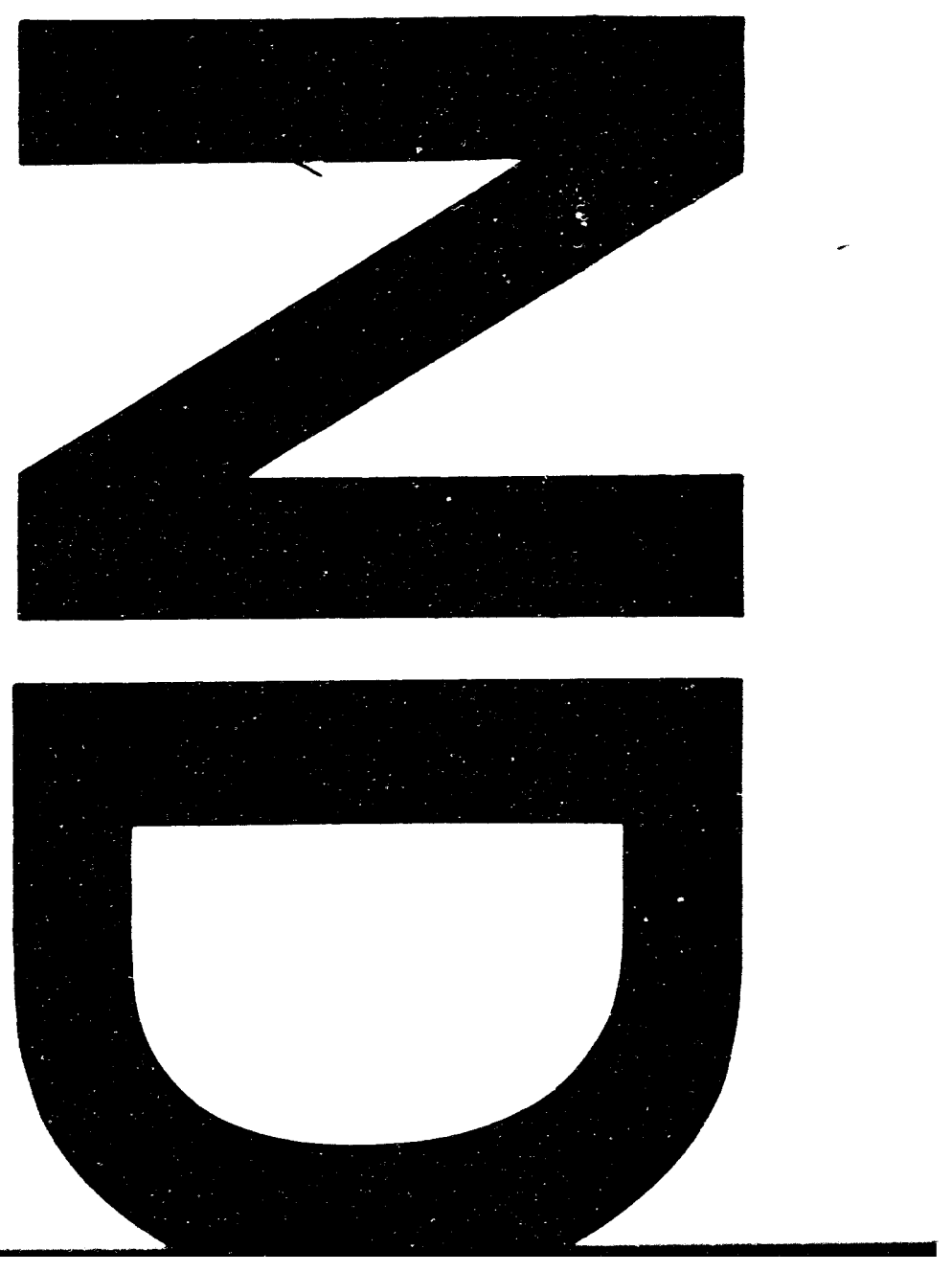
